\title{
Unholy Matrimony: Forced Marriage in New Zealand
}

A Thesis submitted to Victoria University of Wellington in partial fulfilment of the requirements for the degree of Masters in Development Studies

\author{
Priyanca \\ Radhakrishnan \\ School of Geography, Environmental and Earth Sciences
}

February 2012 


\section{Table of Contents}

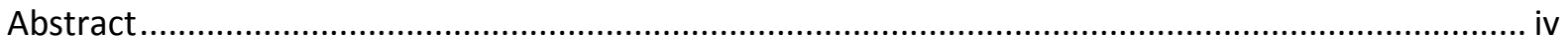

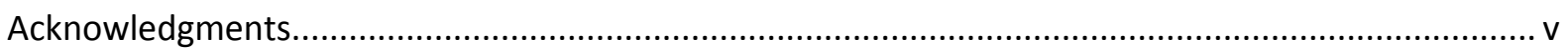

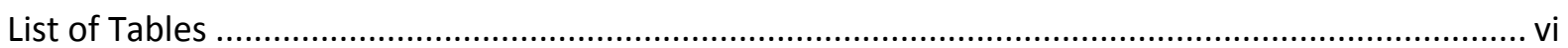

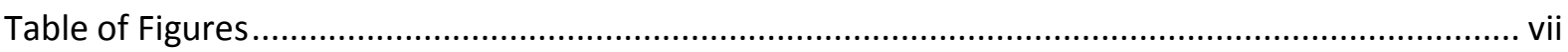

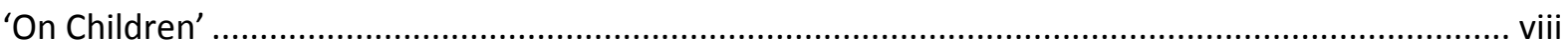

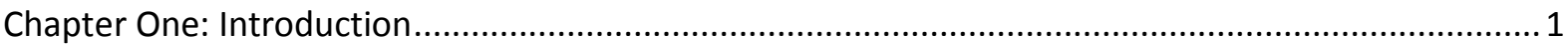

Forced Marriage: Definitions and Debates ............................................................................... 2

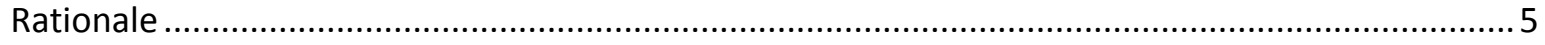

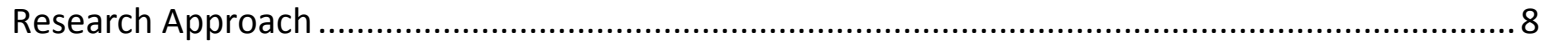

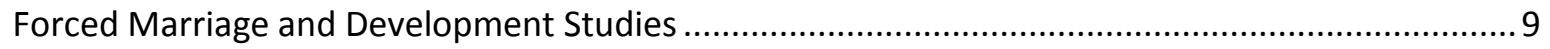

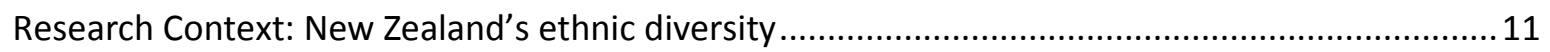

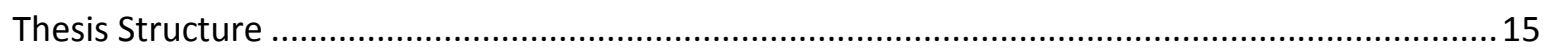

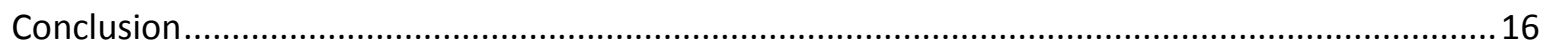

Chapter Two: Violence against Women - Common experiences in Different Countries......................17

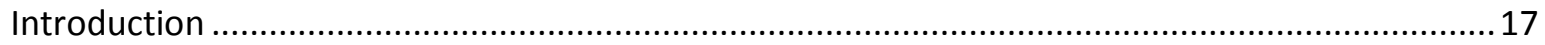

The International Situation: Asia, Africa and the Middle East ...................................................... 17

Violence Travels: International Migration and Diaspora Communities.......................................... 19

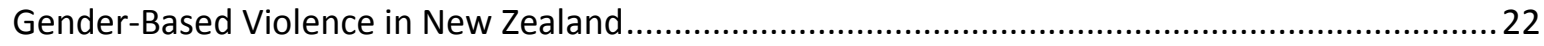

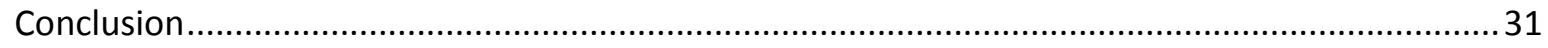

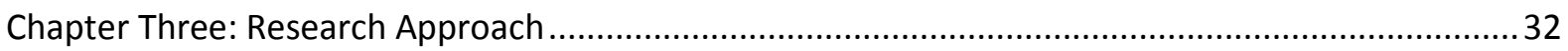

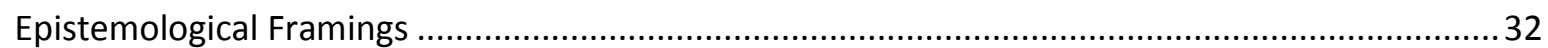

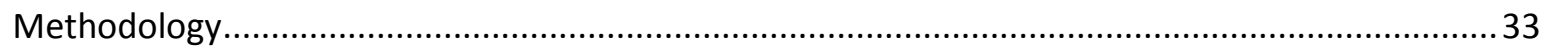

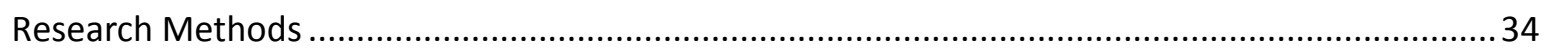

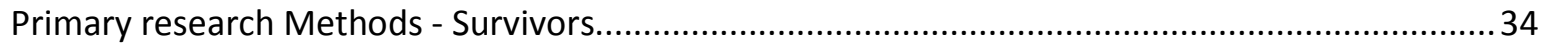

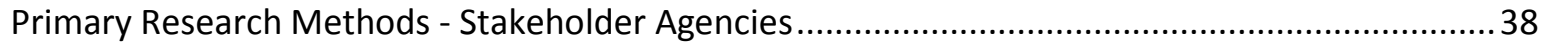

Primary Research Methods - Stakeholder Engagement Workshop .............................................. 41

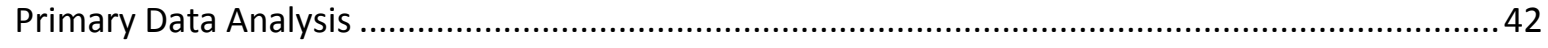

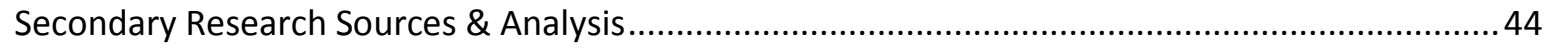

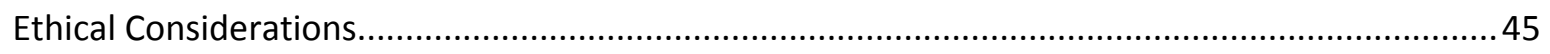

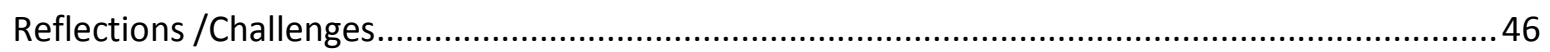

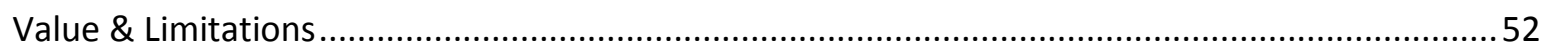




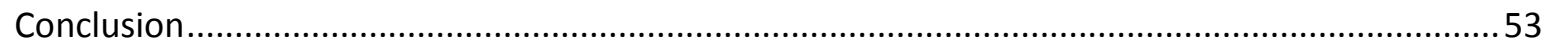

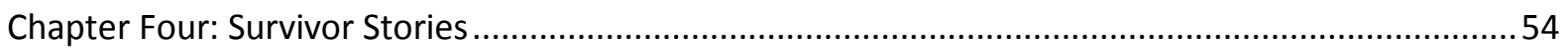

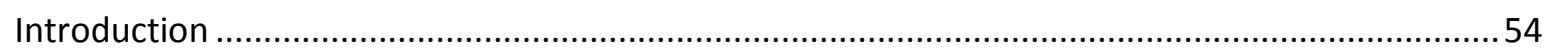

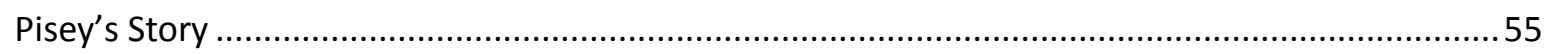

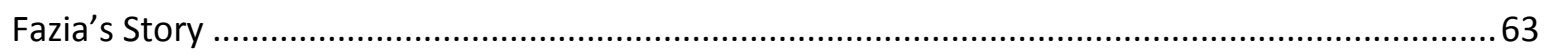

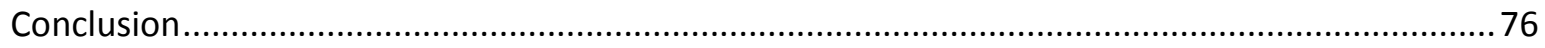

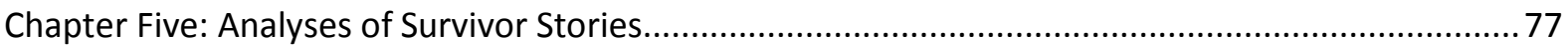

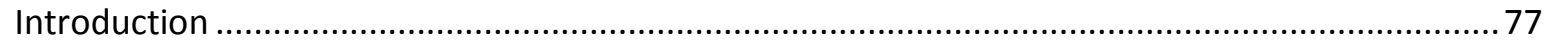

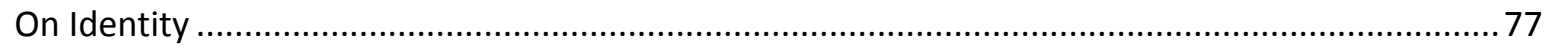

On Marriage, Consent to Marriage \& the Prevalence of Forced Marriage ......................................79

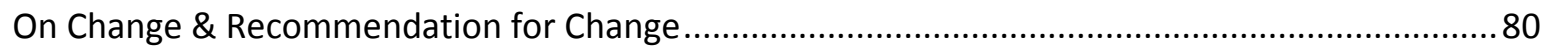

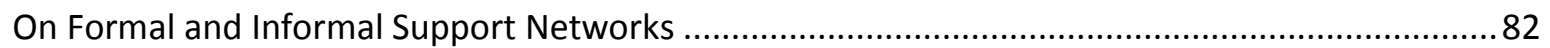

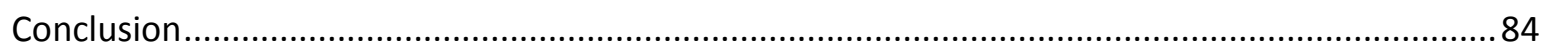

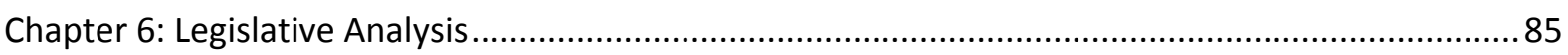

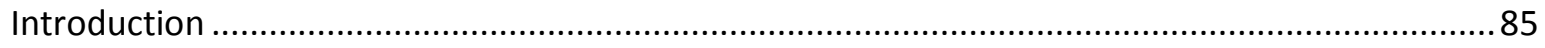

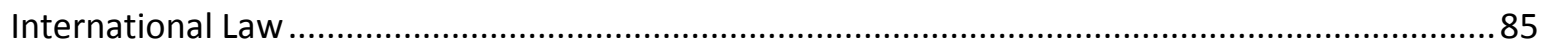

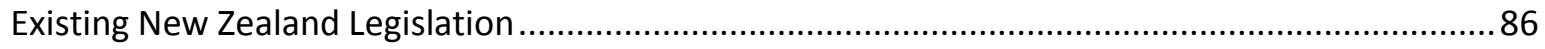

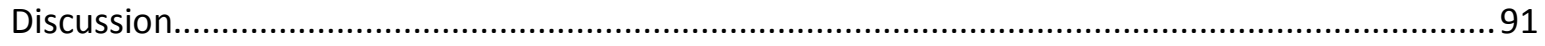

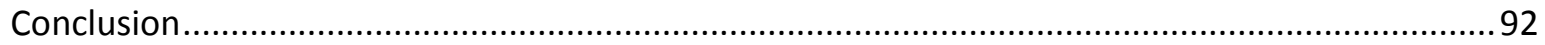

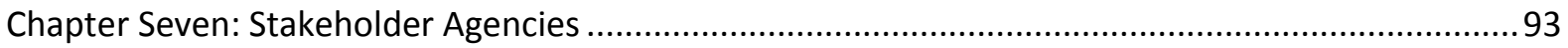

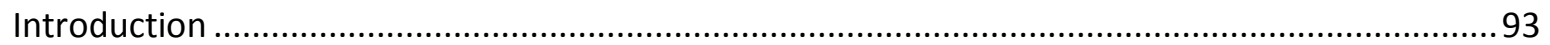

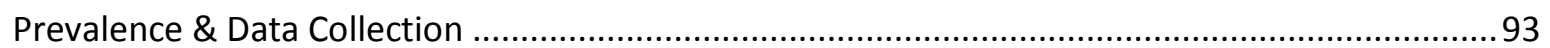

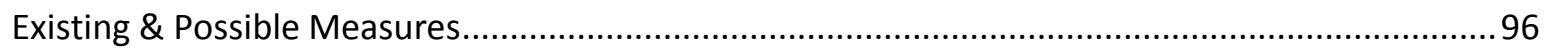

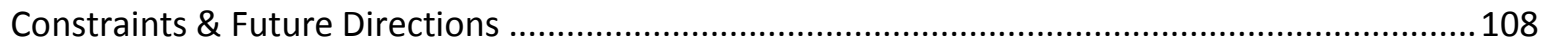

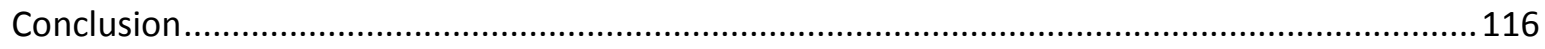

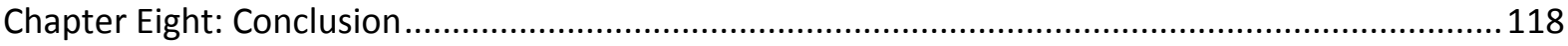

How Have the Research Aims been Achieved? ........................................................................ 118

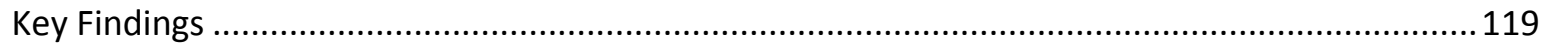

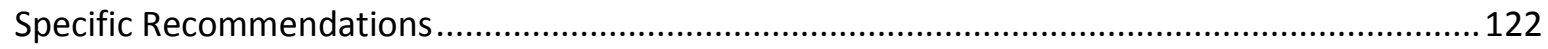

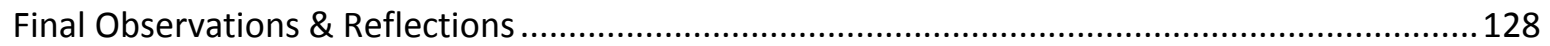

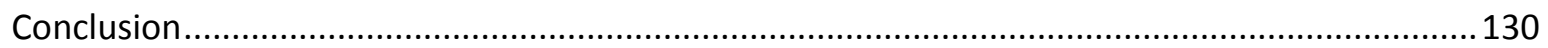

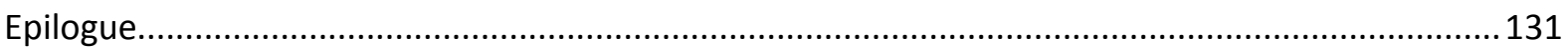

Appendix 1: Participant Information Sheet (Women Survivors) ….................................................. 133

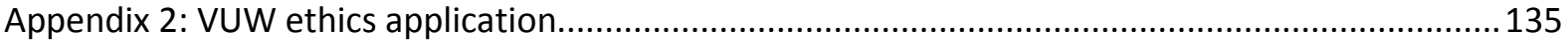




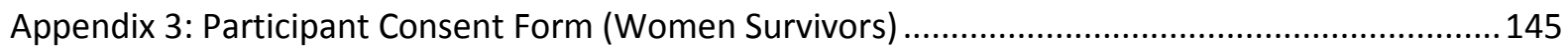

Appendix 4: Aide Memoire (Women Survivors) ……................................................................ 146

Appendix 5: Participant Information Sheet (Stakeholder Agencies) .................................................. 150

Appendix 6: Aide Memoire (Stakeholder Agencies) ...................................................................... 151

Appendix 7: Participant Consent Form (Stakeholder Agencies) ........................................................ 152

Appendix 8: Chart, Stakeholder Engagement Workshop .................................................................. 153

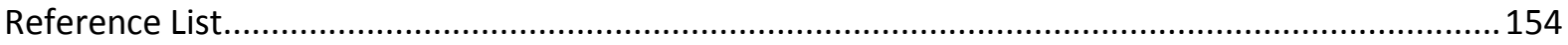




\begin{abstract}
This study explores the issue of forced and underage marriage in Aotearoa New Zealand. It documents the stories of survivors of actual and threatened forced marriage. It also records the survivors' analyses of their experiences and their recommendations for changes that may deter the practice in New Zealand. This study postulates that forced marriage is not a cultural issue per se, but a form of violence against women, shaped by socio-political forces and practised by some. It examines notions of 'honour' and 'shame' which are often inextricably linked to the issue of forced marriage. The study goes on to provide an overview of genderbased violence in Asia, Africa and the Middle East as well as diaspora communities internationally and in New Zealand. This research study is heavily influenced by GAD thought and by various epistemologies including postcolonial feminism, subaltern studies and participatory action research. As such, it emphasises self-reflexivity and focuses on 'gender relations' than 'women' as the category of analysis.
\end{abstract}

The views and potential contributions of eleven stakeholder agency participants in terms of addressing the issue of forced marriage are also included in this study. The study also examines relevant existing New Zealand legislation in light of the country's international obligations regarding marriage. Specific recommendations on both social and legislative reforms are provided in an attempt to promote a collaborative, multi-sector response to address the issue from the perspectives of both intervention and prevention.

In conclusion, this study, which is the first of its kind in New Zealand, hopes to shed light on an issue that is a human rights violation. It aims to promote action to deter the practice and to progress the rights of ethnic minority women in New Zealand without fuelling an antiminority discourse. Finally, it attempts to fill a number of knowledge gaps in academic, policy and legislative literatures. 


\section{Acknowledgments}

I am immensely grateful to the two women survivors who took the time and effort to share their sorrows and triumphs with me and to the Shakti caseworkers without whom much of this thesis would not have been possible. I also thank the stakeholder agencies for their participation in this study. My supervisor, Sara Kindon, deserves special thanks for her wisdom, encouragement, positivity, patience and guidance which kept me motivated throughout the research journey. I thank Victoria University of Wellington, Shakti Community Council Inc., Tangata Whenua Community and Voluntary Sector Research Centre and Women's Studies Association New Zealand (Rosemary Seymour Award) for their financial and other support. I am grateful to the Families Commission for their support of the thesis and the stakeholder engagement workshop.

I am ever grateful to my mother and father for their love and guidance, for inspiring me to think critically and most importantly, for instilling in me the values that continue to guide my life. I thank them for encouraging the activist in me, for reminding me that 'tough times never last, but tough people do,' for living what they preach and for never once implying that marriage is inevitable.

I thank the Richardsons and Snooks for the love, laughter and numerous family discussions that have helped fine-tune my arguments. I thank my friends and colleagues, near and far, who have offered me their time and support without always realising it. Last, but definitely not least, a special thank you to Ewan for being my sounding board and for giving me the unconditional support that kept me going when times were tough. Thank you for being my rock. 


\section{List of Tables}

Table 5.1 Shakti Youth Unit Data on Forced Marriage cases...........................94 


\section{Table of Figures}

Figure 1. Forced Marriage 'You Have a Right to Choose' $\quad$........................132 


\section{'On Children'}

By Kahlil Gibran

Your children are not your children.

They are the sons and daughters of Life's longing for itself.

They come through you but not from you,

and though they are with you yet they belong not to you.

You may give them your love but not your thoughts,

for they have their own thoughts.

You may house their bodies but not their souls,

for their souls dwell in the house of tomorrow,

which you cannot visit, not even in your dreams.

You may strive to be like them,

but seek not to make them like you.

For life goes not backwards nor tarries with yesterday. 


\section{Chapter One: Introduction}

Every three seconds, somewhere in the world, a girl is forcibly married. Forced marriage is a violation of women's and children's rights, one that often keeps them trapped in a cycle of poverty and abuse (Van der Gaag, 2012).

This study explores the issues of forced and underage marriage in Aotearoa New Zealand ${ }^{1}$ within the context of gender and development. More specifically, the study documents the experiences of young women in New Zealand who have either been married forcibly or have been threatened with forced marriage. It situates the practice of forced and underage marriage within a wider continuum of violence against women, a key focus of gender and development policy and practice worldwide. It also examines the issue of 'honour' within the context of forced and underage marriage.

For ease of reading, the term 'forced marriage' is used, in this thesis, in place of 'forced and underage marriage' as an umbrella term that includes underage marriage. This is in acknowledgement of research conducted by the United Nations Children's Fund (UNICEF) on the practice of child marriage. UNICEF states that "all underage marriages should be considered 'forced' since minors are unable to express consent [and] cannot be expected to understand the implications of accepting a lifetime partner" (Innocenti Research Centre, 2001, p. 8). UNICEF considers everyone under the age of 18 a child or a minor in accordance with its guiding document, the United Nations Convention of the Rights of the Child (United Nations, 2011). New Zealand law also defines a minor as a person under the age of 18 (New Zealand Parliament, 2011).

This study documents survivor experiences and explores the impacts forced marriage has had on their emotional, social and economic well-being. The study also includes the perspectives of various government, quasi-government, non-government and UN agency stakeholders on issues of intervention and prevention. It examines gaps in relevant current New Zealand legislation that may unintentionally allow the practice to take place here within the context of New Zealand's international obligations on the issue of forced marriage. Preliminary findings

\footnotetext{
${ }^{1}$ Aotearoa is the Maori name for New Zealand (Pember, 1899) and literally translates to 'the land of the long white cloud'(see www.maori.com/aotearoa). I use 'New Zealand' throughout the thesis for ease of reading. However, I acknowledge the bi-cultural nature of New Zealand as laid out in its founding document, Te Tiriti $\mathrm{O}$ Waitingi (The Treaty of Waitangi) which was signed between Maori and the Crown on $6^{\text {th }}$ February 1840 (ibid.).
} 
and potential collaborations were discussed with stakeholder agencies that participated in the study and attended a workshop held in December 2011.

Specifically, this study aims to answer the following questions:

- How do women survivors of forced marriage in New Zealand describe and explain their experiences?

- What types of change, according to women survivors of forced marriage, are necessary to deter the practice in New Zealand?

- What are the gaps in existing New Zealand legislation that may unintentionally allow the practice of forced marriage to continue?

- What measures, including intervention and prevention, are currently being taken to deter the practice in New Zealand?

- What further action could be taken to deter the practice of forced marriage in New Zealand, to provide adequate support to victims and to hold perpetrators accountable for their actions?

\section{Forced Marriage: Definitions and Debates}

Research from the United Kingdom (UK) indicates that both men and women may be victims of forced marriage. In 2010, the UK's Forced Marriage Unit (FMU) which is a joint initiative between government and non-governmental agencies noted an increase in the number of men accessing support as a result of the practice (Foreign and Commonwealth Office, 2010). This finding is supported by a separate study of 120 refugee cases from the United Kingdom, Australia and Canada where actual or threatened forced marriage formed part of the claim for protection (Dauvergne \& Millbank, 2010). However, the majority of victims still appear to be female, based on data from the FMU and the study on refugee cases. Despite the awareness that forced marriage affects men as well, this thesis focuses on the issue as it impacts upon women and girls in New Zealand. This is largely due to the suggestion that women are disproportionately impacted by forced marriage, as well as the lack of accessible data on male victims of forced marriage in New Zealand and the limited scope of the thesis. 
Forced marriage sits squarely within the continuum of violence against women and is often closely linked to honour-based violence. Forced marriage occurs for many reasons. Often, young girls are pressured into marrying to sponsor their spouse for immigration purposes (Shakti Community Council Inc., 2010). In many cases, parents are mortified when their children, especially daughters, having been exposed to different social norms, want to date or dress in ways considered unacceptable. In many such cases, the girls are coerced into marriage to preserve their 'honour' and that of their families. Actual and threatened forced marriage are used to control sexual interest or behaviour, protect perceived religious/cultural ideals and/or honour long-standing family commitments (ibid.).

A forced marriage occurs when individuals are coerced into marriage. Duress is not confined to physical coercion, but often includes psychological, sexual, financial and emotional pressure. Forced marriage is clearly distinguished from arranged marriage, as in the latter, consent is required from both parties and either one has the right to withdraw from the marriage (UNICEF Innocenti Research Centre, 2001). Societal perceptions of the significance of marriage complicate understandings of 'force' as coercion is often expressed "in idioms of love, duty and filial obligation." Such expressions cause the lines between "cultural compulsion, social realities and individual desire" to become blurred (Siddiqi, 2005, p.282).

In many cases, the emotional coercion exerted on a victim of forced marriage includes repeatedly telling her that the family's social standing and reputation are at stake if she does not agree. Often, she is told that it is her obligation to her family and that quite simply, children must obey their parents. Physical abuse, ostracism by her family and isolation may also be used as forms of coercion.

Emotional and psychological abuses are often not considered forms of coercion by perpetrators and victims. They are not considered coercion because of a prevalent and deepseated attitude that marriage is inevitable rather than optional (Siddiqi, 2005). When the inevitability of marriage is combined with the idea that 'parents always know best' and notions of filial piety, parents often believe that they are merely acting the best interests of their daughter; the daughter feels obligated to agree.

Emotional and psychological coercion, therefore, are often more difficult to detect than physical coercion. As a result, determining where consent ends and coercion begins becomes 
very tricky (Siddiqi, 2005). Sigma Huda, UN Special Rapporteur on human trafficking, states that

[a] marriage imposed on a woman not by explicit force, but by subjecting her to relentless pressure and/or manipulation, often by telling her that her refusal of a suitor will harm her family's standing in the community, can also be understood as forced (United Nations Human Rights Council, 2007, pp. 10)

Forced marriage may also be used to ensure that another marriage does not take place (Siddiqi, 2005). Such a situation usually arises because the daughter has expressed a desire to marry someone of whom the parents or other family members disapprove (ibid.). In some cases, she is then forced to marry someone of her parents' choosing instead. In others cases, if she refuses, she may be killed, or may feel compelled to commit suicide (Sanghera, 2007).

The issue of forced marriage is often positioned as a cultural rather than a human rights issue. Yet the Parliamentary Assembly of the Council of Europe (2005, p. 223) has argued that

forced marriages and child marriages constitute serious and recurrent violations of human rights and the rights of the child. It is an outrage that, under the cloak of respect for the culture and traditions of certain communities, there are authorities which tolerate forced marriages and child marriages although they violate the fundamental rights of each and every victim.

The position adopted in this thesis is that it is important not to succumb to cultural relativism by turning a blind eye to the issue or condoning it as a 'cultural' issue. Firstly, forced marriage is practiced in many societies around the world and is not confined to specific 'cultures' or 'religions.' Secondly, no major world religion condones the practice of forced marriage. Finally, such profiling is inaccurate given that whole communities do not condone these practices; it is only an issue amongst those who choose to exert power and control over the women in their families. I argue, therefore, that forced marriage is not a cultural issue per $s e$, but a form of violence against women, shaped by socio-political forces and practised by some. It should not be framed as anything other than a form of violence against women as this detracts focus from the issue. It also merely serves to perpetuate negative and inaccurate stereotypes of entire communities.

In attempting to understand the origins and forms of forced marriage around the world, it could, perhaps, be more constructive to adopt the idea of "mature multiculturalism" rather 
than 'cultural determinism'. Positioning the practice within this framework would help to provide equal protection to women from minority communities in places like New Zealand and work against the essentialising and 'othering' of these communities that commonly occurs when forced marriage is positioned as a cultural issue unique to them (Siddiqui, 2005, p. 279).

\section{$\underline{\text { Rationale }}$}

This research study is the first of its kind in New Zealand. My decision to research the issue of forced marriage in New Zealand was informed by my paid work with Shakti Community Council Inc. (Shakti). Shakti is a national, non-governmental organisation that provides culturally appropriate domestic violence intervention support services to women of Asian, African and Middle Eastern origin in New Zealand (Shakti Community Council Inc., see http://www.shakti.orgnz/). Shakti provides crisis and non-crisis intervention support, a 24hour national crisis line and four culturally-appropriate refuges around the country. In addition to direct service provision, Shakti also strives to ensure that the voices of the women who access their services are heard at a central government level. Shakti continues to lobby for social change and to challenge mindsets that promote the tacit acceptance of domestic violence as a 'cultural' norm.

In 2007, Shakti in association with Pacific Women's Watch New Zealand (PWW (NZ)), raised, amongst others, concerns regarding the practice of forced marriage at the $39^{\text {th }}$ Convention on the Elimination of all forms of Discrimination Against Women (CEDAW). In the Committee's concluding comments to the New Zealand Government, it highlighted the following as one of its principal areas of concern:

26. The Committee is concerned that violence against women within families and illegal practices relating to marriage on the basis of culture and religion take place within immigrant communities and may not be adequately addressed because of the dependency and isolation of the women concerned (United Nations CEDAW, 2007, pp. 6)

In November 2009, PWW (NZ) hosted "Young Women of Tomorrow - Changes and Challenges," a conference that was held in commemoration of the World Day for the 
Prevention of Child Abuse and Universal Children's Day (Pacific Women's Watch (NZ), 2009). Shakti participated in this conference. A debate on the issue of forced marriage ensued when a young girl, who had previously accessed Shakti's direct services, spoke about her experience of being forced into marriage at the age of fourteen.

Three days after the conference, a petition by Jane Prichard, from PWW (NZ) signed by 46 others was presented to Parliament by National Party List Member of Parliament, Dr Jackie Blue. It was then referred to the Justice and Electoral Select Committee. The petition requested

that the House of Representatives examine the practice of cultural marriages to underage females and to initiate legislation that will effectively intervene in the prevention of abuse of human rights arising out of such marriages in New Zealand (House of Representatives, 2009, pp. i).

In February 2010 Shakti drafted an exhaustive supporting submission to the Select Committee outlining the organisation's concerns and requesting permission to speak at the Committee's oral hearing. The oral hearing, which was held in May 2010, involved presentations by Shakti and the National Collective of Independent Women's Refuges (Women's Refuge) as well as a presentation by the young survivor who had initially spoken at the PWW (NZ) conference. As a result of the information presented during the hearing, the Select Committee requested that Shakti provide them with additional information on the steps that have been taken internationally to address the issue and invited Shakti to respond to the submissions by the Department of Internal Affairs and the Ministry of Justice on the issue.

The Select Committee outcome report to Parliament in November 2010 acknowledged that forced and underage marriage was an issue. It urged the Government to "consider following the Australian example and make it an offence to marry a person under the age of 16" (New Zealand House of Representatives, 2010, p. 8) and made the following overall recommendation:

We recommend to the Government that it consider the concerns raised in each section of this report and determine what actions it should take in order to prevent the practice of forced underage marriage from continuing to occur in New Zealand (New Zealand House of Representatives, 2010, p.8). 
The Government final response to the Select Committee's outcome report was presented to Parliament in March 2011. The report stated that the Government's view on the issue is that there are offences that already make forced marriage illegal in New Zealand and that more legislation "is unlikely to have a significant impact on the incidence of forced marriage" (Ministry of Justice, 2011, pp. 6). However, the report also stated that the Government would review relevant legislation to determine whether further legislation would accord victims more protections and if so, how best these changes could be progressed. In conclusion, the report emphasised the Government's view that education and "building relationships of trust with migrant and other groups" (ibid., pp.6) was more important. Continued provision of support services through government agencies and community groups was also deemed necessary.

Over the five-and-a-half year period that I have been working with Shakti, I have personally supported women and girls who have experienced actual or threatened forced marriage. As their support person, I often found it extremely challenging to advocate on their behalf with government and non-governmental agencies. There was a distinct lack of awareness and understanding of the issue, which translated into a dearth of service provision options for the women and girls. For example, young girls who had displayed suicidal tendencies could not be accommodated in Shakti's refuges as refuges are only monitored during office hours. However, there is no other youth service in New Zealand that could cater to these young girls' needs for safe and culturally-appropriate accommodation. Advocating on their behalf for a legal immigration status was also an uphill task, as they often did not fit into established policy categories. Advocacy had to be on a case-by-case basis. Many survivors had been disowned by their families and had no means to support themselves. Some had dependent children, health issues, minimal or no finances and many did not have Permanent Residency or New Zealand citizenship. As a result, some of these women and young girls became disillusioned and often chose to stay within the marriage.

Conversations between Shakti and representatives from the Ministry of Justice, Women's Refuge and other stakeholder agencies prior to the thesis highlighted the dire need for research into the nature and scale of the issue as it presents in New Zealand to inform evidence-based and well researched change. Question and answer sessions at various conferences, forums and workshops I have spoken at over the years also emphasised the need for research. 
During a brief internship with UNICEF New Zealand in 2010, I produced a pamphlet that contained information on what forced marriage and underage marriage are, where women could access support in New Zealand, some of the prevalent reasons for both forced and underage marriage, the impact that the practices have on women, international statistics on forced marriage and brief information on what needs to change. Much of this information was gleaned from Shakti's submission to the Select Committee earlier in 2010.

My decision to embark upon this research journey was largely shaped by the helplessness I experienced while working with survivors. I was also determined to play my part in raising awareness of a practice which is, in fact, a human rights violation.

\section{$\underline{\text { Research Approach }}$}

The research design was guided by the central tenets of feminist research which emphasise self-reflexivity and the acknowledgement that the researcher is also part of the "matrix of what is known" (Fine, 1994, pp.15). Feminist research epistemologies acknowledge that research is situated and that knowledge construction is informed by the knower's perspective. The view that knowledge is situated rejects the "scientific ideal of an objective, value-neutral observer who is distanced from, and has no vested interest in the object of his or her research" (Llewelyn, 2007, pp. 300). Llewelyn goes on to discuss Haraway's metaphor of diffraction which is a tool used to understand feminist research practice based on "interaction, interruption, difference, and surprise" (Llewelyn, 2007, p. 301; see also Haraway, 1997). The metaphor sheds light on the ever-changing directions of feminist research which is akin to a beam of light that splits and bends as it shines through a crack (ibid.). As this research delves into the quagmire of values, beliefs and attitudes towards gender and genderbased violence, I was conscious of the need to be constantly self-reflexive. I strove to challenge my own beliefs and basic assumptions so as to stay true to critical feminist epistemologies and to myself as an activist, community researcher and a woman from an ethnic minority group in New Zealand. I was cognisant of the need to avoid the pitfall of representing minority communities as homogenous entities. I constantly reminded myself that the category 'ethnic women' was also not homogenous. We have different experiences shaped by different values and belief systems and, ultimately, different goals. While this study focuses on experiences of women from ethnic minority communities who have been subjected to violence, it is important not to assume that all women from ethnic minority communities have similar 
experiences. In the same way that all ethnic males are not abusers, all ethnic women are not oppressed.

\section{Forced Marriage and Development Studies}

I chose to research the issue of forced marriage under the auspices of Development Studies because of its multidisciplinary nature and its recognition of women's empowerment as central to sustainable development. The United Nations Development Programme (UNDP) acknowledges that "development cannot be achieved if fifty per cent of the population is excluded from the opportunities it brings" (Clark, 2010, n.p. see http://www.unifem.org/cedaw30/cedaw_and_the_un/).

Despite the apparent focus on gender and empowerment in Development literature, however, there appears to be a discrepancy in the way 'progress' is measured. In India, for example, genderbased violence is described as a "never-ending phenomenon" which persists despite legislative change and increased service provision (Sharma \& Gupta, 2004, p.1). It is, therefore disheartening to note that a 2005 UN Millennium Project report states that "progress in India and China is to be lauded as a global-scale triumph" (UN Millennium Project, 2005, p.3).

The two dominant paradigms in development policy and practice that describe women's relationship with development are Women In Development (WID) and GAD. In the early 1970s, women began to critique the dominant development framework that focused on men and surmised that men's economic prosperity would eventually 'trickle down' to benefit women (Beetham \& Demetriades, 2007). The WID approach was based on a liberal feminist framework and was heavily influenced by women researching development. Esther Boserup, often considered a pioneer, was one such woman whose research influenced WID considerably. Her work, Women's Role in Economic Development (1970), situated women as "productive agents contributing to development, rather than needy beneficiaries" (Razavi, 1997, p. 1113).

However, WID assumed that women's subordination was solely linked to their exclusion from the formal economy and it came to be known as the "efficiency approach" (Beetham \& Demetriades, 2007 , p. 201). WID was a successful political strategy that made a "lasting impact on the way in which development planners [thought about] women" (Razavi \& 
Miller, 1995, p.2). Third-World feminists, in mid- to late 1970s and 1980s critiqued the WID framework. They argued, based on post-colonial analysis, that WID was premised upon Western feminism. The WID approach ignored the lived realities of many third world women for whom labour force participation, in addition to existing household responsibilities, resulted in a "double burden" (Beetham \& Demetriades, 2007; Sharp, et al., 2003, p. 282). WID was also a top-down approach which did not take cultural contexts into consideration.

These critiques led to a shift in development policy and practice to a GAD framework. While WID had focused solely on women-only research and programmes, GAD moved towards a consideration of 'gender relations.' The GAD approach recognised that women's subordination was the result of power hierarchies. Subordination was constructed at various levels and perpetuated by various institutions. As such, the shift to GAD was a move towards recognising the need to challenge gender roles and norms in addition to addressing immediate practical needs (Sharp et al., 2003).

GAD recognises the potential tension between addressing immediate practical needs and strategic aims of empowerment. Such tension may be exacerbated by 'patriarchal bargains' (ibid.). Patriarchal bargains are a choice made by some women to collude with "gendered structures that ensure their continued subordination rather than seeking approaches that will allow them to break free of this" (Sharp et al., 2003, p. 281). Women who are subjected to prescriptive gender roles and norms that differ from the norms of the host country, may choose to adhere to these roles because of the sense of security and identity it gives them. Since a definition of empowerment is the ability to "make a choice in a situation where there is the possibility of choosing otherwise," (ibid., p.281) choosing to adhere to 'honourable' gender roles and norms may be viewed as empowerment. The tension between the immediate practical need for security and a sense of identity may be perceived to be in direct contradiction with the longer-term strategic goal of the emancipation of women. In these cases, the women's understandings of their own potential and their self-image are shaped by the ideas of gender prevalent in their societies. Their actions are also unconsciously influenced by their socialisation. Change in such societies/families will only come about when the "benefits of change outweigh the status quo such that any changes will represent empowerment rather than an act of last resort” (Sharp et al., 2003, p. 293).

GAD has a stronger understanding of the need for cultural sensitivity than previous frameworks. However, some researchers are critical of its muted relationship with religion, as 
religion and spirituality are important to many of its beneficiaries (Adamu, 1999). Adamu argues that GAD should take both cultural and religious sensitivities into account if it is to be successful in different societies. This does not mean that GAD should allow violations of womens rights to be perpetrated in the name of religion. It means that religion, like culture, must be acknowledged as an important force that shapes women's "analysis and critique of their position in [their] society" (Sharp et al., 2003, p. 292). Acknowledging the role that religion plays in shaping identity is especially important in countries like New Zealand where ethnic diversity continues to grow.

This research study was heavily influenced by GAD thought and so, acknowledges the need for cultural sensitivity. It also recognises that both practical and strategic aims are needed to address the issue of women's empowerment effectively. (Beetham \& Demetriades, 2007; Sharp et al., 2003). This study is premised on the acknowledgement that empowerment is not a zero-sum game "where women's advantage is men's disadvantage" (Sharp et al., 2003, p. 282). Instead, increased empowerment of women benefits the community as a whole (ibid.). This approach is possible only when men are not viewed uniformly as "the enemy, as powerful and always dominant" (ibid., p. 282) and when they too are included in the debate and the solution.

Situating my research within Gender and Development (GAD) policy and practice represents an attempt to re-emphasise the centrality of gender relations within sustainable development. In addition, I chose to situate my research study within a discipline that traditionally only focuses on progress in the global South, to make a political statement. The need for progress exists everywhere; it is not limited to specific geographical locations.

\section{$\underline{\text { Research Context: New Zealand's ethnic }{ }^{2} \text { diversity }}$}

Census data over the years clearly indicates that New Zealand's society has been growing more ethnically diverse. It is, therefore, crucial to acknowledge the ethnic community's heterogeneity and to ensure that there is an increased understanding and respect of different lived realities, experiences and needs.

\footnotetext{
${ }^{2}$ Although the Office of Ethnic Affairs defines "ethnic" people as those who identify as African, Asian, Continental European, Latin American or Middle Eastern, I have adopted Shakti's definition of "ethnic" people as those who identify as Asian, African and Middle Eastern.
} 
Inward and outward migration in the recent past has resulted in significant changes to New Zealand's ethnic make-up. In the year 2010-2011, 40,737 people had their applications for Permanent Residence approved and permanent long-term migration to Australia increased by 12,492 (46 per cent) (De Bres, 2011).

In 1976, 86 per cent of New Zealanders identified as European. This figure dropped to 80 per cent in 2001 and 67.6 per cent in $2006^{3}$ (De Bres, 2011). In the 1976 and 2001 census, there were no recorded figures for Middle Eastern, Latin American, Asian or African (MELAA) groups. According to the 2006 census, however, ten per cent or approximately 400,000 people identified as being Asian, 17,514 as being Middle Eastern and 10,647 as being African (Office of Ethnic Affairs, 2006, n.p.). As such, 509,358 people speak a language other than English, Māori, Samoan or New Zealand Sign Language (Statistics New Zealand, 2006).

A government survey indicates that New Zealanders are generally positive about migrants, although migrants from the United Kingdom and Australia are viewed more positively than the others (IMSED Research and Department of Labour, 2011). Research also indicates as compared to the New Zealand population as a whole, Asians are more than twice as likely to have a degree (Pearson, 2011). When it comes to employment, however, skilled migrants from countries such as India and China find it hard to find suitable employment. This is because of the perceived inferiority of these countries and the "high level of ignorance around education and qualifications" in such countries (Coates, 2005, p. 590).

There is a significant amount of research that highlights the poverty and social exclusion of specific groups of former refugees in New Zealand (Chile, 2002) and ethnic migrants to New Zealand in general. The struggles that Indian women experience in securing skilled employment in New Zealand (Pio, 2005) are also well documented. Research has highlighted the existence of structural discrimination that results in systemic barriers to ethnic equality (Human Rights Commission, 2011). There is also significant research that highlights the positive contributions made by ethnic minority groups to New Zealand society. One example of this is Trailblazers, a publication by the Office of Ethnic Affairs. It showcases the skills of ethnic women entrepreneurs in New Zealand and reveals "the array of skills, attitudes, tenacity and [the] rich cultural heritage that exists within our communities today" (Office of

\footnotetext{
${ }^{3}$ The sharp decline in the number of people who identified as New Zealand European between in 2001 and 2006 could, in part, be attributed to the addition of a new category, 'New Zealander', in the 2006 Census.
} 
Ethnic Affairs, 2011, p. 2; Immigration New Zealand, 2011). TVNZ magazine programme Asia Downunder, which ended in 2011, did an excellent job of showcasing the lifestyle, culture and accomplishments of the Asian diaspora in New Zealand. The Asian Report on Radio New Zealand highlights both potentially controversial issues and achievements of the Asian community. The Aotearoa Ethnic Network is an email forum with a membership of over 500 individuals from different walks of life, all of whom have a keen interest in the ethnic sector (Aotearoa Ethnic Network, 2005).

The term 'the ethnic community' is used throughout this thesis despite an awareness of the diversity of the group referred to. I have no intention of implying that they have a shared heritage, language or culture; the term is used in the singular to draw attention to their shared identity as individuals belonging to minority groups in New Zealand. The term 'minority groups' is used to refer to all ethnic minority groups in New Zealand including those that are not of Asian, African and Middle Eastern descent. The term is also used in places to distinguish these groups from the 'majority' population which is made up of tangata whenua ${ }^{4}$ and New Zealand Europeans.

A considerable amount of sensitivity is required when highlighting controversial issues such as domestic violence within ethnic minority groups without tarring the entire community with the same brush. The need for sensitivity is something I was inordinately conscious of throughout the research process. I was also aware that the frequent citation of negativities could serve to perpetuate negative stereotypes of specific ethnicities, which could become a barrier to addressing underlying causes of ethnic inequality (Human Rights Commission, 2011). The perspective that underlies this research study is that the ethnic community, like the rest of society, is not perfect. In New Zealand, "approximately one in three ever-partnered women reported that they had experienced at least one act of physical and/or sexual violence by an intimate partner" (Fanslow \& Robinson, 2004). Genderbased violence exists in every society across the globe and the ethnic community is no exception. There is also no evidence to suggest that domestic violence is worse within the ethnic community. Given that the different ethnic groups have come to New Zealand from varied socio-political and economic contexts, violence against women may manifest differently in the ethnic community. Therefore, while the form of violence may differ, the difference per se does not lend itself to a value judgement;

\footnotetext{
${ }^{4}$ Tangata Whenua Literally translates to mean 'people of the land' in Te Reo Maori and is understood to refer to the indigenous people of New Zealand.
} 
the ethnic community is no better or any worse than any other community within which genderbased violence exists. Just as it is "inaccurate and dangerous" to portray child abuse as a race issue (Cummings, 2011, para. 2), honour-based violence and forced marriage too should not be seen as race issues. The distinguishing factor between 'honour-based violence' and other forms of violence against women, however, is the level of social collusion experienced (The Crown Prosecution Service, n.d., Honour Based Violence section).

Social and communal collusion within diaspora communities in New Zealand may differ greatly from practices in the home countries. In South Asia, for example, punishments for marriages deemed inappropriate are often made by panchayats, which are local selfgovernments at the village or small town level. The punishments meted out by the panchayats often included "revenge rapes, burning down of homes of those judged to be transgressors of caste boundaries, lynchings and beatings" (Baxi, Rai, \& Sardar Ali, 2006, p. 1243). One of the most famous incidents of panchayat-sanctioned genderbased violence is the gang rape of Mukhtar Mai in 2002 in the Muzaffargarh District of Pakistan (Mai, 2006).

The Mastoi clan, which is richer and more powerful than the clan Mukhtar Mai belonged to, alleged that her 12 year old brother had had an affair with a woman from their clan. The panchayat ordered that Mukhtar Mai, the only girl in the family, be raped by six Mastoi men as a form of honour revenge. Mukhtar Mai gained international acclaim when she chose to speak up about the incident rather than to commit suicide as many other Pakistani women had done (ibid.). In 2011, Pakistan's Supreme Court acquitted five out of six men on grounds of 'insufficient evidence' and reduced the sixth man's sentence from the death penalty to life imprisonment (BBC News, 2011).

While such a high level of collusion may not exist in the New Zealand context, Shakti has anecdotal evidence of women who have experienced community pressure to stay within abusive marriages (Bay of Plenty Times, 2009). Many of these women had approached community leaders for support only to be rejected and told to keep quiet about the violence. In other cases, women have been approached by men from their religious institution and told to withdraw their Protection Orders and return to their abusive husbands (ibid.). They were also told that what they had done (leaving their husbands and thereby breaking up the family unit) was wrong in the eyes of God. Such collusion on the part of community members with the abuser places the safety of women and children from these communities in further jeopardy. The use of religio-cultural frameworks by individuals to perpetuate violence against women 
causes their religions to be perceived in a negative light, although no major religion condones genderbased violence. In addition, members of ethnic cultural and religious organisations appear to focus on blame-shifting and the denial of issues such as forced marriage and honourbased violence rather than a concerted effort to investigate and address them. This tendency towards denial and blame-shifting is evidenced by news articles and comments by representatives from ethnic cultural and religious organisations in early 2011 and 2012 ((Indian Weekender, 2011).

The denials appeared to be either due to a lack of knowledge, as these representatives have not personally heard of such marriages taking place, or out of fear of further "damaging and degrading" the reputation of the minority communities concerned (ibid.). Few comments by members of minority communities indicated an acknowledgment of the need to further look into forced marriage and to prohibit the practice. The majority of commenters, however, missed the point completely and opted instead, to become incensed by what they perceived were accusatory remarks levelled against specific communities rather than to address the issue of violence against women and specifically, forced and underage marriage in their communities.

This study, therefore, aims to shed some light on an issue that is potentially invisible to the majority and hidden by the minority but is the gruesome reality for many women and young girls in New Zealand. It aims to do so without fuelling an anti-minority discourse. The study, using a GAD framework, strives to promote constructive change and the improved protection of minority women's rights in New Zealand.

\section{Thesis Structure}

The next two chapters of the thesis (Chapters Two and Three) provide a context and conceptual framework for the study respectively. Chapters Four and Five present survivor stories and documents the survivors' analyses of their experiences and the changes they feel are required to deter the practice of forced marriage. They are premised upon the understanding of narrative research as the "key to the self" and on Spivak's concept of subaltern agency in order to facilitate change at the individual level and ensure that hitherto silenced voices are heard as they see fit (Kimura, 2008, p.1). Kimura (2008) and Spivak (cited in Kimura, 2008) argue that there cannot be agency without subject-formation and that 
each woman's narrative should be viewed as a space for subject formation. Chapters Four and Five are a documentation of that space for subject formation. Chapter Six provides a brief analysis of current New Zealand legislation relevant to the practice of forced marriage and situates this analysis within a wider context of New Zealand's international obligation on the issue of forced marriage. Chapter Seven discusses the views of various stakeholder agencies and their potential contribution to addressing the issue of forced marriage. It also reflects on potential multi-sector collaborations and national strategies as discussed in the stakeholder engagement workshop held in December 2011. The eighth (final) chapter offers a discussion and analysis of key findings in relation to the research questions outlined earlier in this chapter and also to the wider development discourse. This chapter also provides specific recommendations for legislative, and other, changes that could be taken in New Zealand to deter the practice of forced marriage. The thesis is brought to a close by the Epilogue, which outlines an incident that took place at the time of writing this thesis. The incident highlights the need for increased awareness and understanding of issues of honour-based violence and forced marriage in New Zealand. It also highlights the need for immediate action on several different levels.

\section{$\underline{\text { Conclusion }}$}

This chapter has introduced the rationale and aims for this thesis. It has defined some key terms and situated the study personally and within a wider landscape of advocacy and activism on the issue of forced marriage in New Zealand. It has provided a brief background to the growth of New Zealand's diverse populations, the practice of forced marriage and linked this to GAD literature. The following chapter will delve into genderbased violence and the notion of 'honour' in home countries, diaspora communities internationally and within New Zealand. 


\section{Chapter Two: Violence against Women - Common experiences in Different Countries}

\section{$\underline{\text { Introduction }}$}

International migration has led to the birth of diverse, interconnected global societies. This phenomenon has both positive and negative ramifications on the social, economic and political landscapes of host countries. One negative ramification is that issues that may have once been contained in the home country may now be transposed to the host country. The host country is understandably unaware of the nature of the issue, its implications and of the best ways to address it without causing offence. To provide a context for the issues of honour-based violence and forced marriage as they manifest in New Zealand, this chapter begins with an overview of genderbased violence in parts of Asia, Africa and the Middle East $^{5}$. It then looks at genderbased violence within diaspora communities internationally before exploring literature on violence against women in New Zealand.

\section{The International Situation: Asia, Africa and the Middle East}

Eleven year old Pushpa from a village in southern India woke up one morning and found out that she was going to attend a wedding: hers. Her parents and relatives had arranged for her to marry her 25 year old first cousin ${ }^{6}$ (CRS, 2011).

Khalida is 9 or 10 years old, says her father Sayed Shah who loves his ten children but is unable to keep track of all their birth dates. Khalida is also a loan bride. When Sayed Shah, a poor Afghan opium farmer, had to borrow $\$ 2000$ from a local trafficker and was unable to repay his loan, the tribal council ruled that he would have to repay the loan by giving Khalida in marriage to the 45 year old trafficker (Newsweek, 2008).

\footnotetext{
${ }^{5}$ Other geographical areas are excluded from this study due to limitations in terms of the scope of the study and in keeping with the ethnicities of potential research participants i.e. women and girls who access Shakti's services. I do not mean to imply that genderbased violence is more prevalent in these locations.

${ }^{6}$ The stories (in italics) have been paraphrased from the original and the narrative style of the source has been adopted to retain the sense and feel of how the information was originally communicated.
} 
Eleven year old Mwaka Simbeye from Malawi was sent to a neighbour's house to be his second wife in return for a 2000 kwacha (US\$16) loan that her father could not otherwise repay. Her mother said she objected as she felt her child was too young for marriage. However, her pleas fell on deaf ears. She says, "the control is with the man [as] the daughters belong to the man" (The New York Times, 2005).

In 2008, a feud that started out over a dog in Pakistan's remote western Baluchistan province was resolved through the exchange of 15 girls aged between three and ten years, for marriage. The marriage was in keeping with an ancient tribal practice called 'vanni' (The Guardian, 2008).

In 2003, thirteen year old Naila Farhat had acid thrown at her by a rejected suitor - her parents had refused his proposal as she was too young and they wanted her to continue studying. Naziran Bibi, a widow at the age of 23, was forced by her mother-in-law to become her brother-in-law's second wife. Abused by her new husband and his first wife, she was subjected to an acid attack while she was sleeping. Naziran, her two young daughters and Naila are currently being supported by the Acid Survivor's Foundation in Bangladesh (The Times of India, 2009).

The stories above are gruesome reminders of the low status accorded to women and girl children in many parts of the world. In these places, girls are considered dispensable and disposable. Gender-based violence, or violence that is inflicted on a woman because of her gender, and violence which disproportionately affects women and girls, is one of the most systematic and prevalent human rights abuses in the world (Dickson, Herbert, \& Hill, 2009).

The United Nations Declaration on the Elimination of Violence Against Women states that:

violence against women constitutes a violation of the rights and fundamental freedoms of women and impairs or nullifies their enjoyment of those rights and freedoms ... [it] is a manifestation of historically unequal power relations between men and women ... [and] is one of the crucial social mechanisms by which women are forced into a subordinate position compared with men... States should pursue, by all appropriate means and without delay, a policy of eliminating violence against women (United Nations, 1996, p.1). 
Gender-based violence refers to violence that disproportionately affects women more than men and violence that is perpetrated towards women just because they are women (Herbert, Hill, \& Dickson, 2009). Forms of gender-based violence including female foeticide, female infanticide, female genital cutting, loan brides, acid attacks on girls and women, forced marriage and dowry/bride-price abuse are rife in many parts of Asia, Africa and the Middle East. Girl children are also often denied education and other basic rights such as adequate nutrition.

According to the Population Council, 47 per cent of girls in India aged between 20 and 24 were married by the age of 18 (Population Council, 2011). India's total population in 2011 was 1.21 billion of which 586.5 million were female (Census Commissioner of India, 2011). This meant that approximately 275.6 million girls in India alone were married before the age of 18. Researchers estimate that one-third of the girls in the developing world (excluding China) are married before the age of 18 (Population Council, 2012). These millions of girls are considered 'children' or minors, as discussed in the previous chapter, and should be protected by the United Nations Convention on the Rights of the Child. A research study published in the International Journal of Gynaecology and Obstetrics indicates that 43 per cent of girls who have undergone underage marriage are subjected to domestic violence (Raj et al., 2010). It also noted that the violence often continues through pregnancy and childbirth and found a disturbing correlation between underage marriage and infant, child and maternal mortality rates (ibid.).

\section{$\underline{\text { Violence Travels: International Migration and Diaspora Communities }}$}

Outward migration from Asian, African and Middle Eastern countries is not a new phenomenon. In addition, international migration has increased from an estimated 150 million in 2000 to 214 million in 2010 (International Organisation for Migration, 2010). Literature on the topic of migration and development appear to draw a common consensus international migration has had a significant impact on development in home and host countries. Outward migration is on the rise and the number of destination countries is also increasing (ibid.). The Fourth World Migration Report indicates that India, China and Bangladesh are among the top ten emigration countries worldwide and that the United States of America "remains the top migrant destination in the world" (ibid., p.150). In 2009, there was a sharp increase in migration from China and India into New Zealand (ibid., p.223). This 
indicates that a large number of migrants from Non-English Speaking Backgrounds (NESB) are moving to countries wherein the predominant culture is significantly different and where English may be the first language.

With a marked increase in international migration and globalisation, certain issues that were previously confined to certain geographic locations are now found in diaspora communities internationally. This is not to suggest that genderbased violence did not previously exist in countries like Canada, the United States or the United Kingdom. It is merely a different form of genderbased violence, nuanced by a different set of socio-political factors that has been translocated to these countries through international migration.

In June 2000, 25 year old Canadian-born Jaswinder Kaur Sidhu flew from her home in Canada to India in order to reunite with her husband whom she had married in secret on a previous trip. She was kidnapped, tortured and murdered upon orders from her mother and uncle who were still in Canada and who had disapproved of the match (The Washington Post, 2003).

In her autobiography, Jasvinder Sanghera tells the story of a 15 year old Sikh girl, born and raised in the UK, who ran away from her family to escape a forced marriage. She was subsequently disowned by her family and ostracised by her community. When her younger sister killed herself to escape a forced marriage which she was not allowed to leave, Sanghera established Karma Nirvana, a nonprofit organisation that supports victims of honour-based abuse and forced marriage (Sanghera, 2007, 2009).

In 2009, the story of 15 year old Tulay Goren shed light on honour killings in the United Kingdom. Tulay's Turkish Kurd father had drugged, tortured and killed her in 1999 because she had fallen in love with a man from a different sect of Islam (The Telegraph, 2009).

Also in 2009 in Phoenix, United States of America, 20 year old Noor Almaleki was "mowed down" by her father, who wanted her to act like a traditional Iraqi woman and was angered when she refused an arranged marriage, went to college and had a boyfriend (Tang, 2009). 
In April 2010, 18 year old Aliza Mirza was stabbed and left to bleed to death in East London by her Afghani ex-boyfriend after she ended their violent relationship (BBC News London, 2010).

In October 2010, 40 year old Assia Shahzad was stabbed to death by her two sons in her home north of London, allegedly for divorcing their father and seeing other men (Fernandez \& Andrew, 2010, What's On Xiamen, 2010).

According to World Health Organisation statistics, each year about 5000 women are murdered by family members in the name of honour worldwide (World Health Organisation, 2009). There was a sharp increase in the number of honour-based crimes in London from 2008 to 2009. According to The London Metropolitan Police, there were 129 honour-based crimes between April and October 2009 in London compared to 132 in the year 2008/09. Migrant women's rights groups believed the official figures to be the 'tip of the iceberg' and added that figures were on the rise with growing religious fundamentalism. The UK's Forced Marriage Unit reported a rise in Lesbian Gay Bisexual Transgender (LGBT) victims seeking help as a result of being forced into marriage by parents who have "deep religious and cultural objections to homosexuality" (Goldberg, 2010, para. 15). One girl who had been forced into marriage for this reason and had accessed support through the unit spoke to a UK newspaper about her experience. She had been subjected to severe physical violence including burning, signed away in an Islamic marriage to a strange man in another country and when all else failed, taken her to her grandmother's house in the Middle East where her parents tried to persuade her to commit suicide (ibid.).

As mentioned previously, genderbased violence may manifest differently in different countries, given varying socio-cultural norms as well as different legal and political systems. Diaspora communities are often caught between two very different worlds where practices and beliefs deemed unacceptable at home are the norm in the new society.

I acknowledge that migration involves millions of diverse people, different waves and numerous push-pull factors. However, research suggests that knowledge of a common language is crucial to integration and that migrants from NESB take a longer time to integrate into an English-speaking host country's culture (Ebaugh \& Yang, 2001). As such, many of them tend to live in clusters and form a subculture within the host country. The collectivistic nature of these communities can be both beneficial and detrimental as, on one hand, they provide each other with a support network. On the other hand, these groups also tend to be 
insular and cling to their ethno-religious identity, using it to help them adjust to the challenges of surviving in a demanding and often threatening environment (ibid.). Some of these socio-cultural practices may, in actual fact, be human rights violations that are enforced out of fear of losing one's culture and protecting one's daughters in an alien environment.

Abuse that is inflicted upon women in the name of honour is rife in societies wherein socially constructed ideals of masculinity are underpinned by notions of 'honour' such that the honour of a man, a family or a community is vested in the women of the group and "frameworks of 'honour', and its corollary 'shame', operate to control, direct and regulate women's sexuality and freedom of movement by male members of the family" (Coomaraswamy, 2005, p. xi). Collective groups - both families and communities - that operate according to 'honour' codes exist in New Zealand as well. While there may be a comparative lack of visibility of honour-based violence and honour crimes in New Zealand as compared to the United Kingdom, this does not necessarily mean that they do not exist.

\section{Gender-Based Violence in New Zealand}

In 2004, 23 year old Gulshad Banu Hussein was burnt to death by Ahmad Riyaz Khan in Otahuhu, Auckland. Her crime was that she had rejected him and therefore, brought 'dishonour' to him (New Zealand Herald, 2011).

In 2005, a 14 year old girl of African descent who had lived in New Zealand since the age of six was forced by her parents to marry her rapist who had impregnated her. As she was underage, she was denied medical care by her family at the time of delivery and when she finally left her husband, was disowned by her family and ostracised by her community for bringing 'shame' on them. In 2011, at the age of 19, she has three children and is focused on rebuilding her life and coming to terms with the trauma she has experienced (Shakti Community Council Inc., 2010).

Also in 2005, 32 year old Chitralekha Ramakrishnan had her throat slit by a husband who claimed he was provoked by her lack of subservience to him. He was also enraged that she had spoken to a friend about their abusive marriage and her desire to leave it (Du Chateau, 2006). 
More recently, in January 2010, Ranjeeta Sharma was set alight by her husband and left to burn to death at the side of a road near Huntly (The Timaru Herald, 2011).

These stories represent the experiences of some girls and women who have been abused and killed in New Zealand. There are many more whose stories are never heard. There is no systematic data collection on the rates and prevalence of honour-based violence and forced marriage in New Zealand. The data collected by Shakti ${ }^{7}$, while an excellent starting point, has geographical and demographic limitations. It is, therefore, not reflective of the extent of the issue in New Zealand. Yet there exists a growing body of anecdotal evidence from women and girls who have experienced actual or threatened forced marriage.

As mentioned in Chapter One, comments from representatives of some ethnic cultural and religious organisations published in the ethnic media in 2011 (The Indian Weekender) suggest that there is a tendency within ethnic communities to deny the existence of forced marriage. This tendency may be due to a genuine lack of awareness of the issue or a desire to avert further marginalisation. In either case, such an attitude only serves to further marginalise women and girls who have been subjected to abuse within these communities. The true extent of VAW in New Zealand is unknown, partly due to its hidden nature and also because of the lack of sufficient sex-disaggregated national data. The latter was noted in the 2007 concluding comments by the CEDAW Committee to the New Zealand Government (United Nations, 2007). Literature on the issue, however, appears to draw a common consensus: it is very high and it needs to be addressed (Pillai, 2001; Tse, 2007).

Over the past decade, the high levels of domestic violence in New Zealand have been brought into the public sphere by a number of research studies and reports. The literature also documented and analysed its impact on women's health and advancement as well as its social, economic and political implications. A 2004 study of 2855 women aged 18-64 years in Auckland and North Waikato found that roughly one in three women who had ever had a partner reported that they had "experienced at least one act of physical and/or sexual violence by an intimate partner" (Fanslow \& Robinson, 2004, p.9). The study's results are consistent with the findings of other national studies such as the New Zealand National Survey of Crime Victims and the 1995 Hitting Home Survey which found that 35 per cent of a nationally representative sample of men had been physically violent to an intimate partner in their

\footnotetext{
${ }^{7}$ See Table 5.1, Chapter Seven.
} 
lifetime (ibid.). The 2009 Leitner report, as it is commonly known, noted that domestic violence in New Zealand was still "surprisingly high" despite significant efforts to eliminate it (Leitner Centre for International Law and Justice, 2009, p. 20).

A report released by UN Women in July 2011 ranked New Zealand as one of the worst affected countries in the Organisation for Economic Cooperation and Development (OECD). The study noted that one third of New Zealand's women had reported domestic violence between 2000 and 2010 (UN Women, 2011). Sexual violence levels were also found to be high. International research indicates that reported figures of domestic violence usually reflect the tip of the iceberg. As such, it is possibly quite safe to conclude that the real extent of domestic violence, internationally in New Zealand, remains submerged and invisible to the public eye (Gracia, 2004). The prevalence of domestic violence despite concerted efforts towards its elimination is corroborated by a New Zealand Government report also released in July 2011. According to this report, police records indicate that 74,785 children were present during domestic violence incidents and offences and that 27 per cent of New Zealand children aged between nine and 13 years reported witnessing violence against adults (Centre for Social Research and Evaluation, 2011). The New Zealand Government's Campaign for Action on Family Violence, popularly known as the 'It's Not Ok' Campaign is a communityled campaign that aims to challenge "attitudes and behaviour that tolerate any kind of family violence" (New Zealand Government, 2005, n.p). The highly visible social marketing campaign also includes activities, interventions and resources that perpetrators could access. The campaign received top rankings in a study that analysed 16 campaigns targeting perpetrators of intimate partner violence in five English-speaking countries - the United States, the United Kingdom, Canada, Australia and New Zealand (Cismaru \& Lavack, 2011). The It's Not Ok campaign was one of only two such campaigns that addressed most of the stages of change considered important for perpetrators to change their behaviour (ibid.).

It is acknowledged that literature on the prevalence of domestic violence does not necessarily shed light on causal factors. Feminist analyses of the issue indicate that domestic violence is "a consequence of patriarchal power, with social and economic structures making women dependent upon men and therefore vulnerable to abuse by them" (Hayden, 2010, p. 7). Research conducted in the United States examines whether there are certain types of family structures that promote violent or non-violent relations (McCloskey \& Eisler, 2008). The conclusion is that beliefs about aggression and male privilege are central to the perpetuation of domestic violence. Beliefs are both created and supported by various institutions including 
the family and the larger social structure and when these become the prevailing values and beliefs of a particular set of people, it comes to be known as their 'culture.' Therefore, as McCloskey and Eisler (2008) point out, "the family is not only influenced by, but in turn also influences, the larger social structure and culture of which it is a part. In short, what we view between families and culture is a transactive process" (p. 1).

The interconnectedness between families and culture is an important aspect to consider when examining structures that contribute to the perpetuation of VAW and more specifically, honour-based violence and the influence of 'culture'. While culture does not determine whether or not violence exists, it could play an important role in its perpetuation.

Literature on VAW in Asian communities in New Zealand acknowledges that domestic violence exists within these communities. However, there is limited research on the causal factors, prevalence and impact of domestic violence on women and children from ethnic minority groups (Pillai, 2001; Tse, 2007). There is a consensus in the literature that women and children from these communities are further disadvantaged due to a number of factors including settlement issues and the social sanction of male privilege and dominance over women (ibid.). Pillai (2001) stresses that "the issue of cultural and structural violence among ethnic communities is of particular importance [to understand] domestic violence in immigrant communities" (p. 968). At the same time, she cautions against grouping all ethnic minority communities in the same basket and assuming that they have similar social and gender structures as there is a high level of diversity within and between each community. As such, "perceptions of violence vary from culture to culture [and] the perspectives of other ethnic groups cannot be accepted as universal" (ibid., p. 969). However, Pillai draws upon the commonalities between the social and family values shared by many Asian societies to form the basis of her analysis of domestic violence from an Asian perspective.

Many first generation Asian immigrants chose to migrate to New Zealand because of Immigration policy. For some of them, the experience was often very difficult as they were faced with disempowering unfamiliarity. The lack of familiarity served to exacerbate women's gender-related vulnerabilities and contributed to increased domestic violence (Pillai, 2001; Tse, 2007). Pillai (2001) and Tse (2007) explored the lived reality of migrant men and women as well as the link to domestic violence.

As Pillai points out, domestic violence does not exist in a cultural vacuum. The beliefs and value systems brought with the communities are often maintained with extra zeal in the face 
of cultural difference and the threat of cultural erosion. Tse's interviews with Asian female survivors of domestic violence reveal societies that privilege men and reinforce this privilege through the (mis)interpretation of values, beliefs and religious texts. Values and beliefs that reinforce male superiority, practised over a significant length of time may result in societal norms that include a tacit acceptance of VAW. Societal norms may also promote the objectification of women such that married women are considered the property of their husbands. The beliefs and value systems are then internalised and translated into practice. Practices such as dowry, forced marriage, arranged marriage, as they are observed today, further devalue women and sanction violence against them.

Reports and papers written from a non-ethnic perspective tend to place considerable distinction between arranged and forced marriage. The former is often referred to as a respectable, legitimate, consensual practice. Some genuine arranged marriages entered into with the full and informed consent of both parties, may still exist. However, ethnic feminist academics and practitioners alike point out that the line between the two may be extremely fine. The line is blurred further by the "dominant ethos of marriage and family as being sacred" (Pillai, 2001, p. 965; Gupta, 2003). Many women do not question the inevitability of marriage as this is an attitude that is ingrained in boys and girls alike from childhood. This attitude leads to a confusion between forced and arranged marriages as is highlighted, inadvertently, by one of Tse's (2007) research participants. Her marriage was arranged and conducted, in her home country where she lived, to a New Zealand citizen of the same ethnicity. A few months after she moved to New Zealand to be with her husband, she discovered that he had had a girlfriend all along and had no intention of ending that relationship simple because he was married to someone else. He had agreed to the arranged marriage merely to obey his parents' wishes. When she objected to the situation, she was abused. She says, “I wasn't his choice. It was an arranged marriage” (Tse, 2007, p.180). An attitude towards marriage as inevitable rather than optional could lead to a blurring of lines between coercion and consent.

A 1997 episode of the magazine series Asia Dynamic (later known as Asia Downunder) entitled Henna on my Hands, follows New Zealand-born Indian, Nalini Chhima on a trip to India. She was in India for a few weeks and was expected to choose a life partner during the trip (Barrett, 1997). The focus of the documentary was on the struggles migrants face settling into a new culture. However, it inadvertently highlighted Siddiqi's (2005) point that coercion is often expressed through idioms of love, duty and filial piety and therefore, the line between 
consent and coercion becomes blurred. In one particularly poignant scene, Nalini sat next to her mother and talked about the pressure she was under to find a husband in such a short time. She said that she felt as though she had no option but to find someone whom she could at least get engaged to, before her return to New Zealand. Her mother sat next to her throughout, as Nalini stared at the floor and explicitly stated that she felt "forced" to get engaged quickly. Her mother's response was that she, too, had rebelled against the idea of an 'arranged ${ }^{8}$ ' marriage, but had eventually succumbed. She acknowledges that the first few years of marriage were extremely difficult. She said that she and Nalini's father grew to love each other. She wished the same for her daughter. It was clear, as the documentary progressed, that Nalini's parents loved their daughter and believed that their actions were in her best interests. As such, it shed some light on the mindsets of well-intentioned parents who use emotional coercion to get their daughters to agree to the marriage and are unable to identify that their behaviour is coercive. It also dispels the myth that forced marriage only takes place amongst new migrants as both Nalini and her mother were born and brought up in New Zealand; it was Nalini's maternal grandparents who had moved to New Zealand. Finally, the documentary highlighted the misery that girls, like Nalini, undergo when they are brought up in a home environment that considers marriage inevitable and are exposed to very different social norms outside. Nalini had been told that she needed to pick a suitor, out of two candidates, for an engagement. She only realised after the event, that what she had been told was an engagement, was actually a wedding. Her parents had agreed to this at the last minute at the request of the prospective groom's old, ill parents. As Nalini did not understand the marriage rituals (which were in Sanskrit), she did not realise that she had sat through her own wedding. It was not clearly mentioned, in the documentary, whether it was a legal marriage in India or a customary wedding. After the wedding, and a few days of misery, she returned to New Zealand while her parents remained in India for an extra month. On the flight back, she had some time to reflect on what had happened, without any parental pressure. By the time her flight landed in Auckland, she had decided to end her marriage (Television New Zealand, 1997).

Often, women who have internalised deeply patriarchal ideas of gender in societies that normalise domestic violence are unable to identify abuse and gender inequality. They begin to do so only when they are faced with a culture that actively promotes women's rights and

\footnotetext{
${ }^{8}$ It did not even cross Nalini's mother's mind that Nalini felt coerced into making a quick decision. It did not appear to have ever crossed her mind to ask Nalini whether she wanted to marry at all and if she did, whether she wanted to find a spouse in a different manner.
} 
allows issues such as domestic violence to be discussed in the public sphere. Sharp et al. (2003) support this view. They note that culture is dynamic and responds to both "environmental changes and to contact with a number of other groups" (p. 292). In many Asian societies, women are controlled by their fathers until they get married, by their husbands after marriage and by their sons in old age. It is only when Asian women stop playing the part of obedient wives and daughters and identify that which they considered to be a "normal part of married life" as domestic violence, that the real trouble begins (Pillai, 2001, p. 965).

A study by the Ministry of Social Development indicates that immigrant women from Asia and the Pacific are more likely to be killed by male partners than any other group in New Zealand (Martin \& Pritchard, 2010). During a five year period from 2002 to 2006, there were 15 Asian victims of domestic violence homicides. The report acknowledges the difficulty in distinguishing between the risk of violence as opposed to the risk of homicide and stresses that individual factors do not elevate risk. Instead, it is the cumulative effect of factors such as the threat of financial ruin, separation risk $^{9}$, substance abuse and mental illness that exacerbate the risk of homicide. The report does not, however, state whether all 15 Asian victims were female and also does not provide gender- and ethnicity- disaggregated analyses of the findings. Ethnicities recorded are limited to Māori, New Zealand European, Pacific and Asian with no definition of the category labelled 'Asian'.

The report by Pillai (2001) appears to be the first report to acknowledge the existence of domestic violence within Asian communities in New Zealand. It is also a valuable piece of research as it provides a feminist analysis of the violence and attributes the perpetuation of domestic violence to patriarchal structures and systems. Tse (2007) examines South and East Asian women's individual experiences of domestic violence through interviews and focus groups. This report also explores barriers to accessing support services and identifies trigger factors. Most of the triggers have their roots in the structural perpetuation of male dominance. Other factors include racism, discrimination, immigration, financial hardship and the stresses of settlement which exacerbate male desire to control their wives. Both papers, however, fail to address intergenerational violence and the abuse that is meted out to daughters who experience a clash of cultures- male privilege at home versus gender equality and women's

\footnotetext{
${ }^{9}$ Studies have shown that the risk of violence increases at the time of marital separation.
} 
freedom of expression at work or school. There is no mention of the violence that may be used to control young girls who attempt to negotiate two very different worlds.

Robertson et al. (2007), presents a much more in-depth analysis of domestic violence experienced by ethnic minority women in New Zealand. The study analyses the impact domestic violence has on them, the barriers they face in accessing support and concludes with an analysis of changes that need to take place to eliminate violence against women. The focus of the report was on women's experiences of Protection Orders and the justice system. Therefore, it included but did not focus specifically on ethnic women's experiences. However, over fifteen ethnic women were interviewed and the analysis of their experience is very thorough.

The report discusses the increased vulnerability of women in abusive situation who do not have Permanent Residence and women who do not speak English or speak heavily accented English. The report also discusses the abuse they are subjected to both in the home environment and by a justice system that displays a distinct lack of understanding of the women and/or their needs. In their analysis of state interventions, Robertson et al. (2007) observed that service providers were often impatient with women who spoke little or no English or heavily accented English. More importantly, conclusions drawn about them by legal professionals (including judges) were made solely by others' accounts, thus removing the women's sense of agency and disempowering them further.

The acceptance and perpetuation of male privilege, male dominance and violence against women is examined in light of women's individual experiences. One of the interviewees reveals the extent to which 'cultural' norms and values are internalised when she says that she was often openly criticised by women from her community, and called a "bad woman" for leaving the abusive situation and applying for a Protection Order against her ex-husband (ibid., p.95). In another account, the interviewee had returned to the abusive situation over five times due to family and community pressure and only finally left when her husband's best friend's wife committed suicide as a result of the abuse.

In another account of a third generation Indian-New Zealander, the interviewee noted that she and her siblings were raised "as Kiwis" in all respects except when it came to the issue of marriage (Robertson et al, 2007, p. 229). She was not allowed to choose her life partner and 
had to have an "arranged"10 marriage. In keeping with what was supposedly Indian tradition (her parents had lost touch with Indian tradition and had to rely on the prospective husband's family to enlighten them), she was not allowed a long engagement and had to marry him within a few months. She later found out that the short engagement was more about the prospective groom's visa which was about to expire rather than Indian tradition. She also realised later that marriage practices had changed in India and that the so called traditions she was forced to follow were no longer strictly followed in the home country. She had been conned into marrying a man she did not know; a man who had already begun deceiving her.

She was subjected to high levels of abuse and developed serious health issues as a result of the abuse. She experienced high levels of family and community pressure to stay within the marriage, despite the abuse and its impact on her health. Her family witnessed the physical abuse but due to a combination of what they termed 'culture' and fear for their own safety, they did not support her. The fine line between arranged and forced marriage, however, was not mentioned by the report.

Interestingly, the only mention of forced marriage, in this report, was by an interviewee who was from one of the Pacific Islands and was not of Asian, African or Middle Eastern origin. She was from a strict Christian family and her parents were well-educated high-achievers who were well-respected within Church circles. She was expected to study medicine at university in accordance with her parents' wishes or get married to a Pacific Island boy chosen by her parents. The physical abuse intensified when her parents saw her talking to a boy and later, when she told them that she was scared of dissections and did not want to become a doctor. She contemplated suicide and finally decided to run away. After months of harassment and stalking, her parents told the community that she had run away with a man with the intention of tarnishing her reputation so that she would have to return to them if she wanted to be accepted into the 'fold' again. Later, they abandoned her and returned to their home country. She suspects this was because her siblings were growing up and her parents were concerned that they would lose control over their other children as well if they remained in New Zealand.

This story is important as it indicates that the practice of forced marriage may be an issue within Pacific Island communities as well and not just in Asian, African and Middle Eastern

\footnotetext{
${ }^{10}$ The interviewee refers to her marriage as an 'arranged' marriage when it was actually a forced marriage since she was not allowed to choose her partner.
} 
communities. The causal factors, impact and implications of forced marriage on women and young girls, however, was not examined by the report.

\section{$\underline{\text { Conclusion }}$}

This chapter provided an overview of genderbased violence as it manifests both in home countries as well as in diaspora communities in host countries. It emphasises that while genderbased violence exists in all societies, the violence may be carried out differently given different socio-cultural norms and varied legal and political systems. This chapter also provided an analysis of genderbased violence with majority and minority populations in New Zealand.

There is virtually no literature on the issues of honour-based violence and/or forced marriage in New Zealand. It is this gap that my thesis aims to fill. The following chapter outlines the research approach in detail. It discusses how and with whom the research was conducted. It also focuses on the ethical considerations and challenges faced while in 'the field' as well as during the 'writing in' phase. 


\section{Chapter Three: Research Approach}

This chapter discusses the epistemological and methodological frameworks that informed the research design as well as the execution of the research study. It outlines the research methods used to generate, analyse, interpret and 'write in' data. This chapter also includes reflections on the challenges encountered and overcome along the research journey as well as observations on the value and limitations of this research study.

\section{Epistemological Framings}

The research study has been greatly influenced by feminist approaches. Throughout, I have sought to ensure that gender is at the "centre of [my] social inquiry" (Sarantakos, 2004, p. 56) via the perspectives of women survivors of forced marriage who participated and in the recognition of the plurality of their roles and experiences (Tolich \& Davidson, 1999; Sarantakos, 2004). As mentioned in Chapter Two, feminist approaches also informed my decision to remain self-reflexive throughout the research process. In keeping with feminist epistemologies, I recognised that no research is value-free and I strove to be critical of my own beliefs, attitudes and value-systems (Sarantakos, 2004). As discussed in the first chapter, my research is influenced by a Gender and Development (GAD) approach and therefore, sees women as "agents of change rather than as passive recipients of development" (Rathgeber, 1990, p. 494). The GAD approach recognises the interconnectedness of women's subordination with social, political and economic structures, the need to challenge these structures and to focus on gender relations rather than on 'women' as the category for analysis.

As a non-Western feminist in New Zealand, this research study is also heavily and more specifically influenced by postcolonial feminism and subaltern studies. As a paradigm of inquiry, postcolonialism challenges the 'West is Best' mentality (Howitt \& Stevens, 2010; Narayan, 2008). It also aims to challenge the stereotypes about non-Western people that are generated through ethno-centric research (Racine, 2011). Quayson (in Racine 2011) argues that the "central feature of postcolonialism is to deconstruct ideologies that create the material effects of subjugation" (p. 17). This feature is relevant to my research in two ways. Firstly, it cautions against essentialising ethnic communities and ethnic women to avoid further marginalising minority communities. Secondly, it emphasises the need for critical 
perspectives. Postcolonial feminist epistemologies attempt to balance the "assertion of the value of a different culture or experience against the dangers of romanticizing it to the extent that the limitations and oppressions it confers on its subjects are ignored" (Narayan, 2008, p. 757). As such, it allows for difference to be recognised, without a value judgement being placed on it and is, therefore, respectful of and attracted to difference rather than wary of it (Howitt \& Stevens, 2010).

Narayan (2008) suggests that non-Western feminists often find themselves in a "curious bind" (p. 759) when attempting to negotiate feminist epistomology. Some feminist themes may be problematic for non-Western feminists who need to think and function within societies that systematically oppress women and value women only if they adhere to the place prescribed to them (ibid.). As such, it may be counterproductive for non-Western feminists to uncritically accept feminist epistemologies that strive to "restore the value, cognitive and otherwise, of 'women's experience"” (ibid., p.759) when, in reality, what we need to do is renegotiate our place and identities in our societies such that we are no longer second class citizens in our own world.

The subaltern, according to Spivak, is often used inappropriately. It is not "just a classy word for oppressed" (De Kock, 1992, p. 45) but refers, specifically, to those who are oppressed as a result of cultural imperialism or the dominance of one culture over the other. Subalternity depends on the mechanics of discrimination and can only apply where a hegemonic discourse exists. What this research study aims, in part, to do is to "work for the subaltern [and] to bring it into speech" (ibid. p. 46) by speaking to rather than for women survivors of forced marriage; by working with them to analyse their experience and the change they feel is needed and finally, by re-working the power differential so that they are the mistresses of their own knowledge.

\section{Methodology}

As a result of these epistemological framings, the research design was initially almost completely influenced by a Feminist Participatory Action Research (FPAR) approach. One of the goals of this research was (and still is) to use the description and analysis of a social reality to help change it (Kindon, 2010). However, one of the basic principles of a FPAR approach is to involve all participants at every level of the research process including its 
focus and direction (ibid.). I soon realised that this was near impossible given the contraints of a Master's thesis and the vast differences between research participants. In keeping with the tenets of both participatory research and action research, however, this research study aims to be both "emancipatory and [to] foster radical social change" (ibid., p.259). Change is needed to ensure that the practice of forced marriage is deterred, victims and survivors are provided adequate protections under the law and perpetrators are held accountable.

Although a participatory approach is adopted while working with women survivors, given the constraints mentioned above, its methodology is on the whole, more closely allied to feminist research. This is evidenced by its orientation to qualitative data generation that focuses on foregrounding women's voices and experiences while aiming for social change.

\section{$\underline{\text { Research Methods }}$}

Data was collected through primary research methods as well as secondary data analysis. Primary data was generated with women survivors of forced marriage as well as representatives of government, quasi-government, non-governmental and United Nations agencies in New Zealand who were interviewed for information on their level of knowledge of, experiences with and commitment to deter the practice.

Secondary data collection and analysis involved a review of relevant texts and literature such as the Marriage Act 1955 and Crimes Act 1961, other government and select committee responses to the petition as well as supporting submissions on the issue. Relevant United Nations conventions were also analysed for their relevance to the debate on forced marriage.

\section{Primary research Methods - Survivors}

\section{$\underline{\text { Recruitment and Location of participants }}$}

The women survivors recruited had either experienced or been threatened with a forced marriage and had previously accessed support services through Shakti Community Council Inc. (Shakti). Women were considered for participation on the condition that they had passed the crisis stage and were considered, by Shakti caseworkers, to be able to recount and analyse their experiences in a safe manner. 
The first step in the recruitment process was to engage with Shakti to obtain organisational approval to work with women service users and to document their experiences through the study. The second step was to engage with Shakti caseworkers through the Youth Unit, which sees the highest number of forced marriage cases, and to discuss the aims and design of the research with them. They were then requested to identify potential participants, contact them and speak to them about the research to ascertain their interest. If they sounded keen to participate, they were given a copy of the Participant Information Sheet (see Appendix 1) and asked to let the caseworker know whether they were keen to participate or not. The information sheet contained details of the study and outlined the commitment that was expected of research participants. Participants were also informed that interviews would be audio recorded but that they could request, at any point during the session, for the recording to be paused or switched off. Those who were keen to be a part of the research were asked if I could then contact them directly and if they agreed, I was given their contact details.

The third step of the research process was to contact each potential participant and introduce myself. I also talked a bit more about the aims of the research and the importance placed on confidentiality. I explained that participants' names would not be used and that pseudonyms would be used instead. I clarified that the research was designed so that women could participate to the extent they desired or could manage. The participants were informed that one of the main aims of the research was to advocate for change that would, hopefully, ensure that other girls and women are not subjected to forced marriage. After a few days, I contacted each potential participant once again for her decision and if she agreed to participate, I scheduled one or two meeting dates and times for interviews to take place. Of the four women and girls who initially agreed to participate in the study, three lived in Auckland and one, in Wellington.

The second step took longer than I expected as I could not begin until VUW ethics approval was granted (see Appendix 2 for application). The process for acquiring ethics approval was slow given the highly sensitive nature of the research. The ethics approval process was extremely worthwhile, however, as it required me to think through the research process in minute detail and consider a number of aspects that I had not thought of beforehand. The importance of self-care, in terms of my own emotional wellbeing, was one of the aspects I had not paid much attention to prior to the ethics approval process. Initially, I had intended to recruit women survivors who had not accessed Shakti's services. I had received information, through the grapevine, of many young girls who had chosen not to access support services. I 
felt that including them as research participants, if they agreed, would add a new dimension to the data generated by the research study. Comments made by members of the ethics committee prompted me to think the recruitment process through in greater detail. I realised that it was potentially unsafe for research participants who had not previously accessed Shakti's services to participate in the study as they were not provided with the same safety checks and balances as the other participants.

\section{Conducting Research}

Although four survivors initially agreed to participate in the study, only two were finally interviewed. The third potential participant relocated to Australia before interviews could take place and the fourth postponed her first interview due to illness. Despite numerous attempts, I was unable to make contact with her again.

Interviews took place in participants' hometowns at locations that were secure, comfortable and conducive to audio recording. Participants were informed, again, that interviews would be audio recorded but that they could ask for the recorder to be paused or switched off at any point. Participants were requested to sign a consent form before the interview commenced and to indicate, on the form, whether they wanted to view their transcripts (see Appendix 3 for a copy of the consent form). One participant indicated that she wanted to view her interview transcript while the other did not.

Light refreshments were provided during each interview session and participants were informed that they could take a break whenever they chose to. One of the participants, who was both studying and working, was only able to meet for interviews in the evening after a full day of classes. The interview location chosen was within walking distance of her educational institution. However she lived in a different suburb and had to travel for over an hour to reach home after each interview. During our first meeting, she inadvertently disclosed that there were times when she was unable to attend classes as she could not afford the bus fare. In appreciation of this and the time she volunteered to participate in the study, I bought her some dinner after the second interview.

Prior to each interview, I prepared an aide memoire that outlined the broad topics or areas that I wanted to cover during the interview. I used the aide memoires to jog my memory during the interview sessions (see Appendix 4 for a copy the aide memoire). I had decided to 
use oral history as my tool of choice instead of surveys or other structured interview techniques. As such, I was able to adopt a narrative, informal style that provided the girls with a 'space' in which they could construct their own identities through their experiences and their analysis of these experiences (Lieblich, Zilber, \& Tuval-Mashiach, 2008). It also allowed me to record the "firsthand knowledge and experience" of girls whose "views have been ignored [and] whose lives pass quietly" (George \& Stratford, 2010, p. 141). Using a survey or structured interview technique would not have allowed me to capture their stories in as much depth.

Two interviews, on two separate days, were conducted with each survivor. Each interview lasted between one and a half to two hours. The participants were unable to volunteer any more time since they were both studying and working. However, I found that this was an optimum length of time as longer interview sessions would have been extremely tiring for them. Both participants appeared comfortable with the use of the digital recorder and apart from needing to take breaks, neither asked for the recorder to be paused or switched off. I was pedantic about testing the digital recorder before each interview since I had decided not to rely on handwritten notes. I took very few notes while they were talking, as I wanted to concentrate on their stories and be able to engage with them throughout the session. The notes that I took were mainly to remind me of follow up questions and clarifications so that I could listen to them with minimal interruptions and ask my questions when there was a natural pause in the story. I also made notes of hand gestures and facial expressions that were relevant to the story or indicative of the participants' emotions.

I reviewed each interview soon after it took place in order to familiarise myself with the details. I also used it to inform changes to the aide memoire for the next interview. Given time constraints, however, (with each participant, the second interview took place either the next day or within two days) I was unable to provide the participant who requested it, with a copy of her transcript until both interviews were completed. The transcription and 'writing in' process are detailed in the 'data analysis' section of this chapter. 


\section{Primary Research Methods - Stakeholder Agencies}

\section{$\underline{\text { Recruitment and Location of Participants }}$}

Stakeholder agencies were identified through existing networks. I had worked with most of them previously either on the issue of forced marriage or on similar issues.

The stakeholders who were invited to participate in the study include (in alphabetical order):

- Child, Youth and Family*

- Families Commission*

- Family Violence Unit, Ministry of Social Development

- Human Rights Commission*

- Immigration New Zealand

- $\quad$ Ministry of Justice*

- Ministry of Women's Affairs*

- National Collective of Independent Women's Refuges*

- New Zealand Police*

- Office of Ethnic Affairs (Department of Internal Affairs)*

- Pacific Women's Watch (New Zealand)

- $\quad$ Rural Women New Zealand

- Shakti Community Council Inc.*

- United Nations Children's Fund (UNICEF)*

- UN Women*

Of the fifteen agencies invited to participate, eleven agencies (those marked with an asterisk * on the above list) eventually agreed to be interviewed. The four remaining agencies did not respond to the invitation on time, expressed interest but did not get back to me with a specific liaison person or ran out of time to participate due to heavy workloads. All research participants were located in Auckland and Wellington.

The first step of the recruitment process was to send each agency contact an email invitation to participate in the research. A Participant Information Sheet (see Appendix 5) was attached to each email to provide them with pertinent information about the aims and design of the research study. Information provided included the need for research participants to have the 
authority to speak on behalf of their agency. While individual participants would not be named in the study, the agency they were representing would be named. Participants were also informed that participation is voluntary and that they may withdraw from the study at any stage up to four weeks after the data is analysed. The next step was to contact those who agreed to participate, either via phone or email, and confirm the date, time and venue of the interview.

I decided to employ a semi-structured interview format for these participants so that the interview was "organised around ordered but flexible questioning" (Dunn, 2010, p. 110). Although I had drafted detailed aide memoires covering a broad spectrum of topics, I ended up narrowing them to include just five or six questions that were used in each of the interviews (see Appendix 6 for aide memoire used). This narrowing was done to ensure that interviews were focused. Interviews with these participants were more streamlined so that an analysis of the current landscape within which forced marriage is practised, and the role that stakeholder agencies may be able to play in deterring the practice, was possible. The recruitment process for these research participants was relatively straightforward as most were keen to participate and contribute to the research study.

Each research participant was interviewed once and the length of the interviews varied between half an hour and two hours. The variation in interview length was the result of different speaking styles and the level of agency involvement on the issue of forced marriage. Ten of the interviews took place in the research participants' offices or in meetings rooms located within their office premises. One interview took place in a hired meeting room. All interviews were audio recorded using a digital recorder. One participant expressed discomfort at being recorded. She was informed that the recorder could be switched off, but chose to continue with it on.

Once again, I was pedantic about testing the digital recorder prior to the commencement of each interview. While I was doing so, the research participant was given a Participant Consent Form (see Appendix 7) to read and sign. Participants were urged to indicate, on this form, whether they wanted to view a copy of their interview transcript. They were given the option, if they chose to view their transcript, to receive it via email or postal mail. They were also asked to indicate whether they would be keen to attend the stakeholder agency engagement workshop that would take place towards the end of the data generation process. Ten participants chose to view their interview transcripts; all ten chose to have the transcripts 
emailed to them. All eleven participants indicated that they would be keen to attend the workshop as long as their schedules permitted it.

Each interview began with a synopsis of the research study, its aims and a brief overview of the data collection methods and where that particular interview fit into the research design. I also touched on the kinds of information I hoped to garner during that particular interview. A combination of the introductory email with a copy of the Participant Information Sheet attached to it coupled with an attitude of collaboration, served to put the interviewees at ease and lead to open communication (Dunn, 2010).

\section{$\underline{\text { Recording \& Storage of Data }}$}

The venue and setup of the room were both crucial to recording quality. One of the initial interviews, with a survivor, was conducted in a room that was stuffy when the windows were shut. When the windows were opened, however, the room was not conducive to optimal recording quality as it overlooked a busy road. However, as that particular interviewee spoke clearly and had a naturally loud voice, the quality of the recording was not adversely impacted. The other survivor interviewed, however, was extremely soft-spoken and rather hesitant in her manner of speech. In this case, despite a quiet location, the recording was unclear in parts. Audio-recording the interview was useful as it allowed me to take fewer notes and therefore, be more attentive to the interviewees' expressions and non-verbal cues. It also enabled the interview to flow smoothly and for me to maintain the "conversational nature of the interview" (Dunn, 2010, p.111). Despite frequent checks and battery changes, the digital recorder refused to work on one occasion. I was then forced to take notes by hand and since I am not well versed in shorthand, this was an arduous task. Thankfully, the participant being interviewed that day offered to read the interview transcript thoroughly and promised to add any information I might have inadvertently omitted.

The recorded interviews were transferred to my laptop after each session. The data was stored in a password-protected laptop to which only I had access. All the interviews were personally transcribed and stored in the same laptop. All hard copy information was stored in a locked cabinet that only I could access. All raw materials in digital and hard copy formats will be destroyed after a period of two years. Research participants were informed of this timeframe in the Participant Information Sheets. 


\section{Primary Research Methods - Stakeholder Engagement Workshop}

One of the main aims of the research study has been to identify the changes that need to take place to deter the practice of forced marriage. The study also aims to ascertain what roles stakeholder agencies may play towards deterring the practice. As this involves a multi-sector response, I felt it would be pertinent to discuss preliminary research findings and potential collaborations in a workshop setting. The stakeholder agency workshop also aimed to reach a consensus with regards to the next step and to explore what each agency could feasibly achieve.

All stakeholder agencies who participated in the research study were sent email invitations to attend the workshop. The workshop was organised to take place as soon as all the interviews were conducted. As the interview process ended only in the last week of November, given scheduling and other constraints, the workshop was organised to take place in the second week of December. This was to allow time for preliminary findings to be determined and to ensure that the session was completed before agencies closed for the Christmas break. I had initially intended to provide stakeholder agencies with two possible dates for the workshop and pick the date that was popular with the majority. However this proved unrealistic given the time constraints and the necessity to hold the workshop before the year end to allow time for 'writing in'.

The workshop was held in Wellington on Friday, December $16^{\text {th }} 2011$ at a meeting room located within the office premises of the Families Commission. Earlier in the research process, I had approached the Families Commission with a request for the workshop session to be sponsored by them. They kindly agreed to sponsor the venue, refreshments and a notetaker for the session, since the research study was relevant to their work in the area of family violence prevention. Operational details were discussed during a face-to-face meeting with a Families Commission-appointed liaison person and subsequent emails.

The three hour workshop was attended by six agencies. The first hour was taken up by a discussion of the two survivor stories and analyses (Chapters Four and Five) as well as preliminary findings (Chapter Seven). Findings were presented in the form of an environmental scan that outlined measures, including direct services, which are currently being taken to deter the practice of forced marriage. An overview of New Zealand's international and domestic obligations was also provided. Attendees were encouraged, over the remaining two hours, to talk about agencies' constraints and how these could be turned 
into opportunities. They were also encouraged to discuss goals and steps that their agencies could take to deter the practice. Chapter Seven includes the outcomes of the workshop discussion.

\section{Primary Data Analysis}

\section{$\underline{\text { Transcription }}$}

I transcribed the recorded interviews as soon as possible to ensure most accuracy. The interviews were transcribed verbatim and non-verbal communication such as expressions and gestures were also included. In the case of survivor interviews, laughter and pauses were also included as I felt that they may provide further insight into the interviewees' emotional state at the time.

As mentioned previously, only one survivor wanted the interview transcript emailed to her. As such, I emailed the transcript to her as soon as it was completed. I informed her, once again, that she was free to make amendments and requested, if she did make amendments, that she use the 'track changes' feature. She did not make any amendments to the transcript and emailed me back saying that she had looked through most of it and it was "pretty accurate" (personal communication, 20 January 2012).

As most of the agency participants had opted to have their transcripts emailed to them, I sent these out as soon I had completed the transcription. I included, in the email, that the interviews had been transcribed verbatim and requested them not to make grammatical amendments and to use the 'track changes' feature if they needed to make any changes. One participant made a few relatively minor amendments and another emailed me back concerned that she had repeated herself throughout the interview. I reassured her that the interview would not be used wholesale in the thesis but that only the salient points would be picked out. She had no further concerns. The participants were emailed when the data had been analysed and informed that they would no longer be able to withdraw from the study. Although I had meant to email them before the four week period ended, a hectic schedule meant that I was only able to email them, in most cases, the week after the period officially ended. None of the agencies provided any indication that they wished to withdraw from the study. 


\section{$\underline{\text { Data Analysis and 'Writing In' }}$}

A significant amount of data was generated from the interviews in the form of interview transcripts. Some agency participants provided me with additional data in the form of notes of relevant meetings they had mentioned in their interviews. As is often the case with qualitative data, the raw data was "unwieldy [and required] some coherence and structure" (Huberman \& Miles, 2002, p. 309). Soon after most interviews were conducted in November 2011, I presented preliminary findings to academics and practitioners at a seminar held in Auckland, jointly organised by the Tangata Whenua Community and Voluntary Sector Research Centre and Unitec Institute of Technology. As I was a grant recipient, I had also been invited to participate in a full-day workshop organised prior to the seminar. Workshop discussions and my own preparation for the seminar presentation meant that I had to analyse and organise the data within a relatively short period of time ${ }^{11}$.

The focus of the research seminar, and therefore the presentation, was on research methods and 'doing community research' in academia. As such, only brief summaries of the survivor stories were required. I drafted the summaries by picking out key experiences from the narratives and substantiating them with relevant quotes so that the participants' voices were heard. Similarly, key points were identified from the transcripts of agency interviews and an overview of existing measures, potential future measures and agency constraints were presented. As a result, a basic data analysis process had commenced even before I was technically out of 'the field'.

Once all the interviews and transcriptions were completed, the next phase of data analysis commenced. Analysis of themes present in the survivor stories was done using coloured postit notes; different colours were used to denote different themes. The various themes and corresponding quotations were then transferring to a large A3 sized flipchart so that I could view the themes concurrently. Having clear summaries, quotes and themes helped during the 'writing in' phase.

Further analysis of the basic findings presented at the community research seminar led to the decision to sort data generated from agency interviews according to two themes intervention and prevention. Agencies that fell into both categories were represented in both. Key points from each transcript was organised in accordance with the two themes. They were

\footnotetext{
${ }^{11}$ The seminar took place on November $17^{\text {th }}$ and at the time, I was still in the process of conducting stakeholder agency interviews.
} 
then further organised into existing measures, possible measures and constraints. Instead of using coloured post-it notes, relevant paragraphs from the transcripts were highlighted in three different colours, each colour corresponding to a particular theme. This information was then used to develop a chart (see Appendix 8) that was distributed to attendees at the stakeholder engagement workshop.

The process of making sense of qualitative data, is often termed 'writing up' and presented as the final stage of a linear progression in which, a singular truth generated from data collected, is reflected (Coffey \& Atkinson, 1996). This notion of a singular truth could not be further from the truth. The influence of feminist epistemologies on my research had resulted in a research process that is one of 'writing in' (Mansvelt and Berg 2010) - cyclical, self-reflexive and one that rejects the notion of a singular truth. As mentioned in Chapter One, the researcher is part of the "matrix of what is known" (Fine, 1994, p.15). From that perspective, only subjective, or situated truths exist.

The 'writing in' phase, especially with regards to survivor stories, was wrought with anxieties: will I be able to protect their identities sufficiently? How much should I include, what should I leave out? Is there enough information included so that the stories will resonate with readers? Have I preserved the 'integrity' of the stories? These challenges are explored in more depth further on in this chapter (see 'Transcribing \& Writing In').

\section{Secondary Research Sources \& Analysis}

Secondary research is the "re-analysis of data" for the purpose of answering research questions (Glass, 1976, p. 3). In this study, secondary research was conducted to answer the following research question: what are the gaps in existing New Zealand legislation that may unintentionally allow the practice of forced marriage to continue?

Secondary sources analysed include United Nations (UN) conventions, relevant New Zealand Acts and relevant reports by various Government departments. Although some researchers have experienced difficulty accessing secondary sources (Glass, 1976) all the sources I required were easily available online. 


\section{Ethical Considerations}

At a recent research seminar, I happened to mention that I was grateful to the VUW Human Ethics Committee for their insightful questions and comments. My expression of gratitude was met with snorts of derision from more experienced researchers. Their attitude surprised me although I was aware that many researchers view procedural ethics as a "formality, a hurdle to surmount to do the research" (Guillemin \& Gillam, 2004, p. 263). One of the researchers in the group remarked that university ethics committees rarely had anything useful to say and that the real concerns while conducting research were generally quite different to the type of information required by the ethics committee. She was referring to the "ethics-committee speak" which is meant to "reassure the committee that we are competent and experienced researchers who can be trusted" (ibid., p.263).

I am extremely thankful that my experience was quite different. I do understand that procedural ethics, or the "seeking [of] approval from a relevant ethics committee" may differ from "ethics in practice" as the latter refers to "difficult, often subtle, and usually unpredictable situations that arise in the practice of doing research" (all quotes Guillemin \& Gillam, 2004, p. $262 \& 263$ ) as our engagement with ethical behaviour does not end once we have been granted ethics approval (Dowling, 2010). However, the VUW ethics application challenged me to think through issues and to consider scenarios that I had previously taken for granted both in terms of physical and emotional 'harm' that the participants - and I - may be exposed to as a result of participation in the study (Dowling, 2010). A face-to-face meeting with the head of the ethics committee was incredibly valuable as she patiently talked me through various concerns and potential pitfalls. In addition, she pointed me in the direction of some extremely valuable pieces of literature on the emotional impact of researching domestic violence and the importance of self-care.

Although critical reflexivity has not traditionally been seen as an ethical notion, I do agree that theoretically informed, self-critical reflexivity is a useful tool "for understanding both the nature of ethics in qualitative research and how ethical practice in research can be achieved" (Guillemin \& Gillam, 2004, p. 263). In keeping with the postcolonial feminist framings discussed earlier, each time I found myself faced with an ethical dilemma, I consciously reflected on and analysed it. I asked myself what the implications of that particular decision or question would be on the research participants and how it may impact their wellbeing. For example, I was aware that although survivor participants were past the crisis stage and 
considered ready to recount their stories in a safe manner, recounting traumatic experiences could potentially lead to emotional harm in the way of retraumatisation of the survivors. Bearing this in mind, the research study was structured such that the narrative style allowed me to adopt conversation-guiding techniques that could contribute to the participants' curative or healing process so that the research process is supportive rather than burdensome (Rosenthal, 2003). On a few occasions, when I felt I needed a sounding board, I discussed my concerns at the next supervision session.

I also took the necessary precautions to protect myself from both physical and emotional harm. I ensured that my cellphone was always charged and within easy reach, that the venue chosen was secure and that someone outside the research process was aware of the dates, times and locations of all my interviews. I also made sure that I took adequate breaks and pampered myself occasionally (Jordan, 2008) in order to relieve some of the stress.

\section{Reflections /Challenges}

As a first time researcher exploring a sensitive topic, there were a number of challenges I needed to overcome throughout the research process. Some of these challenges stemmed from inexperience and naiveté while others were beyond my control. I recorded some of my experiences in the 'field' in a journal. While I was not as regular a writer as I had hoped to be, the journal entries helped me to reflect on the research process as well as my reactions to 'doing research'.

\section{$\underline{\text { Recruitment of and Interviews with Survivors }}$}

The recruitment process was more difficult than I anticipated it would be. This was partly because the Shakti caseworkers I was liaising with, while extremely helpful, were busy with their workloads. It was also partly because, as I was reminded when I re-read a particular journal entry, "I was being a bit of a control freak" (reflective journal, 13 Sept. 2011, p.1). The idea that I had to work around someone else's schedule was frustrating. As I had been a Shakti caseworker myself for many years prior to this research study, I was aware of the difficulties involved in contacting service users whose files had been closed. In many cases, addresses and contact numbers may have changed. Also, many women often did not have 
email addresses. I was also aware, based on experience, that women often found it too painful to recount their experiences and thereby reopen old wounds. As a result, I spent many sleepless nights “terrified that the girls wouldn't agree to participate and that I would be stuck without any survivors to interview" (ibid., p.1).

Literature I had read on good interview practice combined with years of conducting needs assessments with service users meant that I was well aware of the importance of the interview relationship. Given that I was new to the research process, my initial contact with each of the two interviewees was much less relaxed than I had hoped it would be. I found myself apologising for disturbing them with my phone call and thanking them, perhaps more effusively and more often than was strictly needed, before I'd even met them.

The logistical arrangements of booking accommodation and meeting rooms in a city that was gearing up for the opening week of the 2011 Rugby World Cup added to my stress. I had focused a bit too much on the recruitment process and had overlooked the implications of such a largescale event. As a result, the week preceding the interviews was more hectic than it needed to be.

Prior to the first interview, I tested and re-tested the recording equipment as I waited for the interviewee to arrive. While I was nervous about asking the right questions and getting sufficient information from the interviews, I was confident of my ability to deal with the emotions I would undoubtedly experience while listening to a painful story. I was under the impression that my years of experience supporting women and girls who had been subjected to abuse had prepared me adequately for the experience of interviewing survivors of forced marriage. I soon found out that I was wrong. The feelings of guilt I had experienced during my initial contact with them were heightened during the initial face-to-face interviews with both girls. I felt guilty that they had to recount traumatic experiences just for the purpose of my research study. I was also saddened and angered by the abuse they had been subjected to. I was mystified at the depth of emotion I felt and also at my apparent inability to deal with it. This was especially confusing considering the stories were not too different to the ones I had heard on a regular basis at work.

Upon reflection, I realised the difference lay in the tangible benefits to the survivors. In my role as a caseworker, I listened to each survivor's story with a purpose. I could then channel my emotions into producing an action plan alongside her. There was a positive outlet for my anger and sadness in the advocacy that resulted in tangible benefits for the survivor. Women 
generally received professional counselling, legal protections, medical attention, Immigration advocacy, accommodation, financial support and/or a shoulder to lean on for a brief period of time, as a result of telling their stories. In my role as a researcher, I was asking them to recount their stories with no immediate benefit for them. All I could offer them at that point in time in the way of tangible benefits was some food and a supermarket voucher in appreciation of their participation.

I was, however, also offering them the opportunity to be a part of the first piece of research on the issue of forced marriage and more importantly, longer-term social change (hopefully). While my initial reaction to requiring their involvement was that it was not enough to off-set the pain involved in recounting trauma, I constantly reminded myself that the survivors had agency and that it was my duty to respect their decision to participate and tell their stories. This experience led me to truly appreciate the need to reflect on and come to terms with my own reactions to the interview process and to become more aware of my "sense of self in the process of eliciting knowledge” (Hämäläinen, Pirskanen, \& Rautio, 2011, p.4).

\section{$\underline{\text { Stakeholder Agency Interviews }}$}

Organising interviews with stakeholder agency representatives was relatively easier as most were prompt with emails. In addition, as they were representing their agencies, interviews could be scheduled during office hours. Of the four agencies who did not participate in the study, two were keen but unable to and the other two did not respond to the initial email.

These interviews, compared to the interviews with the survivors, were much less stressful as the content of the interviews was much less sensitive. The semi-structured nature of these interviews meant that the data generated was more focused and less emotionally-draining. As such, it could be processed immediately and so, I was not too anxious about asking the right follow-up questions.

However, I was equally mindful of the need to build a rapport with these participants too, so that they felt comfortable providing me with their opinions and insights. In some cases, this was especially important with the government agency representatives as many of them ostensibly knew that I worked with an NGO that had a loud voice when it came to migrant women's rights. However, I was wearing a few different hats during the interview and my aim was to gain information that could foster collaboration between the different agencies. 
Keeping the survivor stories and opinions in mind, I endeavoured to keep an open mind and adopt a positive attitude that was focused on learning and sharing. Many government agency representatives visibly relaxed once I started to talk about the research design and the focus of my work.

\section{Stakeholder Engagement Workshop}

The Families Commission was the first (and only) agency I approached for sponsorship of the workshop. I was hesitant as I had never before approached an organisation with a personal sponsorship request. However I was pleasantly surprised at and grateful for the support I received from the Commission. The process of organising the workshop was also smoothsailing due to the efficiency of Commission staff members.

I approached the task of preparing for the workshop with much trepidation, as I had never before facilitated a three-hour long session. After considerable reflection on outcomes I hoped to achieve, both for myself and for attendees, and with significant guidance from a supportive and experienced supervisor, I organised preliminary findings in the form of a chart.

One of the main outcomes I had hoped for was for attendees to provide one or two tangible steps that their agencies could take, in the next three months, to deter the practice of forced marriage. I had planned to request attendees to discuss possible measures in smaller groups before presenting them to the group as a whole. However, the majority of those present were government agency representatives. As such, they expressed dissonance; they could not confirm measures since their agencies' priorities were set by their Minister. Agency bureaucracy and hierarchies also meant that the representatives present did not feel they had the authority to even suggest possible steps to their superiors. While this was disappointing, I understood that their hands were tied and did not press the issue. Instead attendees chose to discuss, as a single group, possible steps for New Zealand as a nation to deter the practice.

\section{Transcribing \& 'Writing In'}

I approached the task of transcribing without much enthusiasm as my understanding of the process of transcribing, from friends' experiences and relevant literature, was that it was 
mechanical, tedious and time-consuming. Even with this knowledge, however, I underestimated how difficult it was to transcribe survivor interviews for many reasons. Firstly, I had to listen to the abuse all over again. Emotions of anger and sheer sadness I thought I had dealt with, resurfaced. Again, I had no option but to confront the emotions, analyse them and negotiate my way through to the other side. Secondly, the inclusion of nonverbal communication like laughter and a series of full stops to denote pauses meant that most of the sentences looked odd. Finally, a number of words and phrases used by one of the interviews were distinctly Hinglish, or English as spoken in Hindi-speaking parts of the Indian subcontinent. I understood them perfectly, almost instinctively, and have tried to keep translations as close to the original meaning as possible. However, some meaning and certain nuances have unavoidably been lost in translation.

Transcribing stakeholder agency interviews was more straightforward since the interviews were semi-structured and comments were more focused. Interview lengths were also shorter than survivor interviews. In addition, many of the agency participants had some public speaking experience which meant that recordings were clearer and easier to transcribe. Of the ten participants, only one made amendments to the transcript. The changes made were predominantly to 'tidy' up the transcript and fix a few grammatical errors. If any of the other participants had chosen to 'tidy' their transcripts, I would have been disappointed since I wanted to include conversational tones in the study to maintain participants' sense of agency. However as the transcript that was amended, was of the one interview that had not been recorded, due to technical difficulties with the digital recorder, I was thankful for the amendments.

The process of 'writing in' survivor stories took much longer than I expected it to. I was focused on ensuring that the stories were accurate and that survivor identities were adequately protected. My work experience in this area had taught me that even the slightest carelessness in this regard, could jeopardise the survivors' safety with disastrous consequences. I felt even more responsible, and slightly protective of them, because both survivors were younger than me. Also, while I was a stranger to them (and they were strangers to me) when we first met, I had become reasonably friendly with each woman by the time the interview process ended. As such, I felt my responsibilities regarding their portrayal and the protection of their identities, even more keenly. 
Once they had finished telling me their stories, I felt the burden of ensuring that I recounted their experiences accurately. I also wanted to write their stories in such a way that their voices could be heard. Despite attempts to include non-verbal communication such as pauses, laughter, gestures and facial expressions, it was near impossible to include the energy that was palpable during both interviews. I found this disconcerting as it resulted in a chapter that told a story but could not even hope to do justice to the vitality and resilience of its protagonists.

Writing in stakeholder agency opinions and comments had its own challenges. Throughout the research design and execution, I was intent on approaching agencies in the spirit of collaboration. As such, I wanted to make sure that agency portrayals were accurate and fair. Given that the issue is potentially politically sensitive in that it could be used to inflame race relations issues, I was conscious of the need to preserve the tone used by the agencies in original interviews so that they were not inadvertently misrepresented.

\section{$\underline{\text { Wearing Different Hats }}$}

As mentioned in Chapter One, my involvement in the issue of forced marriage in New Zealand began even before I embarked upon this research study. My paid work with Shakti meant that I was actively involved in lobbying central Government for social and legislative change and speaking on the issue through the media. I was also involved with the issue at a service provision level, on occasion, as I advocated on behalf of service users with complex cases. I spoke on the issue at various conferences, seminars and training sessions both in personal and professional capacities. During the same period, I completed an internship with The United Nations Children's Fund (UNICEF) and developed a pamphlet, also on the issue of forced and underage marriage. As an ethnic woman who is passionate about women's rights but also proud of much of her heritage, I had vested interests in the portrayal of the issue in the media and often struggled when it was presented as a race relations issue.

I am convinced that the intertwining of experiences and roles has enriched the research process as it has allowed me to view the issue from various perspectives. At the start of the interview process, I felt that it would be best for me to keep my roles separate to avoid potential confusion. For example, when I was interviewing survivors, after informing them at the start, of my connection with Shakti, any reference to Shakti was in the third person. I soon 
realised, however, that the survivors made no such distinction and often referred to Shakti caseworkers and the work done by the organisation as work that was done by "you people" (Reflective Journal, pers. comm., 12 October 2011). Upon reflection, I realised that it was near impossible to keep my various personas separate and that there was really no need to do so either. FPAR considers the diversity of experiences and roles as "an opportunity to enrich the research process" and, in fact, as one of the key characteristics of FPAR (Kindon, Pain, \& Kesby, 2007, p. 14).

\section{$\underline{\text { Value \& Limitations }}$}

The value of this study lies, first and foremost, in the survivor stories that will hopefully provide readers with a clearer understanding of the dynamics of honour-based violence and forced marriage as they manifest in New Zealand's diaspora communities. Secondly, the analyses of the stories and the changes needed as perceived by the survivors contain valuable information for policy-makers and practitioners alike. Thirdly, the 'environmental scan' provided through a synthesis of stakeholder agency information will be valuable to decisionmakers and policy analysts at various levels from local through to central Government as well as to practitioners in the field of violence against women. Finally, this study hopes to have a positive impact on both minority and majority communities such that the men and women from both are able to acknowledge the issue as a form of violence against women and work together to deter it.

As this is a Master's thesis, the study had to be given a narrow focus and completed within a year. Additional time constraints imposed by my involvement in demanding paid work throughout the research process meant that I had to limit stakeholder agency engagement to the fifteen agencies that were invited to participate. Some readers may consider it a limitation of the study that only two survivor stories were included. Shakti's statistics (see Table 5.1, Chapter Five) indicate that there are many more women and girls who have faced actual or threatened forced marriage. The emotional risks involved in recounting traumatic experiences, is considerable. In addition, the ethnic community's tendency to deny the existence of domestic violence within their community, coupled with issues related to community pressure/social collusion as discussed in Chapter One, mean that there are, potentially, significant physical risks involved. Shakti caseworkers had initially identified around ten survivors of forced marriage, actual and threatened, whom they felt may have 
been keen to participate in this study. Of the ten potential participants, four agreed to participate and finally, only two agreed to be interviewed. Readers must also remember that this is the first piece of research on the issue of forced marriage in New Zealand and as such, provides a platform from which further research can be conducted.

\section{$\underline{\text { Conclusion }}$}

This chapter discussed the methodological and epistemological framings that have informed my research process and kept my research 'real'. The processes involved in generation, analysis and 'writing in' of data were discussed in depth. Considerable focus was also provided on the ethical considerations as well as the challenges faced and overcome along my journey as a first-time researcher, in the hope that these may benefit other researchers in future. 


\section{Chapter Four: Survivor Stories}

\section{$\underline{\text { Introduction }}$}

This chapter aims to keep the survivors' stories 'pure' and to keep them as close to the original as possible. In an attempt to preserve the authenticity of the stories and the survivors' voices, direct quotes have been used liberally. Direct quotes have not been 'neatened' and often contain words and phrases that are grammatically incorrect. These have been retained to preserve the survivors' voices but have been clarified in footnotes ${ }^{12}$. Non-verbal communication, such as pauses that indicated a sense of hesitancy, was recorded in transcriptions. Pauses in direct quotes, in this chapter, are denoted by the use of [...].

All names have been changed to protect the identities of those involved in the following stories. The pseudonyms 'Pisey' and 'Fazia' are relatively common names that were chosen by the survivors themselves. Rotha and Vivek are also pseudonyms; these were picked by me. The ethnicities of the survivors have been withheld along with their cities of residence and other potential identifiers such as their educational institutions and places of employment. The decision not to identify the survivors' ethnicities was deliberate. Firstly, it is a safety precaution since many ethnic communities in New Zealand are small and closeknit; individual members are, therefore, easily identifiable. Secondly, it is an attempt to draw the reader's focus towards viewing the issue as a violation of women's rights rather than one pertaining to 'culture' or race relations. Religious affiliations have been retained as omitting them would have detracted significantly from the stories and the analyses that follow.

\footnotetext{
${ }^{12}$ These words and phrases that are grammatically incorrect in a context where English is the first language are actually perfectly acceptable 'Hinglish' colloquialisms. Spoken English that is literally translated from Hindi and/or contains a mix of Hindi and English words, is colloquially known as 'Hinglish'. 'Hinglish is a popular form of informal communication in many South Asian communities and in South Asian diaspora communities.
} 


\section{Pisey's Story}

Pisey came to New Zealand when she was two years old as a refugee with her parents and four brothers. She was living in a city in the north island at the time of the violence and turned 20 in 2011. She did not know where exactly in her home country her family was from; all she was told was that she was born in Thailand, presumably when her parents were at a Thai refugee camp. Her parents almost never talked about their lives before New Zealand.

Her memories of childhood were not pleasant. Pisey's father worked in a factory and her mum was a stay-at-home mother. Pisey became even quieter and more withdrawn when I asked about her earliest memories in New Zealand. Her recollection of day-to-day events is hazy but her accounts of the abuse she was subjected to are surprisingly detailed in comparison. She says that her father was very abusive, but her mother chose to stay with him because they had separated once, a long time ago. Before she was born, her father had had an affair back in their home country, which resulted in a son. He left Pisey's mother but they later reconciled. Pisey's mother lived in fear that he would leave her again. Pisey found out about her half-brother only when she was about 18 or 19 years old. I asked her "was your father abusive to your mother ....to you?" Her reply was muted. "to everybody," she said. Her mother was also abusive.

I remember she used to...like... hit me and all that...over the littlest things and because our house had only three bedrooms, and my brother had...no, we were renting out one bedroom to help the income and then my brothers shared a room and then since I was little... and my littlest brother slept with my parents in their room, I had a bed on the side in their room... and I was peeling...coz I couldn't sleep, I peeled some wallpaper off and my mum found it and she started hitting me and was like pulling my hair, dragging me across the room by my hair... and she hung my upside down and started shaking me and threw me across the room.

Pisey thinks she was about six years old when that incident took place. She describes it as a "pretty normal" form of discipline when she was young. Her brothers were also physically abused when young.

She was not allowed to have any friends as she grew up because her father did not think friends were important and her mother thought they would be a bad influence on Pisey. I asked Pisey whether her mum had friends of her own. 
Yes, she had friends...but she just didn't like us having friends coz she thinks that they'd influence us...making us rebel against her and just start doing drugs and all that kinda stuff...she's always like you know, kids these days raised in this country are just bad, they're like a bad influence...coz she sees kids on tv.

Pisey was not even really allowed to mix with other children her age who were of the same ethnicity as her unless her mother approved of their parents.

In the community, the parents always judge their children by their parents... if she doesn't like who their parents are, she tells us not to hang out with them...like my best friend who is also [of the same ethnicity], but she doesn't like her mum coz her mum's had like three husbands and all that and she said that she would also be like her mum so she doesn't want me to get influenced by that.

Pisey's mother could not really stop her from seeing her best friend as they were both in the same school. Things changed, however, when her best friend moved to a different high school.

We couldn't really see each other so we'd talk on the internet and everything but my parents always...like they see us.... they say you guys always so on the internet just to chat with friends and all that...because back then we had dial-up so at night, they'd just take the cord so we can't connect to the Internet and the computer would be in the hallway or in the living room or something.

Things started to change as she and her brothers grew older and were able to defend themselves. The physical abuse from her parents slowly died down. However, by then, her eldest brother who is six years her senior took over.

My eldest brother, when he finished high school and started going to study, like university and stuff, he kinda became the head of the family and then my parents, they left it all to him...so he was the one abusing us like if we got into trouble, he'll be the one to punish us like smack us with a belt or whatever.

Pisey left home soon after she turned 18 unable and unwilling to put up with the abuse any longer. Her parents had found out that she had a boyfriend and they disapproved because he was of a different ethnicity. The emotional abuse intensified as they tried to talk her out of the 
relationship by telling her that he probably just wanted her for sex and New Zealand citizenship.

Pisey had not told her parents that she was moving out or left them any information indicating where she was going. She just packed her bags and left. That same day, her father and four brothers turned up at her boyfriend's house where she was staying and tried to persuade her to return home. This was the first time they met her boyfriend and at the time of the interview, she still had no idea how they found her that day.

Her father took her aside to talk to her. Meanwhile, her boyfriend came out of the house. Her brothers saw Pisey's boyfriend for the first time and

as soon as they saw him, they just didn't really like him and like my brother even wanted to smash him and all that...but my oldest brother was like...don't...told him not to do anything.

Her father soon realised that it was futile expecting her to move back home and they left. After that, there was very little contact between her and her family. None of her brothers were supportive of her decision. Her parents were embarrassed that she had moved out, bringing shame and disgracing them in the eyes of the rest of the community.

[The community] don't know that I had moved out. My parents tell them that I'm still living and people who come over or ask for me, they'll just be like she's out at the moment or she's gone for study or something like that.

On one hand, her parents were embarrassed that a child of theirs had chosen to move away from the family home thereby indicating that all was not well within their family unit and casting aspersions on their role as good parents. On the other hand, they were protecting their daughter from slander.

[If the community knew, they would] pretty much just call me a slut and say that I just wanna go out and do stuff and be with guys and that my parents are bad parents for raising such a child.

On one of her infrequent phone conversations with her mother, the topic of marriage was brought up. Pisey was living with her boyfriend and his mother, and as she did not have a job at the time, was relying on him for financial support. However, as he was a year younger than 
her, he was still at school. Pisey's mother's solution to her daughter's situation was to suggest that she marry for money.

After few months, they were just like...you should get married...just for the money. Pretend you're married, just get the money and be supported and all that.

Pisey's mother had been offered NZ\$ 60,000, for Pisey to marry Rotha, a boy from their home country who wanted New Zealand citizenship. The proposition was conveyed to Pisey's parents by a marriage broker and the payment would be made by Rotha's family. Half the amount would be paid once the wedding had been conducted and the other half would transfer hands once he was granted citizenship. Pisey had never met the prospective groom. He had been identified by a marriage broker whose job was to arrange 'fake' marriages. Soon, the emotional pressure from her mum began to intensify.

They were kinda guilt-tripping me into it. They were saying that they need the money as well...coz my mum was gonna take half the money and I was gonna take half and then she was saying that she needs the money as well, she needs it for the family and all that so I kinda felt sorry, thinking that I'd left them already and had broken up the family and...so I didn't wanna make them more disappointed...

Pisey was constantly reminded that her family was poor and that they needed the money. She was made to feel guilty for not contributing to the family's income; she used to work weekends at an Asian grocery store and often shared her earnings with her family. She was blamed for "being a bad child" and moving out of the house before she was married, thereby bringing shame to her family. Often she was also told that it was her fault that her mother had to do all the chores in the house. If she had not left, her mother would have had some help.

Mum said "without you here, I'm the only girl...it's all guys and they don't do anything, they don't help with the chores or anything" and she was just pretty much saying that I was a bad person for making her go through so much pain... when I was there, I would cook, wash the dishes, clean. Just because I'm a girl...I think it was really stupid and I just felt like a slave...just felt like I didn't have my own life... 
Eventually she succumbed to the pressure. She agreed to the marriage to keep her mother happy and to help her family financially. Pisey, along with her mother and the marriage broker, met Rotha for dinner.

[The evening] was really awkward...I didn't really talk at all. It was mainly my mum and the guy who was organising it [the marriage broker] ...they were pretty much just talking and I was just sitting there. And then my mum was talking to the guy I was supposed to marry as well... and like...I don't know.... just didn't really...I wasn't really into it and it was really awkward for me.

Soon after the dinner meeting, Pisey's mother began planning the wedding. There was to be a legal wedding in New Zealand and an elaborate ceremonial wedding in the home country in keeping with the marriage traditions of the diaspora community in New Zealand.

Pisey was trapped. Her life was in a state of turmoil and in the months that followed while her mother was excitedly planning the wedding, she was apathetic and refused to join in. Although she had agreed to keep her parents happy and be the filial daughter they wanted her to be, she had misgivings about the whole situation. To complicate matters further, her boyfriend was angry with her for agreeing to go through with the fake wedding and constantly tried to talk her out of it. She had no support network as all her friends were going through their own relationship issues and there was no adult with whom she could discuss the situation. She was also afraid that her brothers, who had been physically abusive towards her in the past and are volatile, would hurt her boyfriend if she refused. As such, she just went through the motions and existed on a day-to-day basis without giving much thought to what she was doing. When I asked her how she coped, she replied that she emotionally distanced herself from the wedding planning, just went along and did whatever she was asked to do and left the rest to her mother. She also did not talk to her boyfriend about the impending wedding and didn't give him much detail about it. There was no one, she said, with whom she could sit down and talk.

As her mother did not feel the need to consult her and there was no interest on her part, she had no idea about the details of the wedding. She did not know what she would wear, where it was going to be held, what the ceremony would entail, it or who her bridesmaids would be. She knew that she would have some because her mother casually remarked, one day, that 
Rotha would be paying for the bridesmaids' clothes. Once her mother realised that Rotha's family was rather well off, she changed her tune.

She kept talking about like how...he's such a nice boy, and his family's got so much...like if we go to [our home country], we can stay at his hotels and all that and then she was like...you know there are some cases where people actually like do fall in love after they marry and then she was like but if you do fall in love with him, make sure it's after we got all the money and then you can fall in love with him.

She knew, however, that vows would be exchanged and that the wedding would be conducted by a Buddhist priest. She was unsure whether the priest would be aware that the marriage was a sham.

One day, a close friend of Pisey's told her that Immigration was very strict on fake marriages and that Pisey could get jailed if she was caught. She knew this because another friend of hers had been in a similar position. This played on Pisey's mind and she became increasingly frightened of the possible repercussions of breaking the law.

The next time she met Rotha was at a shopping mall for a photo-taking session.

We went to Botany Downs to take pictures of me and him looking like a couple to make it look like it was a real wedding...like we were actually dating before and we were going to get married...that was the second time we met...after that, we didn't really hang out...it was just meetings for what's gonna happen... what we were gonna do...like discussing the wedding.

By this time, Pisey's parents had persuaded her to move back home so that they could make it look like both she and Rotha were living together with them under the same roof. Pisey is convinced that one of the main reasons her parents forced her into marriage, apart from the monetary gain, was to get her to move back home before someone in the community saw through their ruse and word got out that Pisey had run away from home against her parents' wishes.

[They said] if I'm living with them, it would make it easier to make it look like he's living there as well! Coz it's fake, but they'd set up my room to have pictures of us but he'll be living somewhere else but his name would be under our address 
and everything and they said like if Immigration comes, they can deal with it... and all that.

She later found out that the reason for the hastily planned wedding was that Rotha had already been in New Zealand for a month and needed to get married within the next two months ${ }^{13}$. When I remarked on the high level of thought, planning and energy that had obviously been invested into the fake marriage, Pisey laughed and said that the marriage broker had "done lots of fake weddings." He apparently gets paid by the party that hires him; in this case, it would have been Rotha's family back home that would have paid him.

Pisey, when asked, said that she did not know anyone else personally who had been through a forced marriage, fake or otherwise, but that she had heard of about 20 to 30 girls who'd been through both fake and forced marriages. She did not know them personally because she did not have many friends [from her home country], but had heard about them from her parents and the few friends [from her home country] that she had.

A few months into the planning, with the prospect of jail weighing her down and the realisation that she would have to stay married to Rotha for at least six to seven years in order for him to get his citizenship, she decided not to go through with the marriage. She had also spoken to a few friends who helped her to see that parents who truly loved her would not have pressured her into agreeing to a fake marriage. She went to her parents and told them that she had changed her mind.

I was just like... I should be with someone whom I love and not someone whom you want me to be with just for money...I told them it's kinda like selling off your own child.

They were disappointed, upset and angry with her and told her to pack her bags and leave. They also told her that she would have to explain her change of heart to the marriage broker and the boy herself as they didn't want it to look like this was their decision.

The guy...[she sighs]..the guy who was organising it, he kept pushing it on me. He was like...oh...you're probably just upset right now; just take a week to think about it. And I was like no, I don't want to go through with it at all. Like I know for sure. He's like just take a week, just think about it. After that, they left, my parents were like really angry and saying that it's coz of my boyfriend that I don't

\footnotetext{
${ }^{13}$ Although Pisey did not know what visa he was on, from experience and the details that she did have, I suspect that he was in New Zealand on a Visitor Visa to New Zealand for the purpose of culturally arranged marriage.
} 
wanna do it, when really I just didn't want to do it... They were really angry and just saying that I was a bad child and I was making my family look bad...And after that...yeah...I just told them and then my parents just...umm....I can't remember...I kept telling my parents that I really didn't wanna do it and they wouldn't listen. They're like you should do it; you have to do it and all that, that kinda stuff... and so again [she laughs] I just left. I left home again. And then after that...I think it all just ended. Coz...yeah...

So Pisey left home for the second time and lost all contact with her family except for an occasional phone call, possibly once in three months or less with her mother. Her mother still talks about the possibility, if Pisey were to change her mind, of arranging another fake marriage to someone else.

Her father and mother have since split up and her father has moved to Australia with her eldest brother. Her father got remarried without telling them. Pisey is studying hospitality and hopes to get a job that allows her to travel. She does not talk to or interact with her brothers. One of her brothers is a friend of her flatmates'. When he comes over to hang out, she shuts herself in her room. She's still angry with her parents for putting her through the whole experience and she is angry with herself for allowing herself to have been put in that position by agreeing.

I miss having a family. But [I'm] not actually missing them ...like them. 


\section{Fazia's Story}

Fazia came to New Zealand in 2006 with her parents, two brothers and two sisters. Her father is an educated man who moved to New Zealand with his family as a result of a temporary job transfer. Fazia's father was well known within the diaspora community and was considered a man of good standing. Fazia was 13 years old when they moved to New Zealand and was living in a city in the north island at the time of the interview.

Fazia started attending a girls' school very soon after arriving in New Zealand. She describes the first year of school as a lonely experience and a culture shock as she had never met and interacted with European girls before.

I didn't make any friends coz I was really quiet student...I was really scared coz there were like more white people and I have never seen white people before...they would ask me like what's your name and I would say my name and shut up and didn't talk very much...I was just like looking at them...I was a loner in school but I had my sister there so we used to be together during lunch times.

On weekdays, she went straight home after school, completed her homework and helped out with household chores. Dinnertime was a family affair with everyone required to sit round the table if they wanted their meal. Dinnertime conversation was generally dominated by her father who would vent about his work and enquire after his children's studies. He never asked how they were coping in a new country and in a new school. Her parents wanted their children to excel at school; they did not consider making friends as important. She was then allowed to watch some television before bed or go to her room and read or do whatever she wanted. On the weekends, her parents would take them out to the cinema nearby or for a walk on the beach with ice-creams. On a few occasions they went on holiday to nearby cities and towns to explore New Zealand.

After a year at school, Fazia slowly started making friends. Her parents were very strict about whom she mixed with.

I was only allowed to go to their houses like at daytime and was like fixed-only 2 hours, not more than that. And they were allowed to come to our house but only the fixed ${ }^{14}$ girls, like this girl can come in, she looks nice which means like she's

\footnotetext{
${ }^{14}$ Fazia uses 'fixed' here to refer to girls who have received her parents' approval.
} 
really nice, not the girls who are really oversmart ${ }^{15}$... oversmart as in like if they have a boyfriend, then no they can't come in because they're like we will take in their ways like "you'll have a boyfriend in future and we don't want that"...my friends would come to my house and they [Fazia's parents] would ask them like lots of questions like "do you like your parents?" If the girl says "no I don't like my parents" then this girl's not coming in [laughs] yeah...coz my friends were like straight up...they're like... "do you like your parents?" They'd just say "no", then it's "no" [laughs some more] So yeah...they're like..."she's not a nice girl". Or if they're texting too much then "she's got a boyfriend".

Fazia noticed that her friends at school were allowed to hang out with each other. She resented her parents for not allowing her to do the same. To add insult to injury, her older sister was allowed free reign and could go to her friends' houses for as long as she liked. Her friends were also spared the scrutiny that Fazia's friends were subjected to. Fazia was told that she was treated differently because she was the youngest and was, therefore, more susceptible to various influences. In addition, Fazia's sister had spent her formative years in their home country and this, according to her parents, meant that she was less likely to stray from accepted ways, practices and beliefs. So she did not require as much supervision as Fazia did. When Fazia tried to protest, she was told to obey her parents or she would get a slap. She often did get a slap across the face for speaking out. The physical abuse had started when she was much younger and continued until she was about fourteen years old.

In her second year of school, she started work in a nearby supermarket. She was forced to resign after a year as her sister, who was also working there, saw her talking to a boy and assumed that he was her boyfriend. Fazia's mother was informed and Fazia was asked to quit before her father found out.

I got angry coz I didn't have anything going on and they just assumed things...that was not even right and then after one year they were like just look for a job and then I started working at [another supermarket] after that.

That same year, her eldest sister got married. She had been introduced to a Muslim man who was friends with their father and ten years her senior. Since he was Muslim and her parents approved of him, Fazia's sister was allowed to date him on the condition that there was no

\footnotetext{
${ }^{15}$ This is a Hinglish slang word used to refer to girls who are modernised and outspoken and therefore, too smart for their own good.
} 
sexual behaviour. They were also told to keep their relationship 'under wraps' so that other members of their community were not aware of it and were only allowed to date once they had confirmed that they would eventually get married. Soon after their marriage, Fazia's sister became pregnant and her husband took her back to their home country as he wanted his child to be born there. She was allowed to return to New Zealand when the baby was about six or seven months old. Her husband chose to stay on in their home country. Fazia's sister stayed in New Zealand for year and found work at a spa, but had to return to her husband and life in their home country when the year ended.

A couple of years later, Fazia's second sister began dating. As her boyfriend was Muslim as well, they were allowed to date. They too were expected to adhere to the same conditions as the eldest sister. After a year and a half of dating, they got married.

Fazia's mother had been married at fourteen and while she understood that times had changed such that her daughters did not have to get married at fourteen, she felt that an early marriage was beneficial.

When she was seventeen years old, Fazia met a boy, Vivek, at work. After about a month, they started going out. She kept it quiet for seven months because he was Hindu and she knew that her parents would object to their relationship on that basis. By this time, Fazia was studying and since her course was in Information Technology and there were more boys than girls in her class, she explained this to her parents and told them that she would need to hang out with boys sometimes as she needed their help with her coursework.

In September that year, Fazia went to a family friend's house to celebrate Eid. As is the custom, she was dressed in beautiful clothes, had her long hair done and her contact lenses in. Festivals and weddings are known to be fertile hunting grounds for prospective brides and grooms and in keeping with this tradition, one of her brother's friends, Asif, spotted Fazia and decided that he would like to marry her. Vivek was in India on holiday at the time.

I had a fight with my boyfriend so that's why I wasn't using my phone at all...so it was on silent and he [Asif]came in and his mum was like "she's a really silent girl, she's really nice and she's not even touching her phone" [she laughs]. She said... "look, she's not even touching her phone and she's listening very carefully to every single thing so I think she's a really nice girl" and he [Asif] was like really looking at me and then I started telling my mum that "I'm not really 
feeling comfortable coz that guy's really staring at me" and then my mum's like "oh okay" and after one week they sent a proposal for my marriage and my mum's like “it's your PR [laughs out loud]..your passport's coming up". 16

In a panic, Fazia called Vivek who was still in India. For one whole week, she kept trying his number but was unable to reach him as he was not answering his cell phone. In the meantime, the proposal had been considered by Fazia's family and it had been accepted. Initially, Asif's family wanted the wedding to be in March 2011. Within a few days, however, Asif decided that he did not want to wait so long and that he wanted the wedding to take place in November 2010. The date that was set was two weeks away. Fazia desperately tried to contact Vivek but was unsuccessful. To buy some time until she was able to talk to him, she told her mother that she was alright with the nikah ${ }^{17}$ taking place in November, but only if it was to be an engagement and not a wedding.

Finally, Vivek called her back.

I started crying on the phone and he was like "don't cry, go and tell your mum about me". I did and then she started crying... [and said] "what did I do? When I was little I never did anything wrong like that...I never had a Hindu boyfriend...I never had a boyfriend at all...why did my children have a boyfriend that also Hindu ${ }^{18, " . . . ~ a n d ~ t h e n ~ s h e ~ s a i d ~ " w h a t ~ a r e ~ y o u ~ g o i n g ~ t o ~ d o ~ n o w ? ~ Y o u ~ d o n ' t ~ l o v e ~ t h i s ~}$ guy and everyone knows that you're getting married".

Fazia had taken her mother to a nearby park so that she could talk to her alone. She told her mother that she would go along with the nikah, which was a week away, to keep up appearances. Going along with the engagement meant that Fazia would be allowed to continue to stay at her parents' house until the wedding took place in March. Most of her female cousins had gone through a nikah months before the legal wedding and had been allowed to stay at home during the interim period. Her mother agreed. Fazia's plan was to go through with the nikah and since it was not a legal marriage, she would break it off once Vivek returned to New Zealand and they were able to speak to her parents together.

\footnotetext{
${ }^{16}$ She meant that her mother was encouraging her to marry Asif so that she would get New Zealand Permanent Residence and eventually, New Zealand citizenship.

${ }^{17}$ Fazia explained that a nikah could either be considered a legal marriage or an engagement, depending on the context. See Chapter Five for a discussion on the problematic usage of the word.

18 "that also Hindu" is a colloquialism implying that having a boyfriend was bad enough, but having one that was Hindu was considered much worse.
} 
Fazia and her mother returned home to find her father lying face down on the bathroom floor, foaming at the mouth. He was under a lot of stress as Fazia's younger brother was causing the family trouble.

My brother really troubled my dad too much...he used to drink a lot, come home late and then...you know...do really bad sort of stuff so my dad was already in tension" ${ }^{19}$ because everyone was already talking about us...like "his son is really ruined" and like you know... and "he's too much of a trouble ... he did many accidents"... and he was like really in tension coz he knew that I was not happy with the marriage and he was worried that everyone knows about it...like "if she says no, then my whole pride will go" and you know...in the dustbin.

Although Fazia's father did not know about Vivek at that stage, he knew that Fazia did not want to marry Asif and he was worried that Fazia would cause a scene at the nikah by saying no to the engagement and the subsequent wedding. Fazia's father was also concerned that his work in New Zealand had ended and that he would leave New Zealand that December and return to his home country. His plan was for Fazia and her mother to stay in New Zealand until March when Fazia would be married. Fazia would then settle down in New Zealand with her husband and in-laws, and her mother, whose visa expired in March, would return to the home country.

He was like..."you'll get your life settled here"...that's what he wanted for like all his daughters...to get their lives settled so he doesn't have any burden on him anymore...that's what he wanted... and the main thing was that everyone knew about it [the nikah] by then so my dad was like "everyone knows about it now and they'll say the son was like that, now the daughter is like that... what's in his destiny?

The wider ethnic community that Fazia was from did not know that she had no say in her marriage to Asif. As such, Fazia's father was terrified that the community would guess that the marriage had been forced if Fazia stood up and made a scene during the wedding by not giving her consent. He was worried that she would run away from home after he left New Zealand in December.

19 "In tension" is a colloquial way of saying that someone is tense. 
My dad was pretty upset and said that "maybe she'll run away and won't come back”...coz my dad was about to go back to [the home country] in December...his visa was till that time so he's like "mum's here, but what would a lady do? Coz I'm the head of the family and I can control my daughter, mum can't'...yeah so that's why he was so tense.

One of the reasons Fazia was opposed to marrying Asif was that he was gay. Although she never spoke to him openly about it, Asif alluded to the fact that he often frequented gay bars and some of her friends had seen him there. She tried to tell her mother that Asif was gay, but her mother would not listen to her. Instead she recounted incidents during her own engagement to Fazia's father.

My mum's like "nah... when I got married, my friends used to tell me, my relatives used to tell me he's dark, he's not good but you know, he's real good to me...that's how they tell you that they're jealous of your husband" [Fazia laughs] and he was like...very short to $\mathrm{me}^{20}$ and I was like... "I just don't like him" but she said "you'll start loving him after coz he's your husband” and I just was like "okay...".

The nikah took place a week later. A few days before, Fazia's father had confiscated her mobile phone, saying that she texted too much. The day before the wedding, he checked her text messages and found one from a friend of Fazia's advising her against going through with the nikah. Her father was furious. He called the girl who had sent the message and threatened to call the Police if she ever contacted Fazia again. She was also banned from attending the nikah. Fazia did not get her phone back until a week after the nikah.

On the morning of the nikah, Asif called and asked to see Fazia in the park nearby. She met him and told him that she did not want to marry him but he tried to convince her that she would learn to love him once they were married. Then she told him that she had a boyfriend and that still made no difference to him. She knew then that there was no point trying to talk to him about it.

Fazia went back home to get ready for the nikah which was to take place that evening at her house. The house was filled with friends and family, laughter and much to-ing and fro-ing, which is typical of any South Asian household celebrating a special occasion. Aunties were

\footnotetext{
${ }^{20}$ She means that he was shorter than her.
} 
making sweets in the kitchen while Fazia's mother fussed over her, helping with her sari. Someone else did her make-up and yet another helped her with her jewellery. In the Indian subcontinent (and diaspora communities), such pomp and ceremony is not confined to the wedding day alone; every major festival is a reason to get dressed up and eat sweets. An engagement, in many communities, is given almost as much credence as a wedding ceremony. Some families even hire professional photographers and videographers to capture the event. As such, Fazia did not suspect a thing. She allowed herself to enjoy the festivity and the attention since she knew that the engagement was not legally binding and that very soon Vivek would be back and they would sort things out together.

Soon, the groom and his family arrived and at approximately $5.30 \mathrm{pm}$, the ceremony began.

The boys were in one room and we girls were in one room and my mother wasn't letting my friends sit next to me...she was like getting suspicious...like I might call my boyfriend from their cell phone because I didn't have my cell phone...it was in my mother's bedroom [since her father had confiscated it] ... I was sitting on the bed and there were people all around me, some people climbing on top of me...coz I was sitting on the bed and there were babies looking at my clothes, my bangles [laughs]... my friends were there, my aunties, some people from their side...yeah...there were only, I think 30 people in the two rooms...so everyone was smiling at me...but my friends were sad coz they knew... other people were excited about it but I wasn't coz I knew I wasn't happy with is, even if it was engagement...coz you'll have to meet him anyway, if he wants you to...if he's your fiancé and he says meet, means you have to meet him [she laughs] You have to, so I wasn't happy. And then after...the priest, first he went to [Asif's] room and he's like...do you agree...maybe he said yes [laughs]. And then he came to me and he's like "kya aapko nikah qabool hain" ${ }^{21}$ ?"

Once she voiced her consent to the nikah, the priest left her room. It never crossed her mind to say no because firstly, she was only agreeing to the engagement and secondly, she trusted that Vivek would speak to her parents once he returned as he had promised to. Speaking up during the nikah and saying no was not an option as she was convinced that she would have been on the next flight back home if she had done so, especially as she was under 18 years of age at the time. Her recollection of what happened immediately after the priest left the room

\footnotetext{
${ }^{21}$ This translates to, "Do you agree to the nikah?"
} 
is slightly hazy. She knows that her father came into the room at some point and gave her some papers to sign. She did not read or even really look at the papers since they were given to her by her father whom she loved and trusted. In addition, when she was given the papers, she was trying to communicate with her friends who were seated across the room from her. They were using a mixture of eye contact, hand gestures and lip-reading to communicate since they were seated too far apart to hear each other. Without giving it a second thought, she signed the papers and continued 'talking' to her friends.

As is the custom, she was then taken to another room to change into another outfit.

I was getting changed, my dad came to the room and then he's like..." you have to go off now"... and I was like "go off where?"... and he's like "to your sasural" people" and I was like "ohh...but it was a nikah" and he's like "yeah it's a nikah, it's your marriage now"...he's like "your sisters did it, they went to their husbands' house, what are you gonna do here...go to their house". And then I was like really upset, I was like "there's no legal proof that I'm married" and he's like "the papers you just signed, they are your legal marriage papers". That's how... like I was really doomed and also like... what did I just do?

As was the case with Nalini Chhima ${ }^{23}$, Fazia only realised after the event, that she was married and not merely engaged. Fazia told her father that her mother had given Fazia her word that it would just be an engagement and not a wedding. Her father just told her not to “create a drama here and just go." Shocked, trapped and furious, Fazia had no one she could turn to. All her friends were scared that their parents would disown them if they helped Fazia, the priest had left by then and even if he had not, she said that he could not have done anything to help her. In Islam, only a man can divorce his wife; a woman is not allowed to divorce her husband. There was not one adult in the house who would have stood by her. She did not think of calling the Police although she had, on many previous occasions, told her friends to call them if they were ever in trouble.

I didn't say anything coz I was like really upset...they'll make me go anyway so I was just like...I didn't talk to anyone... my sister wanted to hug me...I didn't hug her...my mum wanted to hug me...I didn't talk to anyone...I didn't even cry coz I didn't know what to do...so I just went there and Asif, in front of everyone Asif

\footnotetext{
${ }^{22}$ In-laws.

${ }^{23}$ See Chapter 2, page 26 for Nalini's story.
} 
was holding my hand and I snapped and was like "don't you dare hold my hand' and then everyone started looking at me and my mum's like "she's shy"...I wanted to cry but it wouldn't come out and then I was like...my mum saw me and then she started crying but she was crying because I was...it was the vidaai ${ }^{24}$ time...that's why she was crying... and then they wanted to hug me but I was like...I didn't even see anyone...I just walked my own way to the car and sat in the car.

Still in shock, Fazia went with the rest of the wedding party to Asif's house for dinner. Filled with anger and fear at the enormity of the situation, she was still unable to cry. She sat through the dancing, silently, refusing to dance. She describes it as a surreal experience: sitting amidst the chatter and laughter, watching her sister and sister-in-law dance, wondering how it was that everyone else was so happy while she, "the main person", was miserable. Her friends still did not know that what Fazia thought was going to be an engagement that she could break had turned into a wedding without her knowledge. As is the custom in her community, she was expected to eat from the same plate as her husband but in attempt to exert some control over the situation, she refused. As her parents left Asif's house, she was told that she had to stay there, that her husband's house was now hers and she could not return to her parents' house. Terrified of having to share a room and a bed with a complete stranger, she chose, instead, to stay in the lounge with Asif's grandmother and a few remaining guests. She stayed there for two hours. While her refusal to leave was partly an act of defiance, she was also repulsed by the thought of spending the night with a stranger. When the guests left, she was forced to go to bed but picked a fight with Asif by refusing to allow him to touch her. His parents became involved, he became angry with her and as a result, slept in the lounge and gave her the bedroom. The next day, a hotel room was booked for their honeymoon and they were expected to consummate the marriage then.

I was like "do you wanna go out for a movie?" coz I didn't want him to touch me so I was finding excuses...so the whole night we were just walking around in town till 3 o'clock in the morning and then I was telling him..."keep the distance, I don't want anyone to know that you're my husband" coz all my friends from uni, they come down to clubbing and stuff so I was like "I don't want anyone to know

\footnotetext{
${ }^{24}$ Vidaai is a ritual that marks the end of the marriage. During this ritual, the bride seeks leave from her parents to leave her parental home and start a new life with her husband, in his home.
} 
that you're my husband" so he was quite upset about that but then he wasn't really curious ${ }^{25}$ about the wedding night.

The pressure was on him from his family, however, to get her pregnant quickly. Asif's parents wanted a grandchild from them in the next nine months. They were convinced that pregnancy and motherhood would prevent Fazia from running away and would strengthen her ties to their family. As such, although he had no interest in her sexually, Asif kept trying to convince Fazia to have sex with him.

One day he did come up to me and...coz his mum was like... "you guys don't sleep and you guys don't sleep together" as in, "you guys don't have sex" and then one day he came up to me and he started touching me and I was like... "look if you want sex, I'll take off my clothes, you do it, I have no feelings for you at all" and then he was all quiet and he just took his pillow and he just went away. That's what he did...

Fazia describes the next three months as a period of captivity and tears. She cried practically every day, worried that she would lose Vivek. She was monitored closely by Asif and his extended family, all of whom lived in the same house. She was not allowed out unaccompanied; they were afraid that she would run away. The week after the nikah, her parents withdrew her fees from the educational institute she was at, although her mother had agreed previously to Fazia continuing her education. When Asif was at work, her parents-inlaw ensured that the door to Fazia's bedroom was always open. They had seen her text her friends quite often and were worried that Fazia, since she was still rebelling against her marriage to Asif, would let her friends, especially boys, into the house if she was not suitably supervised. Throughout the three month period, she refused to talk to Asif and as far as possible, tried not to be in the same room as him. As the family had television sets in different rooms, when Asif entered their room, she would move to another room. She refused to eat if he was in the room and would, instead, take her food to another room and eat alone.

Fazia did not tell Vivek that the engagement had turned into a wedding until she met him briefly, when he returned to New Zealand in November. One day, while Asif was at work, and her sister-in-law was in another part of the house, Fazia jumped out the window and took a taxi to meet Vivek. Her in-laws soon discovered that she had left the house and made

\footnotetext{
25 "He wasn't really curious about the wedding nights." She means he was not interested in sex.
} 
frantic phone calls to Fazia's mother who called her on her cell phone and ordered her to go back to her in-laws place. When she returned, her mother-in-law started crying, her father called her up and abused her verbally, swearing at her and calling her a "motherf**ker." From then on, they kept an even closer eye on her whereabouts. Angry with her in-laws for their part in the trickery, Fazia spent the rest of her time at her in-laws house watching television and texting her friends. She refused to help with household chores.

Fazia's mother visited twice a week and during those visits and was still convinced that she had acted in Fazia's best interests.

My mum used to come every...twice a week? And I didn't really talk to her...so she was really upset about that...she used to sometimes cry in front of my mum-inlaw like "she doesn't talk to me, she should talk to me, I'm her mum. I don't want anything bad for her...I did a good thing for her" and my mum-in-law, she's like "I can't talk to her, she's rude to me"... one day she [Fazia's mother] came to me and she started crying and I was like "why're you crying?" I was like "okay...I'm married now, you should be happy”... and she's like "yeah, but you're not talking to me" and I was like "yeah...well that's your fault"...my mum was like "yeah but it's for your good...you're getting the PR here, you're getting the passport" and she's like "just bring a baby soon".

Fazia ran away from her in-laws' house twice. The first time, she went to a friends' house. After a call from the Police informing her that her mother had a filed a Missing Person's report, she persuaded her friend to take her to a nearby town, just in case her mother managed to find her. Fazia did not have a New Zealand driver's licence and without her passport, which was held by her in-laws, she had no identification. She knew that she would not be able to get a job or support herself in any way without suitable identification. Her friend gave her some money, persuaded her to return home just to get her passport and then leave again.

When she returned to her in-laws' house, she discovered that they had taken her passport and passed it to her mother and Asif had broken her cell phone charger so that she had limited contact with her friends. One day when she popped into the dairy nearby for something, she managed to surreptitiously buy a phone card which she then used to call her friends from her bedroom. On one occasion she was talking to the friend who had helped her escape the previous time. She told him that she would leave her bedroom window open and asked him to come to the house and throw a cell phone through the open window so that she could call the 
Police as she had limited access to the landline. Unbeknownst to her, her mother-in-law had been listening to her conversation from a different handset that was connected to the same line.

They heard that, now they knew they'll be in trouble so they made up a story to my mum - "she was calling a boy inside the room, and you know, maybe for having fun or something like that" and then Asif's like I don't want her anymore and I was like oh ok, I don't want you anyway" and then I was in my room, packing my stuff and then his mum came to me and she's like "you don't really want Asif? Please don't say that" and I was like "I don't want him" and I was like "he can get any other girl" and she's like "no he can't, please don't leave him"... I was like "I can't stay with him anymore" and I was like "you guys took my cell phone"...she was like "we want baby in nine months" and I was like "I'm a baby myself, I can't have a baby" and they were like "no, please don't leave" and I was like "I don't want to stay with you guys anymore" and then Asif was like "I'll get you kicked out of this country" and I told "yeah, sure, just try!"

In February, three months after the wedding, Fazia left her in-laws' house and went back to her parents' house.

My mum was calling my dad...she didn't tell him what exactly was going on, she was like... "oh Fazia doesn't wanna live with Asif, there's too much problem going on between them, Asif's really worried like you know, their relation will break...we'll give her some time, she'll come to [the home country] '... she wasn't really telling him the exact thing coz he once warned mum that he'll kill me if something goes on like that, like if he gives me divorce or something and my mum's like "oh there's some problem going on, but she'll be back soon" and then dad's like "book her ticket... in three days, she should be here... in three days"... and I was listening to the conversation.

Although Fazia had been working prior to the wedding and had saved a considerable amount of money over the years, all her savings were in her mother's bank account. Her mother had convinced her not to get her own bank account as Fazia was not careful with her money and used to spend a lot of it on her friends. As such, she had no access to her savings. 
I took $\$ 200$ out of her [mother's] wallet, went to the kitchen, just to see where they are and then I jumped from my second floor coz my room window was like next to the grass...I jumped from there and there were like two sides...you could either go there or go there and one side, mum would see me and that side goes to town and I was like I won't go to town coz she knows I'll first go to town so I took [the bus] to my friend's house.

Her mother made many attempts to locate her. She called up Fazia's friends and even reported her missing to the Police. Fazia managed to stay hidden for a month at a friend's place. Her friends supported her as she had run away from home with only two hundred dollars in cash and the clothes she was wearing. They bought her clothes, toiletries, food and other basic necessities. They also gave her a place to sleep. Finally in March, Fazia's mother tracked her down and turned up at the house to speak to Faiza.

Mum was like "come" and my dad was talking sweetly on the phone, "please come back" and I was like "oh this is not good" [laughs] I was like "nah, I'm not coming back" and he's like "how are you gonna survive? Your visa's gonna be expiring next month anyway"... I was like "you leave that to me, I'm not coming". And then my mum was like "whatever gold you're wearing, take it off". So I took off all my gold and then they went away. And I went out.

Fazia bought her freedom and since then until the time of the interview, had no contact with her parents, both of whom were back in their home country. In March before her mother left New Zealand, Fazia called the Police for assistance in retrieving her passport which was being held by her mother. Upon Police intervention, her mother returned Fazia's passport to her. Her parting words to her daughter were “"'you'll never be happy in your life”. Until the time of the interview, Fazia lived in fear that her father will return to New Zealand and carry out his threat to kill her. She is convinced that she can never return to her home country, since honour killings are relatively common there.

At the time of the interview, Fazia was studying and working to support herself. She was also saving money to repay her friends for their financial support in her times of need. She recalled times when she was waiting for her visa to be renewed and therefore could not work. During these times, her friends supported her financially. They also paid the fees for her education since she could not afford to. Before she made contact with Shakti, Fazia had already found herself a lawyer and got her marriage annulled on the grounds of coercion. 


\section{Conclusion}

This chapter shared the stories of two very resilient women who experienced actual and threatened forced marriage in New Zealand. Much of the stories were told in their words and non-verbal communication such as pauses and laughter were also retained to preserve the women's voices. Pisey's and Fazia's stories highlight the fact that violence against women takes various forms and manifests in a continuum of multiple, interrelated forms. Violence can include, but is not limited to, physical, sexual, psychological/emotional and economic abuse. Both Pisey and Fazia experienced isolation to varying degrees and both women suffered the consequences of choosing to resist family expectations and re-define honour. The stories also highlight the crucial role played by religion in identity-formation. As this is a narrative chapter, the women's analyses of their lives and experiences, with links to literature and their recommendations for change, are discussed in the following chapter. 


\section{Chapter Five: Analyses of Survivor Stories}

\section{$\underline{\text { Introduction }}$}

This chapter shares the women survivors' analyses of their experiences and the types of change they feel are needed to deter the practice of forced marriage in New Zealand. Although the women's voices are emphasised in this chapter as they were in Chapter Four, they are interlinked with my observations and, where relevant, to literature.

\section{On Identity}

Both Pisey and Fazia appeared to have been exposed mainly to the negative attributes of their ethnic communities. Pisey noticed that life was different for her friends at school, but attributed the years of abuse and control to her ethnicity and having ethnic parents. Fazia described her ethnic community as "narrow-minded people" who are quick to judge and put others down, especially if the situation involved a girl. Interestingly enough, Pisey's evaluation of people from her community was very similar. It was also largely based on her perception of her parents.

Me... and my brothers, we kinda didn't really like the [home country's] tradition and what people are like coz of the way my parents are and we realised that all [people from her home country] are like that and that they're very judgemental...they're all about reputation.

Pisey, along with her parents and her brothers, attended functions at the temple when she was young. However, she never understood the significance behind the traditions as these were never explained to her. Also, as her parents never spoke about their lives in their home country, she was unable to relate to many aspects of her culture and religion. In addition, as she had come to New Zealand when she was just two years old, she had no recollection of her country of birth. Despite her apparent lack of knowledge about her heritage, however, she still felt a sense of connection that she found difficult to explain, with her "roots". 
Sometimes I just miss...coz after I moved out I'm not a great cook, so then there's always food there ${ }^{26}$ and I just miss the traditional food and sometimes I just miss the traditions so then I just go to be there coz you can't really forget your roots.

Having grown up in New Zealand, Pisey's identification with New Zealand as her home was much stronger than Fazia's. Pisey sounded Kiwi and was equally comfortable with Kiwi European friends as she was with the two friends she had from her ethnic community. Fazia was a much newer migrant to New Zealand. Given a choice between her home country and New Zealand, however, Fazia opted to identify with New Zealand primarily because of her negative perception of the people from her community. However, her friends, although not from the same ethnic community as her, were predominantly from countries that shared a physical proximity to Fazia's home country. As such, they shared a similar taste in music, clothes, food and spoke the same language.

Fazia had a much stronger connection to her religion than Pisey. A large part of Fazia's identity was intertwined with Islam. When asked a question regarding Islam and women's rights, Fazia explained that women had distinct rights within Islam. She also mentioned that there were specific hadiths ${ }^{27}$ that recognised a woman's right to say no to a marriage. She narrated an incident, from the Quran, of a woman who had been coerced into marriage and had approached Prophet Muhammad for help. The Prophet spoke to the woman's husband, told him that coercion was wrong and ordered him to give his wife a divorce. Fazia was firm in her belief that she was forced into marriage, not because it was condoned by her religion, but because of the narrow-mindedness of her family. She was equally convinced that women's rights were compromised, not because of Islam but because of misinterpretations of the religion. She explained the determination on the part of many parents, hers included, to break inter-faith relationships before these relationships culminated in marriage as a position that was born of fear. They were afraid that the children of such a union would be raised as non-Muslims. Fazia went on to say that she could understand this fear as she too would like her children raised as Muslims. However, she did not think such a fear was rational as she knew of non-Muslim men who would allow their children to be brought up in the Muslim faith.

\footnotetext{
${ }^{26}$ Pisey was referring to the temple she used to frequent, with her family, when she was younger.

${ }^{27}$ Hadiths are pieces of information on "the way of life prescribed as normative for Muslims on the basis of the teachings and practices of Muhammad and interpretations of the Koran" (see http://dictionary.sensagent.com/hadith/en-en/)
} 


\section{On Marriage, Consent to Marriage \& the Prevalence of Forced Marriage}

Pisey and Fazia approached the question of marriage and consent very differently. Pisey talked about marriage and the issue of consent in general based on her knowledge of how arranged marriages were usually conducted within her community. Fazia focused on her own marriage and the issue of consent as it played out in a personal context.

Pisey used 'arranged marriage' and 'forced marriage' interchangeably. She said that in many arranged marriages, the parents decided whom their daughter married as well as when and how the wedding would take place. Marriage brokers, or close family or friends acting as marriage brokers, would bring photographs of prospective suitors to the parents. The parents would then narrow the selection based on suitors' education level, reputation, family background and other criteria deemed significant by the family. In some cases the best candidate is picked by the parents. In other cases, the daughter is given photographs of two or three different suitors and asked to pick one. She had to decide before she was allowed to meet her prospective husband. Pisey was resentful of this practice and felt that it was "pretty stupid". She said it was also unfair as "boys get more freedom...the girls have to do what their parents say while the guys can disagree and the parents will actually listen to them and go [along] with what they think".

The only point, at which Fazia provided her consent, was during the nikah when the priest asked her if she agreed to the nikah. When she replied in the affirmative, she was only agreeing to the engagement and not to the marriage. The usage of the word 'nikah' appears to be problematic as it is used to refer to a marriage (Al-Johar, 2005; Marsden, 2007), and is also rather vaguely referred to as a contract of exchange (Martin, 2004; Ghori, 2008) with no further clarification of the nature of the exchange. There is also reference to the practice of young brides going through the nikah ceremony and then returning to their parental home until they are ready to live with their husband (Husain, 1967). This is what Fazia thought she would be allowed to do after the nikah.

In Fazia's forced marriage, Asif signed a statutory declaration and her parents provided their consent to her marriage since she was seventeen years old at the time. She was present when her parents completed and signed the necessary forms. However, she was told that they were resolving issues related to her visa renewal. As she knew that her visa really did need to be renewed and that her father had been handling it on her behalf, she did not question their 
explanation.. It was only upon hindsight that she realised that was probably the day that parental consent was provided for her marriage.

According to Fazia, the practice of forced marriage is common in her home country. She was not aware of other forced marriages taking place within her community in New Zealand but immediately qualified this by adding that her lack of knowledge was because she did not have any friends who were of the same ethnic background as her. Pisey was aware, by wordof-mouth, of twenty to thirty girls within her community, who had been through fake and forced marriage. She clarified that some fake marriages had been forced and some forced marriages had not been fake. She defined fake marriages as marriages that were organised purely for monetary or other material gain such as Immigration status.

Both Pisey and Fazia were understandably hesitant when asked about their thoughts on the possibility of marriage in their futures. Until the time of the interview, Pisey's mother still offered, during their occasional phone chats, to arrange another fake marriage for Pisey if she changed her mind. Pisey's view on marriage was that it was not a big deal.

I don't know...honestly, I just think marriage is just a piece of paper...it's kinda like if people want to be together, they shouldn't need a piece of paper to be together...yeah...marriage isn't such a big thing.

Fazia's instinctive response was that she did not want to get married. After a few seconds of thought, however, she added that she did not want to get married until she was at least 25 or 26 years old.

\section{On Change \& Recommendation for Change}

Both Pisey and Fazia were resolute on the need for change such that young women were able to access their rights. Fazia believed that parents should consult their daughters before arranging marriages for them. She stressed that parents should respect their daughter's decision because "it's her life, not theirs [the parents]." Pisey believed that communities' fixation on reputation and honour needed to change. There also needed to be a shift in the definition of what was considered reputable. Pisey was visibly reluctant to elaborate on this position. From previous remarks she had made, however, I gathered that she was referring to the difference between social norms that were applicable to her friends at school and the 
norms she was subjected to at home. She did not think that such shift was possible amongst the older members of her community; she believed they were too set in their ways to change. She was hopeful, however, that future generations who had been exposed to different ways of thinking and behaving may be able to successfully negotiate new social norms and practices. Pisey was also emphatic about the need for the overall economic situation of migrant and refugee communities to improve so that their children did not feel the need to bear the brunt of poverty.

While Pisey had adopted more of a macro-perspective on the types of change required to deter practices like forced marriage, Fazia was focused on specific recommendations to bring about such change. She believed that agencies should organise events specifically targeted at young girls who were potentially more vulnerable to practices like forced marriage. She suggested that events be organised such that they were entertaining, to attract young girls, but also carry a message that was focused on rights. Girls, she said, need to "stand up for themselves...if they won't, then who will? And they'll ruin their lives if they don 't!" She also suggested reaching out to the youth demographic through relevant television programmes containing similar messages. She added that programmes in schools would be another effective way of getting the message across to young girls and boys.

When asked for their thoughts on the possibility of sending such messages through religious leaders and institutions, Pisey and Fazia responded very differently. While Pisey felt that there was a need for religious leaders to promote the right message, she felt that there was not much point in approaching them.

Coz up front they'll just be like yeah ok, we get it. But then behind the scenes, they'll still do it and just be very careful...they've to pretend that everything's ok...so I'm not really sure how...I mean just over time, they can learn from experience, maybe? That would be good....

Fazia, on the other hand, was enthusiastic about the possibility of including such messages in the women's groups and youth groups at her mosque. She was keen to "get the idea ${ }^{28}$ in the boys' heads as well...you know, not to force a girl into marriage when she doesn't want to be with [him]."

Pisey and Fazia viewed the role of legislation very differently as well. Pisey was not convinced that legislation would make much a difference. In addition, she was emphatic that

\footnotetext{
${ }^{28}$ She was referring to the message that forced marriage is wrong.
} 
tightening Immigration laws was not the answer. Although she agreed that people, like her parents, are generally afraid of the law, tightening Immigration laws only meant that they would "be extra careful and try not to get caught." Fazia categorically stated that the option for parents to provide consent on behalf of their children, aged between 16 and 18 years of age, should be removed from the Marriage Act. When asked whether it would help if consent was also required from the parties intending to marry in addition to their parents, she said that it would not. She was convinced that the minimum legal age of marriage should be raised to 18 and the clause allowing those aged between 16 and 18 with parental consent to get married, be removed entirely. Fazia welcomed the idea of Forced Marriage Protection Orders $^{29}$ and said that "would've been [her] first option" if such Protection Orders had been available in New Zealand. Fazia added that training on issues of honour-based violence and forced marriage should be provided to members of the judiciary. She based this on her experience in court when she applied for an annulment. She was terrified that the judge would not believe her, since she had no one whom she could rely on to corroborate her story. She said she was lucky that the judge believed her and her experience with the court system was positive. She was worried, however, that others may not be as lucky as she was and felt that some training would be beneficial.

\section{On Formal and Informal Support Networks}

Neither Pisey nor Fazia felt that they could approach members of their ethnic and religious communities for support. Neither had extended family in New Zealand and neither received any support from immediate family members, including siblings. Both relied, to different extents, on friends and both had very different levels of need. Pisey just needed some "advice and just someone to be there for [her] when [she was] really upset." She had a few friends who helped by giving her information about Shakti. She did not have many friends whom she could turn to because most of them were dealing with their own relationships and family issues. When asked how she coped with all that she had been through, she laughed and said “I don't know... after everything I've been through in my whole life, I've learnt to just accept everything...things happen and then you've just gotta stay strong and just deal with it."

\footnotetext{
${ }^{29}$ Forced Marriage Protection Orders can be applied for in the UK under their Forced Marriage (Civil Protection) Bill 2008. I had asked her if a similar option in New Zealand would have benefitted her at the time.
} 
She added that she had experienced so much physical abuse in the past that she was no longer scared of it. If her brothers ever tried to hurt her again, she would immediately call the Police, she said.

Fazia appears to have received much more support from her network of friends. Fazia's needs were also much more involved. When she ran away from home, she relied on her friends to meet all her basic needs including accommodation, financial support, clothes and food till she was able to renew her visa and find work. She has had to rely on them on many occasions since the forced marriage and understandably, considers them her true family.

Fazia: Yeah I do get [support] from my friends...they're like...they always make me happy, they never let me feel too low...so they're like a family to me now...nowadays I don't really miss anyone that much

Priyanca: You mean your family?

Fazia: Yeah...don't really miss them...coz I have my friends as a family now...they act like you know... some of them act as parents, some of them as mothers...that's the good part of it.

Both Fazia and Pisey were grateful to Shakti for the advocacy and emotional support they received. Both were keen to continue referring others in similar situation, to the organisation. Pisey closed the interview with a story that was disturbingly familiar. She spoke of a friend who had a boyfriend from a different religion. Her parents had found out and threatened to force her into marriage with someone who belonged to the same faith as them. Pisey's friend was upset and turned to Pisey for guidance. Pisey had offered her friend the support and advice that she had looked for but never received from her friends. As Pisey spoke, I wondered, although they lived in different cities, whether she was referring to Fazia. Then Pisey mentioned that she was still in touch (at the time of the interview) with this girl and that she had not been forced into marriage yet. I was surprised that Pisey did not refer to this friend when we had discussed the prevalence in the previous interview. It made me wonder whether forced marriage was so common place that this incident had actually slipped her mind. 


\section{Conclusion}

This chapter shared Pisey's and Fazia's analyses of their experiences of life in New Zealand, the role played by religion and ethnicity in their identity formation, their views on marriage, consent and forced marriage and the formal and informal support networks that were available to them. Both women spoke of the changes required to deter the practice of forced marriage in New Zealand. Pisey adopted a more macro perspective of the change required, while Fazia focused more on how change could be achieved. Many of their recommendations are incorporated into Chapter Eight. 


\section{Chapter 6: Legislative Analysis}

\section{$\underline{\text { Introduction }}$}

This chapter provides an overview of New Zealand's international obligations with regards to forced marriage and goes on to examine existing legislation that is relevant to the issue of forced marriage in New Zealand. It concludes with a discussion and analysis of legislative change that may need to occur in order to effectively deter the practice.

\section{International Law}

International conventions and treaties are "agreements concluded between States in written form and governed by international law" (United Nations, 1969, p.3). Ratifying a convention or treaty implies an obligation on the Government's part to adhere to the concerns outlined in the agreement (Wing, 2006). The Convention on the Elimination of all Forms of Discrimination against Women (CEDAW), which is often described as an international bill of rights for women, defines discrimination against women and forms the basis for national action to end such discrimination (Ministry of Women's Affairs, 2011). New Zealand ratified CEDAW on 20 December 1984 (ibid.). Article 16 of CEDAW states that
State Parties shall take all appropriate measures to eliminate discrimination against women in all matters relating to marriage and family relations and in particular shall ensure, on a basis of equality of men and women (a) the same right to enter into marriage; (b) the same right freely to choose a spouse and to enter into marriage only with their free and full consent (United Nations, 2009, n.p.).

The International Covenant on Civil and Political Rights (ICCPR) and the International Covenant on Economic, Social and Cultural Rights (ICESCR) were both signed on 12 November 1968 and ratified on 28 December 1978 by the New Zealand Government (Human Rights Commission, 2008). Article 23.3 of the ICCPR states that "no marriage shall be entered into without the free and full consent of the intending spouses" (Office of the United Nations High Commissioner for Human Rights, 1966, p.7). 
The Convention on Consent to Marriage, Minimum Age for Marriage and Registration of Marriages 1964, which requires state parties to establish a minimum age of marriage and to ensure the registration of marriage, was ratified by New Zealand in 1964 (United Nations, 1964). Article 1 of this convention states that

no marriage shall be legally entered into without the full and free consent of both parties, such consent to be expressed by them in person after due publicity and in the presence of the authority competent to solemnize the marriage and of witnesses, as prescribed by law (Office of the United Nations High Commissioner for Human Rights, 1964, p.1).

New Zealand's ratification of these four conventions implies an international obligation, on the part of the New Zealand government, to ensure that both parties entering into a marriage have the same right to freely choose a spouse and are able to express free and full consent. As such, the onus is on the government to ensure the existence of appropriate channels and mechanisms to ensure that consent is determined from both parties prior to the marriage.

\section{Existing New Zealand Legislation}

\section{Marriage \& Consent}

According to the Department of Internal Affairs, there are two types of marriage ceremonies that are recognised as legal marriages in New Zealand: a ceremony solemnised by a Registrar of Marriages in a Registry office or a ceremony solemnised by an authorised marriage celebrant at a place other than the Registry office (Department of Internal Affairs, 2011). Prior to the wedding ceremony, one of the parties intending to be married needs to make a formal statutory declaration that there is no lawful impediment to the marriage. In cases where parties are between the ages of 16 and 18, parental consent is required; parents must complete the Consent to Marriage of a Minor form. At least three days prior to the ceremony, a marriage licence must be applied for from a Registrar of Marriages by completing a Notice of Intended Marriage form and paying a fee (ibid.). During the marriage ceremony, each party must say "I AB, take you CD, to be my legal wife/husband" or words to that effect. The vows must be exchanged before a marriage celebrant and two witnesses (Department of Internal Affairs, 2011, p.6).

Shakti and other women's rights activists argue that the condition for 'full and informed consent' is not adequately met by existing legislation as only one party is required to sign the 
statutory declaration and there are no provisions to determine consent from both parties before the wedding ceremony takes place. In cases of forced marriage, it is almost always the party that is not being coerced that signs the declaration. The provision for parental consent allows parents, who are usually the organisers of these marriages, to consent to a marriage on behalf of a minor without necessarily informing the minor concerned of the impending wedding. Options to addressing this issue appear to revolve around raising the minimum age of marriage universally to 18 in keeping with CEDAW, UNICEF and Fazia's recommendations or as Innes-Kent (2007) suggests, determining the consent of the minors involved independently.

Determining consent from both parties midway through the ceremony also does not constitute 'full and informed consent' as illustrated in Fazia's story; it is unreasonable, under the circumstances, to expect a woman or young girl who has been coerced to voice her lack of consent in front of family and friends. Moreover, Shakti has anecdotal evidence of marriage celebrants who are complicit in the practice and in such cases there is often no one who would support her even if she did voice her objection. In addition, since 'forced marriage' per $s e$ is not an offence in New Zealand, "[even] if a victim of forced marriage found enough support and courage to take legal action, there is no obvious reference to the [offence] which she would be setting out to stop" (Innes-Kent, 2007, p.58).

\section{$\underline{\text { Marriage Celebrants }}$}

In New Zealand, legal marriages can only be solemnised by those who are appointed by the Registrar-General as marriage celebrants and whose names appear in the List of Marriage Celebrants in the New Zealand Gazette (The Department of Internal Affairs, 2010). There are three categories of marriage celebrants namely Independent Celebrants, Ministers of Religious Bodies and Organisational Celebrants (ibid.).

Independent Celebrants are individuals from the community who have been appointed by the Registrar-General and who do not operate under the mandate of any church or religious organisation (The Department of Internal Affairs, 2011). Ministers of Religious Bodies are those who have been nominated by the religious bodies named in Schedule 1 of the Marriage Act 1955: Baptists, The Church of the Province of New Zealand (commonly known as the Church of England), Congregational Independents, The Greek Orthodox Church, All Hebrew 
Congregations, The Lutheran Church, The Methodist Church of New Zealand, The Presbyterian Church of New Zealand, The Roman Catholic Church and The Salvation Army (The Marriage Act, 1955). Organisational Celebrants are individuals who are nominated by religious organisations that are not named in Schedule 1 (for example, Hindu, Sikh, Buddhist or Muslim organisations). Organisations may nominate individuals to become celebrants as long as they have "as one of their principal objects the upholding or promotion of religious beliefs of philosophical or humanitarian convictions" (The Department of Internal Affairs, 2011, p.4).

To become a marriage celebrant, an individual needs to submit an expression of interest to the 'Births, Deaths and Marriages' section of the Department of Internal Affairs providing his or her name, contact details, affiliation to any religious body (or specify that he/she intends to become an Independent Celebrant) and any other relevant information. The individual is then sent an application form which must be completed and returned along with two testimonials "vouching that [he or she] is a person of good character" (The Department of Internal Affairs, 2010, p.16). Criteria considered during the appointment process includes whether the applicant is a Justice of the Peace or other person of good character and whether the appointment is in the interests of the general public or specific community (ibid.). Applicants may then be called for an interview during which the Registrar-General advises the applicant on the role and ensures that sufficient information has been provided on which a decision may be made. The applicant is also provided the opportunity to ask questions during the interview (ibid.).

Once the names of successful applicants are published in the Gazette, they are then free to solemnise marriages. Approval must be renewed yearly and is not done automatically; celebrants must complete a renewal form and those who do not will have their names removed from the Gazette list and will no longer be allowed to solemnise marriages legally.

There does not appear to be any process in place for the "marriage rituals of celebrants belonging to religious organisations not listed in Schedule 1 of the Marriage Act to be monitored for consent" (Innes-Kent, 2007, p. 56). The only requirement for celebrants to determine consent by both parties is through the exchange of vows or equivalent words which imply consent. This being the only requirement indicates a "heavy reliance on words used during the ceremony" (ibid., p.56) which in Fazia's case, for example, led her to think that she was only consenting to an engagement and not a wedding. There is also an unfair placing 
of the burden of proof on the victim in expecting her to stand up and voice her lack of consent in front of the perpetrator(s) and disapproving wedding guests. This is discussed in more detail in the following section.

\section{Caveats, Annulments \& Penalties}

“Any person may lodge with any Registrar a caveat against the marriage of any person named in the caveat on the ground that the marriage is one in respect of which a licence should not be issued under this Act" (The Marriage Act 1955, Section 25).

The caveat can be lodged either by the caveator or on his/her behalf. Once the caveat has been received, it will be submitted by the Registrar to the Family Court (or to a District Court judge if the former is unavailable) who will then inquire into the objections stated in the caveat. It is the judge's decision whether the caveat will be discharged or not. If the judge refuses to discharge the caveat, anyone may apply to the Family Court for the caveat to be discharged. In such a case, the judge will take this into consideration and decide whether the caveat should be discharged or not. In all cases, a caveat will expire one year after the date on which it was lodged.

Knowledge of the existence of such a provision appears to be limited even amongst service providers. Shakti, which is possibly the organisation that supports the largest number of forced marriage survivors in the country, was unaware of its very existence. While the provision is mentioned in the Act, there is not information that is easily accessible on the Department of Internal Affairs website. There is, therefore, a high chance that victims are unaware of this provision and the means to access it. The requirement for it to be either retained or discharged by a member of the judiciary indicates the need for training and information sharing with the judiciary such that the dynamics of the issue are understood. The ease with which a caveat may be discharged is especially concerning as anyone and presumably the parents too can apply for the caveat to be discharged and their information may be taken into account. Given the power imbalance between the perpetrators and the victim, the burden of proof is placed unfairly on the victim who often has no support network and no one to vouch for her experience.

The unfair burden of proof and the importance of increased understanding on the part of the judiciary are also evident in the case of annulments which are at the discretion of the court. In 
the interview with the Ministry of Justice, there was mention of a case of a girl from a Pacific Island community who attempted to get her marriage annulled. This case inadvertently highlights the importance of awareness raising and education as well as the burden of proof being placed on the victim. "The judge heard her evidence and basically said that he didn't accept that the standard had been met because even though her mother was very keen on the marriage and was trying to persuade her, she could've still said no" (MOJ, pers. comm. 11 November 2011). The judgement may have been sound in this particular case. However, it is possible that such judgements may be made in genuine cases of forced marriage if there is limited clear understanding of the complexity of emotional coercion with regards to forced marriage. The lack of witnesses who could vouch for her, coupled with overwhelming support for the perpetrators, which is often the case in Shakti's experience, would further complicate matters for her.

According to the Marriage Act 1955, a marriage celebrant who "knowingly and wilfully issues any marriage licence or solemnises any marriage contrary to the provisions of this Act" is liable "on conviction on indictment to imprisonment for a term not exceeding 5 years, or to a fine not exceeding $\$ 600$, or to both” (all quotes Marriage Act 1955, Section 58).

As mentioned above, since 'forced marriage' is not a specific offence in New Zealand, there is no penalty for those who use emotional or psychological coercion to force an individual into marriage. The closest reference to forced marriage being an offence is found in Section 208 of the Crimes Act (1961) which states that "abduction for purposes of marriage and sexual connection" is an offence. According to Innes-Kent (2007, p. 57), records indicate that "this was part of a group of reforms relating to sexual connection, partly to meet New Zealand's obligations under the Optional Protocol to the Convention on the Rights of the Child." In addition, the offence only addresses physical duress and does not acknowledge the significant amount of emotional and psychological coercion that is often used.

The penalties for marriage celebrants are low, especially considering they generally charge a fee and could legally charge a fee high enough to cover the $\$ 600$ fine in the event that they are convicted of an offence. The lack of penalties for other perpetrators translates to a lack of legal incentive for the practice to stop. 


\section{$\underline{\text { Discussion }}$}

New Zealand has partially met its international obligations by establishing a minimum age for marriage and passing legislation to ensure that marriages are registered. However, the criteria for 'full and informed' consent is not met as consent from both parties is not determined prior to the wedding ceremony, consent from minors is not determined and reliance on words spoken during the ceremony is insufficient as consent is only determined mid-way through the wedding ceremony and the safety of the non-consenting party is jeopardised. There does not appear to be a clear process through which the 'good character' of potential marriage celebrants is ascertained and no clear procedure for marriage rituals of organisations not listed in Schedule 1 to be monitored.

Women's rights activists in New Zealand have recommended that the minimum age for marriage be raised to 18 in keeping with international measures and UN recommendations. Raising the minimum age is supported by UNICEF International's view that minors (anyone under the age of 18) cannot consent to marriage and the minimum age of marriage which is prescribed by both the CEDAW Committee and the Committee on the Rights of the Child as being 18 years (De Silva-de-Alwis, 2008; United Nations, 1994). This would automatically result in the removal of the provision for parents to consent to the marriage of minors which may positively impact upon the practice of forced marriage.

The provision to lodge a caveat is insufficient given the imbalance of power and the relative ease with which it may be discharged. Agency in forced marriage, or forcing someone to marry, should be penalised and penalties for solemnising forced marriages need to be substantially increased. Accomplices to the forced marriage should also be held appropriately accountable. While physical force may indeed be used to coerce individuals into marriage, those working at a grassroots level note that emotional and psychological coercion is widely used. As such, the definition of coercion or duress must be broadened to include other forms of coercion including emotional and psychological pressure.

There has been significant debate in many European countries and in the United Kingdom (UK) on the merits of criminalising forced marriage. After widespread consultation in the UK, it was recommended that forced marriage be made a civil offence and not criminalised. The decision not to criminalise the practice was largely due to input from service provision agencies who noted that criminalising the practice may pose a barrier to accessing support since many young women were averse to placing criminal charges on their parents. 
As noted in previous chapters, legislative change as a stand-alone measure to address the issue of forced marriage may be inadequate. However, legislation plays a crucial role both in terms of providing victims and survivors of forced marriage with adequate protections as well as holding perpetrators accountable for their actions. One of its greatest strengths lies in its "ability to act in the face of public opposition" (Rosenberg, 1991, p.22) thereby protecting the rights of the most vulnerable in society, whose voices are usually not the loudest. Legislation is especially relevant in the case of forced marriage given that there is overwhelming denial of the existence of such practices from within the ethnic sector. Legislation also provides a mandate for processes and protocols to be established within statutory and other agencies such that victims are provided with timely and effective service options.

Finally, as noted by the NZ Police, New Zealand legislation pertaining to marriage is problematic with regards to the issue of forced marriage because it was "never drafted with cognisance of forced marriage and needs to be updated to reflect an increasingly complex society and increased understanding of issues" (New Zealand Police, pers comm., 24 November 2011).

\section{Conclusion}

This chapter examined whether New Zealand's existing legislation adequately addresses the issue of forced marriage in relation to expectations set by its ratification of international conventions and treaties. It found that New Zealand has only partially met its international obligations with regards to marriage. This chapter also explored gaps with the legislation which may inadvertently allow the practice to take place. Specific recommendations regarding legislative reform are discussed further in Chapter Eight. 


\section{Chapter Seven: Stakeholder Agencies}

\section{$\underline{\text { Introduction }}$}

This chapter discusses data collected through interviews with eleven government, quasigovernment, non-governmental and UN stakeholder agencies and through discussions at the stakeholder engagement workshop held in December 2011. Each agency was asked three key questions during interviews: 'What are they, or have they been, doing to deter the practice of forced marriage to date?', 'What action could they possibly take in the near future?' and 'What are their needs or constraints to action?'. The aim of the workshop was to discuss the preliminary findings of my research and to explore an action-oriented collaboration between stakeholder agencies in order to effectively address the issue of forced and underage marriage in New Zealand. Six agencies, of the eleven interviewed, attended the workshop. Other agencies, while keen, were unable to attend due to a number of reasons including the recent national Elections and the imminence of the Christmas holiday period. Stakeholder agencies that were represented at the workshop included Shakti, Office of Ethnic Affairs, Families Commission, Human Rights Commission, Ministry of Justice and the New Zealand Police. This chapter aims to consolidate information generated, along the lines of intervention and prevention, and to provide an overview of the current environment in New Zealand with regards to the practice of forced marriage and the opportunities for action.

\section{Prevalence \& Data Collection}

One of the main issues raised by many government agencies during the research process was the question of prevalence. Is forced marriage a significant issue? How many women and girls are subjected to this each year? Although women's rights activists believe that even one woman or girl who is forced into marriage is one too many, policy development and legislative change often require an evidence-based approach. The survivor stories narrated in Chapter Four were an attempt to provide qualitative evidence in relation to questions around how and why women are forced into marriage by providing an insight into two girls' stories.

For many years, Shakti Community Council Inc. through its member organisations has been providing culturally appropriate domestic violence intervention services to women and girls of Asian, African and Middle Eastern origin who have been subjected to and threatened with forced marriage. Quantitative data on the number of girls who have accessed Shakti's youth 
service as a direct result of the practice have only been collected, however, since 2009 . The data collection takes place through the organisation's Youth Unit which was established in 2009 and is based in Auckland as part of Shakti Legal Advocacy \& Family Social Services Inc. Given Shakti's limited resources, data collection has been confined to the Auckland region. In addition, due to resource constraints, it only captures girls and women between the ages of 12 and 24 who are New Zealand citizens or hold a New Zealand Permanent Residence (PR).

All the women and girls captured by the Youth Unit's data accessed Shakti's services directly as a result of threatened or actual forced marriage (see Table 5.1). Data collection by other Shakti centres is more challenging as Shakti notes that older women tend to access the organisation's services as a result of other types of domestic violence and not forced marriage specifically. The fact that they were forced into marriage is often captured much later, after a number of sessions with caseworkers (Shakti Youth Unit, pers. comm., 8 December 2011).

\section{Table 5.1: Shakti Youth Unit Data on Forced Marriage cases}

\begin{tabular}{|l|l|l|l|}
\hline Period & $\begin{array}{l}\text { Total no. of } \\
\text { Youth cases }\end{array}$ & Forced Marriage cases & $\begin{array}{l}\text { Forced Marriage } \\
\text { cases as a of total } \\
\text { caseload }\end{array}$ \\
\hline Jan 2009 - Jan 2010 & 10 & 1 & 10 \\
\hline Jan 2010 - Jan 2011 & 29 & 10 & 34 \\
\hline Jan 2011 - Nov 2011 & 25 & 11 & 44 \\
\hline
\end{tabular}

(Source: Shakti Youth Unit, Jan2009 - Nov2011)

It is important to note that Shakti has nine centres nationwide ${ }^{30}$ and that the abovementioned statistics reflect data collected by only one centre and captures only a specific group of women and girls. Shakti believes that the onus should not be on one not-for-profit NGO to collect national statistics on such a broad issue.

\footnotetext{
${ }^{30}$ Shakti Asian Women's Centre Inc, Shakti Asian Women's Safe house Inc. (this organisation runs two safe houses), Shakti Legal Advocacy \& Family Social Services Inc., Shakti Education Training \& Advisory Company Ltd, Shakti Ethnic Women's Support Group - Central Region (Tauranga), Shakti Ethnic Women's Support Group - Wellington, Shakti Ethnic Women's Support Group - Christchurch and Shakti's latest centre in Dunedin.
} 
During the workshop session, Ministry of Justice (MOJ) and the Police were interested in a breakdown of existing data that distinguished actual forced marriage from threatened forced marriage. Shakti explained that the organisation did not choose to distinguish between the two as there was clear potential for threats of forced marriage to be followed through. Threats often culminated in marriage. As the organisation operates from a rights-based perspective and the threat of forced marriage is often used to control behaviour, Shakti stressed that the threat should in itself be considered a violation. Certain agencies also wanted a further breakdown to distinguish between forced marriage and underage marriage. Shakti clarified, based on experience, many girls appeared to be forcibly engaged between the ages of 14 and 16. In some cases the marriage takes place while the girl is still underage and in many others, it takes place when she is between the ages of 16 and 18 and can be married with parental consent. In many of these cases, Fazia's case included, she is unaware that she is getting married. Shakti emphasised that forced marriage is an extremely complex issue that exists on a continuum; there are a number of different permutations and combinations ${ }^{31}$ of practices, beliefs and justifications that contribute to it and it should not be viewed as a discrete practice. There was some discussion around the best way to get information on existing services out to women and girls who may potentially be subjected to honour-based violence including forced marriage and there was a suggestion, based on Fazia's recommendation (see Chapter Five), that it be disseminated through schools and religious institutions.

Some agencies also wanted to know whether girls were being taken out of New Zealand, back to their home countries to be forced into marriage. Although Shakti was aware that this was happening based on experience and anecdotal evidence, there was no current data on its prevalence. Agencies added that they would be interested to find out how many girls, in that situation, were New Zealand citizens as it would then be "worthwhile to challenge it" (MOJ; New Zealand Police, pers. comm., 16 December 2011).

\footnotetext{
${ }^{31}$ Refer to Chapter Four survivor stories.
} 


\section{$\underline{\text { Existing \& Possible Measures }}$}

\section{$\underline{\text { Intervention }}$}

Women and girls access Shakti's services through one of the organisation's drop-in centres ${ }^{32}$ or the $24 / 7$ crisis line. Many are also referred to Shakti by network agencies such as other refuges, Work and Income and the Police. Once a telephone assessment is completed, a detailed needs assessment is then conducted face-to-face, with an interpreter if required. Those who require emergency accommodation are referred to a Shakti refuge or to another local refuge. A detailed safety plan is developed with women who choose not to move to the refuge but whose cases are considered medium to high risk. Shakti caseworkers also provide legal and immigration advocacy as well as advocacy with various other government and nongovernmental agencies (Shakti Youth Unit, pers. comm., 8 December 2011).

All Shakti caseworkers are trained to work with women from different ethnic and religious backgrounds. They are provided specialised training so that they are able to identify and deal with diverse culturally-nuanced issues including honour-based violence, forced marriage, underage marriage and dowry abuse. The Unit notes, based on their experience, that the primary reasons that parents force their daughters into marriage appear to include perceived or actual 'shame' that the girl has brought, or may bring, upon her family and, to a lesser extent, perceived or actual gains such as immigration status or monetary benefits (ibid.). Actual or threatened forced marriage is also used to break up a relationship that is deemed unsuitable.

The National Collective of Independent Women's Refuges (Women's Refuge) is the largest national provider of domestic violence intervention services in New Zealand. Many independent refuges around New Zealand that are affiliated with Women's Refuge work in collaboration with Shakti to address the needs of ethnic women. Although cases of honourbased violence and forced marriage have not been identified as an issue within the organisation, Women's Refuge acknowledges that this may be due to a "lack of understanding around different levels of violence within different cultural settings" (Women's Refuge, pers. comm., 25 October 2011). The lack of understanding often leads some refuges to work with ethnic women in the same way they work with all other women. A survey aimed, in part, at identifying issues facing affiliated refuges in relation to working

\footnotetext{
${ }^{32}$ Shakti drop-in centres are located in Auckland, Tauranga, Wellington, Christchurch and Dunedin.
} 
with diverse cultures was recently conducted by Women's Refuge. Survey findings revealed a substantial gap in knowledge and awareness around the specific needs of ethnic women and the need for further training in that respect. The lack of awareness results in the inability to identify issues such as forced marriage which is then reflected in the lack of reporting and data collection (ibid.).

While most affiliated refuges work closely with Shakti, some appear to assume that recruiting refuge caseworkers who speak different ethnic languages fulfils the need for culturallyappropriate service provision. These refuges appear to have overlooked the need to ensure that culturally-appropriate caseworkers are provided specialised training to understand the complexity of ethnic women's identities and needs that often transcend language barriers. Shakti and Women's Refuge recognise the potential safety risk involved in a definition of 'culturally-appropriate' that merely addresses language barriers.

[If] we don't understand who our client is, we don't understand her oppression, we don't understand the political views in which she has been brought up, or cared for or she's tied into, don't understand her religious views or perspective or the hold that might have over her, so therefore we're working in complete isolation from that part of her which is very strong in relation to how she defines her identity, her life, her culture, her being and the control...most importantly, we therefore don't understand the control which that has over her decision-making and therefore, we can never really estimate her risk (Women's Refuge, pers. comm., 25 October 2011).

It is also important that agencies dealing with the safety of children and youth are also aware of the culturally-nuanced issues facing those from different ethnic and religious communities. Child, Youth and Family (CYF) is a service line of the Ministry for Social Development whose "statutory responsibility is the safety and wellbeing of children up to the age of 17 " (CYF website see http://www.cyf.govt.nz; Allen and Clarke Policy and Regulatory Specialists Limited, 2007). CYF, along with the New Zealand Police, has been actively involved in drafting internal processes and protocols to address the issue of forced marriage in the northern region ${ }^{33}$. CYF is not aware of any specific notifications that have been made through their contact centre; CYF and the New Zealand Police became involved when the

\footnotetext{
${ }^{33}$ The 'northern region' covers all areas between the Bombay Hills and the northern-most tip of New Zealand's North Island.
} 
issue of forced marriage was highlighted in the news media. After a number of meetings with Shakti, one of which included a meeting with a young survivor of forced marriage who had accessed Shakti's services, both agencies agreed that forced marriage is "an emerging issue in [New Zealand]" (ibid.) and one that needed to be addressed.

CYF together with the Police and in conjunction with Shakti, organised an informationsharing session for relevant stakeholder agencies in May 2011. This session aimed to raise awareness of the issue, discuss best practice guidelines adapted from the UK guidelines and to allow the various agencies present to share their perspectives on the issue of forced marriage. Agencies present were also encouraged to consider measures that could be taken within their agencies to address the issue of forced marriage and to outline the challenges they face and provide suggestions for overcoming these challenges (ibid.).

One of the key outcomes of the session was the need for a statutory response to provide immediate safety to young women who fear or have been forced into marriage. As such, CYF in conjunction with the Police developed an internal process, currently at a draft stage, to manage agency referrals and disclosures made by women and girls who have been or are about to be forced into marriage.

In accordance with the draft process, girls under the age of 17 will be triaged through the CYF Onehunga site and supported both by Shakti and the Police Family Safety Team ${ }^{34}$ based in Onehunga. At the time of the interview, this process was in place but had not been trialled yet. The Onehunga site is comprised of two or three social workers, one of whom is familiar with the issue of forced marriage through work experience in the UK. The site was also identified due to its proximity to the Shakti Asian Women's Centre and the Onehunga Police Family Safety Team. CYF recognises that the agency may need to alter their modus operandi slightly in order to appropriately address the girls' needs so as not to exacerbate their safety risk.

So we can immediately see that we would need to work a little differently with these cases because obviously calling the families together of very vulnerable young women who have been forced by her family into a marriage would not

\footnotetext{
34 Family Safety Teams are multi-disciplinary comprising police, social workers and community agencies (http://www.police.govtnz/tenone/20051209-280/feature_safetyteam.htm.).
} 
necessarily keep her safe and may, in fact, place her in very serious harm or danger and so...we'd have to think of how else we might manage that (CYF, pers. comm. 9 December 2011).

According to CYF's current policy, once a child is uplifted from the abuser(s), the child is then placed in the care of family or extended family. Shakti's experience, supported by international literature, indicates that this may place the young woman in serious danger since family and extended family are generally complicit in the forced marriage. As such, CYF would need to enforce court orders to gain custody of the child/young woman. CYF would then be able to ensure that the child/young woman is not taken out of the country for the purposes of marriage and is also not exposed to further coercion, or other abuse, from immediate or extended family members.

As such, the girls' accommodation presents CYF with a dilemma. The two options currently being considered by CYF are 1) to work with organisations such as Shakti to identify appropriate caregivers with whom the girls may be placed and 2) to work with caregivers of different ethnicities who have already been assessed and approved by CYF.

We might be in the need to go into just a normal caregiver arrangement where we know that they're good caregivers, they're assessed, they're approved...[it is] probably highly risky to place a child with someone from their community or their ethnicity, we're very aware of that...so say we've got a young Somali ${ }^{35}$ girl, [and] there's a Somali caregiver, that could actually place her at risk because the family...they'd all know each other and all those sorts of things...so we're very aware of those sorts of issues (CYF, pers. comm., 9 December 2011).

Shakti has expressed the need for a specific safe house to be dedicated to the needs of young women and girls ${ }^{36}$ who have been subjected to honour-based violence including forced marriage. However, CYF is reluctant, at this point, to provide funding for such a venture as firstly, current funding pools have already been allocated and secondly, CYF would require reports of concern through their system first before any financial commitment can be made.

\footnotetext{
${ }^{35}$ The ethnicity stated was merely used as an example and should not be taken as an attempt to isolate the issue to the Somali community.

${ }^{36}$ The rationale behind this is explained further in section "What is the next step for New Zealand" in this chapter.
} 
Although CYF has a plan in place to address the initial needs of the young women and girls, they "would have to be guided by individual situations as to what [they] did next" (ibid.) since this issue requires the agency to act in a manner that differs from their usual response.

Many girls and young women who are subjected to honour-based violence including forced marriage are considered unruly and wayward by their parents (CYF, pers. comm., 9 December 2011). The challenge that CYF faces is in distinguishing between young women with genuine problem behaviours and those who are portrayed to have problem behaviours by parents. Some parents may be of the opinion that behaviour that pushes the boundaries of what is deemed acceptable within their 'culture' is problematic. Al-Johar explains, in the context of Muslim immigrants in America, that immigrant adolescents and teenagers "continually renegotiate and adjust identity constructions and contend with intergenerational discord" (Al-Johar, 2005, p. 560). This dischord, experienced by immigrant teenagers in New Zealand as well, may be misinterpreted as problem behaviour, as Fazia's parents did. As the period of renegotiation and identity construction may continue past the age of 17 , other agencies would also need to be aware of this potential challenge. CYF does not have a role in the cases of girls aged above 17 years. In such cases, the lead statutory agency would be the New Zealand Police.

The Police have been working, through their cultural responsiveness strategy, with ethnic communities to try and understand the dynamics of domestic violence within the different communities in New Zealand and what a basic plan would look like. One of the aims of this strategy is to "increase the synergy between Police and ethnic liaison officers" (New Zealand Police, pers. comm., 24 November 2011). The Police also aim to develop an appropriate response to issues such as honour-based violence and forced marriage and have been working closely with both CYF and Shakti on this.

If a woman were to call $111^{37}$ today to seek police assistance as a result of honour-based violence or the threat of a forced marriage, she would get a standard family violence response. In South Auckland, however, the response would be different. South Auckland has been identified as a test case of sorts, as it is, according to the Police, the most likely place that such a report would come from (New Zealand Police, pers. comm., 24 November 2011). Although the basis for this decision was not elaborated on, it may have been premised on the only available data which, as mentioned previously, is from Shakti's Youth Unit based in

\footnotetext{
${ }^{37}$ New Zealand Emergency Services.
} 
South Auckland. Police teams in this area are experienced in high level family violence issues have been identified to respond to cases of forced marriage and honour-based violence.

\section{$\underline{\text { Prevention }}$}

Over the past few years, Shakti has played a significant role in terms of raising awareness and providing information on issues such as forced marriage. The organisation has been invited to speak on the issue at a number of conferences and seminars in Auckland and Wellington and has organised conferences on related issues as well. Most recently, the Multicultural Youth New Zealand (MYNZ) conference organised by the Shakti Youth Unit for migrant and refugee-background youth was a success as it attracted around 160 people, the majority of whom (approximately 140) were young people aged between 15 and 24 years (Shakti Youth Unit, pers. comm., 8 December 2011). The turnout, which was a marked increase from the first such conference held in 2010 which was attended by 38 young people, indicates a growing interest in and awareness of relevant issues on the part of ethnic youth in New Zealand. The theme for the 2011 conference was 'Know Your Rights. Step up against What's Wrong' and included a workshop discussion on the issue of forced marriage which indicated a high level of knowledge of honour-based violence and forced marriage amongst that cohort (Shakti Youth Unit, pers. comm., 8 December 2011).

Shakti has also been an active contributor to and collaborator with the media in an attempt to raise awareness of the issue. There have been a number of articles in major newspapers such as the Dominion Post, Sunday Star Times, New Zealand Herald and the Bay of Plenty Times over the years on issues of honour-based violence and forced marriage. Television New Zealand's Sunday programme ran an episode on the issue of underage marriage in New Zealand. The episode, which aired in March 2010, featured an in-depth interview with a young girl who had accessed Shakti's services after she had been forced into marriage at the age of 14 and also featured an interview with one of Shakti's founders, Farida Sultana (Television New Zealand, 2010). More recently in September 2011, TV1's series Real Crime featured a documentary entitled Broken Promises: Broken Brides in which journalist Rob Harvey highlighted a number of issues facing migrant brides to New Zealand, including forced marriage and horrific domestic violence which sometimes results in death (Television New Zealand, 2011). 
Shakti's Youth Unit also delivers workshops on issues like honour-based violence and forced marriage to girls' schools in Auckland to send a very clear message that family violence is against New Zealand law and that there are support services that young women may access in such situations.

As outlined in Chapter One, Shakti has proactively increased the profile of the issue and its adverse impacts on women and young girls and brought it into the public sphere. Over the years, Shakti has effectively brought the issue to the attention of a number of agencies within government and non-government sectors, and lobbied central Government for change that provides victims of forced marriage with adequate protections and holds perpetrators to account.

Government agencies have also been involved in raising awareness of the issue. In 2010, The Ministry of Women's Affairs (MWA) in collaboration with the Office of Ethnic Affairs (OEA) produced a brochure entitled 'Speak up Seek help Safe home'. The brochure aims to increase awareness of domestic violence within ethnic communities. It also aims to provide women from these communities with further information on identifying domestic violence and accessing support services (The Office of Ethnic Affairs, 2010).

Also in 2010, OEA joined the Taskforce for Action on Violence within Families (The Taskforce) which is a collaboration between government and non-government agencies, independent Crown entities and the judiciary to advise the Family Violence Ministerial Team on appropriate responses to address and eliminate family violence in New Zealand (Ministry of Social Development, see http://www.msd.govt.nz/about-msd-and-our-work/workprogrammes/initiatives/action-family-violence/).

The role of the OEA within The Taskforce is to "bring the perspectives of ethnic people to the table on issues to do with family violence within ethnic communities [including] forced marriage [and] underage marriage" (OEA, pers. comm., 23 November 2011).

We've presented to the Taskforce, some of the unique dimensions around violence within ethnic families and what's different within ethnic families compared to other people because there's a whole bunch of stuff that's similar, of course, but there are some unique dimensions for example, things to do with migrant status that creates pressures on communities that may not be experienced by other people, you might have gender roles that are perceived in 
a particular way by people who've come from other countries and then they bring those gender approaches to New Zealand and that replicates or intensifies the violence that people face within their families, particularly women. Then there are other issues around cultural norms around things like the concept of marriage, why women find it particularly hard to leave because the wider family will not accept their departure and they're stigmatised and departure is seen as the woman's fault (OEA, pers. comm., 23 November 2011).

In April 2011, OEA presented some of the key themes from two EthnicA conferences held in Auckland and Wellington, to The Taskforce. Each two-day conference included a panel discussion on family violence within the ethnic sector. Issues identified during the discussions included "loss of face" experienced as a result of family violence which was "seen by some as bringing shame upon the whole family" (Ministry of Social Development, 2011, Family violence in ethnic communities section).

The OEA acknowledges that forced marriage is undoubtedly a form of violence against women that needs to be addressed. However, the Office highlights, based on experience, that there is still a strong resistance from ethnic communities to even engage in conversations around domestic violence. There is also a tendency to deny its very existence. As such, the OEA is of the view that some foundation work needs to be done to provide ethnic communities a safe space within which they are encouraged to shift domestic violence (and other controversial conversations) from the private sphere to the public sphere. The first step is for them to acknowledge that domestic violence is an issue within their own community and that they need to address it. According to the OEA, until this happens, Government interventions will be "doomed to failure" (OEA, pers. comm., 23 November 2011). Ethnic communities need to be responsible for violence against ethnic women, including forced marriage, and discard the current attitude of denial, which only serves to further the very 'Other-ing' of which ethnic minority communities are, quite justifiably, terrified.

The OEA emphasised the need to promote this change through a grassroots approach by working within communities ${ }^{38}$ to shift their definitions of 'honour' and 'shame.' In such communities, notions of honour and shame are currently based on prescriptive gender roles

\footnotetext{
${ }^{38}$ This was not a blanket statement meant to refer to the entire ethnic community, but a reference only to those who exert power and control over the women in their communities/families in an attempt to explain societal forced that contribute to such behaviour and consequently, the kind of change that must take place.
} 
defined by a hegemonic understanding of power and control. Hyper-masculinity, defined through authority and force, is considered honourable in men and similarly, submission and filial piety considered desirable traits in women. Male honour, therefore, may be lost if the men of the family are seen to be incapable of controlling their wives and daughters (and in some cases, their mothers). Women, in turn, lose their honour if they are perceived to have acted in ways that are not in accordance with their prescribed roles. Societies and families who subscribe to such definitions of honour and shame need to "shift the fulcrum of what is privileged" (OEA, pers. comm., 23 November 2011) so that masculinity is defined in such a way that to be truly honourable is to treat the rest of the family with respect; to perpetrate violence, then, would mean losing, rather than gaining, honour.

It's almost like in some communities you get some authority and mana ${ }^{39}$ by asserting your masculinity over your family and the community condones it and even supports it for whatever reason and those reasons need to change because when you look at the media, how they portray ethnic community violence in the family particularly, it then invites a very negative perception on the whole community whether we like or not, that's what happens. So the community, surely, would have an interest in shifting what privilege looks like to themselves because really, in any other situation, if a member of the community was bringing shame upon your community, you wouldn't regard them as being in a privileged position, they would drop several rungs in their mana level" (OEA, pers. comm., 23 November 2011).

If the definition of honour could be changed such that it is an act of violence that is dishonourable and not a man's failure to control the women of his family, this would then shift the entire community's perspective on behaviour that reflects dishonourably or shamefully on the community. It would then be the violence that is frowned upon and not tolerated, since it maligns the entire community in the eyes of the majority population, rather than the perceived transgressions of wives and daughters. The OEA's work, while still in the early stages, hopes to achieve this by initiating conversations around controversial topics such as domestic violence within ethnic communities and taking small but important steps towards

\footnotetext{
39 "Maori term indicating status, esteem, prestige or authority, and in wide use among all Kiwis" (retrieved from: http://www.newzealandatoz.com/index.php?pageid=357)
} 
creating a culture that accepts and addresses domestic violence and brings it to the surface instead of 'sweeping it under the carpet'.

At the same time, the OEA also recognises that preventative measures are only part of the bigger picture. Appropriate interventions that hold perpetrators accountable and accord victims the necessary protections form the other part of the picture.

While violence against women is a key concern of the Ministry of Women's Affairs (MWA), its recent focus has been on re-victimisation specifically in terms of sexual violence. Very little appears to have been done on the issue of forced marriage other than a submission on the petition to Parliament in 2010 and a contribution to the Select Committee report in the same year. MWA is aware that domestic violence is an issue within ethnic communities, however, and has been involved in exploring the possibility of improving quantitative data collection by standardising the data sets that are used by different agencies (MWA, pers. comm., 11 November 2011). Currently, different statutory agencies use different ethnic groupings and define these groupings differently as well. For example, the 2006 census and the 2010 New Zealand Crime And Safety Survey (NZCASS) use different statistical groupings. The 2006 census used the following grouping options in the question on ethnicity: European, Maori, Asian, Pacific Peoples, and Middle Eastern, Latin American, African (MELAA) (Statistics New Zealand, 2007, p.6). The NZCASS uses the groupings 'Maori', 'Pacific', 'Asian', 'European' and 'Other' (NZCASS, 2010, p.137). The lack of statistical consistency across and within agencies means leads to potential inaccuracies in the extrapolation of data and the analysis of trends. The implication of this is that it is difficult for the Ministry to build a bigger picture view on the impact of domestic violence on ethnic women.

As the lead justice sector agency, the Ministry of Justice (MOJ) was responsible for the official Government response to the report of the Justice and Electoral Select Committee on the issue of forced marriage in 2011. MOJ is in the process (at the time of writing) of conducting a review to determine what the issue is, its prevalence and whether legislative change is desirable.

The Families Commission recognises that family violence is an issue within ethnic communities. It is involved in two primary prevention campaigns namely the White Ribbon campaign and the It's Not OK campaign. The Commission is not involved in any work addressing forced marriage specifically and its only involvement with ethnic communities on 
the issue of domestic violence is through the annual White Ribbon campaign, through which it works with ethnic community leaders.

Forced marriage has not come to the attention of the Human Rights Commission until very recently as it has not featured in any complaints or enquiries. The Commission acknowledges, however, that this does not mean that it is not an issue in New Zealand, it merely means that the Commission has not been approached for assistance by those who have experienced or been threatened with forced marriage. The Commission is supportive of measures that eliminate domestic violence, which the Commission strongly views as a human rights violation. In the past, the Commission lent its voice in support of the development of the Victims of Domestic Violence Immigration Policy which provided migrant wives, whose marriages had been broken by abuse, with an avenue to stay on in New Zealand with their children and continue to rebuild their lives here. The policy recognised the stigma attached to divorce in a number of Asian, African and Middle Eastern societies and the lack of support, both social and financial, divorced women faced in their home country. This policy was strongly advocated for by Shakti as the organisation worked with a number of women who were unable to remain in New Zealand and faced further abuse and even death if they returned to their home countries.

The Commission, through its Taku Manawa initiative, works with communities that are considered the most vulnerable to support them "so they are better positioned to identify, address, verify and monitor human rights abuses in their own community" (HRC, pers. comm., 9 December 2011). The initiative uses a human rights community development approach to engage with each community over a period of three years and provides them with support and mentoring in a grassroots approach rather than adopting a colonising, top down approach.

In 1999, the Commission led a street campaign, the Pink Sticker campaign, aimed at assisting Thai sex workers to escape prostitution in New Zealand. It was a multi-agency initiative that was supported by the Mayor of Auckland City Council and various agencies such as Immigration New Zealand, the New Zealand Police, Prostitutes Collective, ECPAT NZ, Shakti, Unifem (as UN Women was known then) and the Thai embassy (Academy for Educational Development, 2006; HRC, pers. comm., 9 December 2011). Although the campaign was not without its flaws, it is an example of successful multi-agency collaboration on an issue that is a human rights violation. The campaign was successful in terms of its 
structure as it was a grassroots campaign that focused on the needs of the community and did not adopt a top-down, authoritarian approach (HRC, pers. comm., 9 December 2011).

The campaign focused primarily on practical interventions. A telephone hotline was established and crisis intervention included emergency accommodation for up to two weeks at Shakti's safe house, legal counselling, direct monetary assistance and assistance to recover money paid to traffickers. The campaign also liaised with women's NGOs in Thailand to ensure the safe return of the women to their home country. Information about the hotline and the safe house, in both Thai and English, was printed on pink stickers which were then distributed to hospitals, red light districts, police stations and other locations in central Auckland (ibid.).

The campaign lasted for about two years and successfully assisted seven women who had been bonded to the industry (Ministry of Justice, 2002). It also resulted in the suspension of the visa-free status between New Zealand and Thailand partly because of the abuse of the system by traffickers and those working illegally in New Zealand (Academy for Educational Development, 2006).

It also generated a significant amount of media coverage and by doing so, highlighted the issue of sex trafficking in New Zealand and the need to address it. The Commission cautions, however, that safety considerations need to be provided to those involved in such high profile, frontline campaigns and that cost-benefit analyses should also be undertaken to ensure that resources are strategically allocated (HRC, pers. comm., 9 December 2011).

United Nations Children's Fund New Zealand (UNICEF) supports the development of an awareness raising campaign aimed and stresses that any national strategy should be based on information and research that provides a clear picture of the nature and scale of the issue (UNICEF, pers. comm., 31 October 2011). The United Nations Entity for Gender Equality and Empowerment of Women (UN Women) was formed in 2010 by the United Nations General Assembly to streamline resources and mandates on gender equality and empowerment for greater impact (UN Women, 2011). UN Women has two main areas of focus in New Zealand. The agency is still involved in the White Ribbon Campaign which was brought to New Zealand by UN Women. As the agency has limited resources, the running of the campaign was handed over to the Families Commission. The agency's second area of focus within New Zealand is on the CEDAW alternative report which is coordinated by the National Council of Women but which UN Women feeds into on the topic of Violence 
Against Women (UN Women, pers. comm., 28 October 2011). In the Pacific region, UN Women's role is mainly in terms of fundraising for projects that are focused on the elimination of violence against women in the region, with a current focus on the Solomon Islands where "domestic violence is endemic" (ibid.).

\section{Constraints \& Future Directions}

$\underline{\text { Intervention }}$

One of the main needs identified by Shakti Youth is a dedicated service for young female survivors of honour-based violence and forced marriage. Currently, youth survivors who require temporary emergency accommodation are given the option of moving into one of Shakti's existing safe houses. However, as the safe houses were established primarily to cater to the needs of adult women, they are only staffed during office hours. Youth survivors are considered more vulnerable than adult survivors as many of them have been disowned by their families or refuse to return to their families out of fear of further abuse or death. Most are not financially independent and many lack the 'street smarts' needed to fend for themselves having led extremely sheltered lives. Add immigration and relationship issues to the mix and what Shakti has found is that a large number of girls have considered attempting suicide (Shakti Youth Unit, pers. comm., 8 December 2011). ${ }^{40}$

Drawing from international research (Ministry for Social and Family Affairs, 2009) and domestic need, the model that Shakti is currently working on includes a safe house, or emergency accommodation, that is monitored 24 hours a day and provides girls with a safe space within which they are supported to negotiate their own identities and needs. The need for a 'wraparound' service that includes a transition programme of some sort has also been identified. Such a service would provide service users with adequate support to transition back into the community in a manner that takes into account both their physical as well as emotional safety. Although Shakti is well placed to run such a service, the organisation has limited resources and would require additional funding support. Shakti believes that a multiagency intervention model would be required so that the girls receive a comprehensive

\footnotetext{
${ }^{40}$ This is supported by findings from the Youth2000 survey conducted by the Ministry of Youth which indicates that there is a correlation between young people experiencing and witnessing violence and mental health problems. The survey found that "the proportions or Chinese students who had witnessed an adult hitting or physically hurting a child in their home or another adult in their home were higher than the proportions among New Zealand European students" (Parackal, Ameratunga, Tin Tin, Wong \& Denny, 2011, pp. 26). The same was noted for Indian students as well. It goes on to report that more female students than male had thoughts of suicide and that prevalence of significant depressive symptoms were markedly higher among females than males (ibid.).
} 
service that addresses their varied needs. For example, some girls may not have done well at school as a result of the trauma of honour-based violence or forced marriage. In such cases, support from the Ministry of Education (MoE) is crucial so that the underlying reason for the poor grades is understood and the girls are not penalised for it. MoE's involvement is also crucial to ensure that girls who have missed lessons have the support they need to get back up to speed. Shakti also believes that schools need to focus on students' wellbeing in a holistic manner and not focus solely on their academic performance. Increased awareness and support from agencies such as Work and Income, Housing New Zealand Corporation and Immigration New Zealand are also required.

Women's Refuge believes, with regards to intervention, that independent refuges require support to better understand the complexity of ethnic women's experiences of domestic violence. Training would also be required in order to promote a better understanding of some of the ways in which violence manifests in ethnic communities and the additional barriers faced by ethnic women in terms of accessing services.

While Women's Refuge and Shakti have a positive working relationship and are supportive of each other, both organisations are keen to strengthen this relationship through a Memorandum of Understanding which according to Refuge, should only be the starting point. Refuge believes that

[It] needs to be part of a whole bigger picture, it's no good just having a MOU and think that it's going to change behaviour because I think it won't. It's got to be a whole package that everyone is actually committed to doing (Women's Refuge, pers. comm., 25 October 2011).

Once the average level of awareness of ethnic women's experiences of domestic violence has been raised sufficiently through appropriate training and the dissemination of information, Women's Refuge feels that it may be possible for Refuge to collect data on issues such as honour-based violence and forced marriage. This would involve significant changes to the existing database and additional training to ensure that Refuge caseworkers understand the need for the change and are able to identify and record the information correctly. For this to be sustainable, however, Refuge would require additional funding as each change that is made to the existing database costs the organisation at least $\$ 15,000$. Women's Refuge is supportive of further research into the issue but emphasised the need for collaboration between government and non-government sectors as well as academia such that the research 
is robust and not overly influenced by any individual agenda. The organisation has also identified the need, from a service provision perspective, for a one-stop shop along the lines of the Forced Marriage Unit (FMU) in the UK. Refuge is supportive of the development of a specialist agency similar to the FMU because they feel

whenever you specialise in something the end result usually is better because when you specialise and you get out really good information, you're able to give time to that issue that you don't normally have the time to do and so therefore you're able to build the awareness, create the information, create the buy-in for it and then that usually results in higher level reporting and more awareness and more knowledge (Women's Refuge, pers. comm., 25 October 2011).

Women's Refuge considers legislation crucial in terms of holding perpetrators accountable and stressed the need to involve Immigration New Zealand on the issue as well. In terms of details of legislative change that may be needed, however, the organisation is happy to be guided by Shakti (ibid.). There would need to be consideration, as there was in the UK, whether civil or criminal legislation would be more appropriate. Women's rights groups in the UK that work with ethnic women, such as Southall Black Sisters, found that criminal legislation was less popular as it was seen as a potential deterrent to reporting as many young women and girls did not want to criminalise their parents (Southall Black Sisters, 2005).

While statutory agencies such as CYF and the Police are aware of the need for New Zealand to recognise that forced marriage is an emerging issue that needs to be addressed, they too face constraints to action (CYF, pers. comm., 9 December 2011;New Zealand Police, pers. comm., 24 November 2011). While CYF does have a procedure in place to manage potential reports of forced marriage in Auckland, the agency is aware that there may be a need to develop policies and procedures around handling such cases nationwide if the issue intensifies and the number of such reports increase. The agency's modus operandi may also need to be adapted in order to ensure the safety of the girls involved. Reallocating resources may be possible if there is clear indication of need.

Such action can only be undertaken if there are reports of concern made through the CYF system.

There'd have to have been some reports...you know, a number of reports of concern where young women have had to come into care for starters, so there'd 
have to have been a cohort of young women through to justify any sort of expenditure (CYF, pers. comm., 9 December 2011).

CYF did not define how many young women would constitute a "cohort" but merely stated that there would have to be a "number of referrals" (ibid.) before expenditure could be justified. During initial meetings with Shakti, CYF expected to be provided with information on the demographic details of the girls who had been forced into marriage.

We went out there essentially saying that we need to know who these young women are, what are their names, their addresses, where are they from and who are they? We didn't get any of those names and to some extent, the staff at Shakti talked about how they were basically lobbying Government for changes in legislation and policy around the management of these sorts of cases but weren't willing to give us any specific details about any actual real cases right now (CYF, pers. comm., 9 December 2011).

The Police National Family Violence Unit recognises the dilemma that service provision agencies are in as a result of such an expectation of transparent data and the need for girls to access CYF services before prevalence can be determined and resources allocated to address the need.

There are problems with data collection. It is Shakti's role to bring this issue to the fore, but the issue is being able to collect data such that it is transparent and can be accepted. This puts service provision agencies in a quandary because they could find themselves in the position of authorities asking why these girls haven't been reported to the right authorities, for example CYF, if the girl is below 17, but the agencies may not want to do this because of the safety risk of the kids. We need to understand that these girls are experiencing a terrible amount of fear and it's a big step for them to take (New Zealand Police, pers. comm., 24 November 2011).

The Police are considering establishing a separate refuge for young survivors of forced marriage, as the Police have identified that 16,17 and 18 year old girls are especially vulnerable, but would require some idea of prevalence to justify the resources required (ibid.). The next step for the Police is to finalise the process with CYF and internal guidelines on managing such cases. They are keen to promote the need for increased understanding of 
honour-based violence and forced marriage within the agency to ensure that Police staff members are able to act appropriately. The Police are also keen to be a part of awarenessraising activities targeting the general public. However the main constraints facing the Police include a lack of "real appreciation of the size of the problem, the prevalence of it [which] impacts [their] ability to rearrange resources to it in a resource scarce environment" (ibid.).

The Police stress that no single measure will work for everyone and that New Zealand's response to the issue of forced marriage should include a larger strategy. According to the agency, the establishment of a national crisis line is something that should be looked into as one of the measures, although it should be considered carefully before it is implemented such that it is able to mitigate potential pitfalls. In certain communities, the resistance to bringing the conversation about domestic violence to the public sphere is so strong that measures other than a crisis line may need to be considered.

I spoke at an Indian women's conference in South Auckland earlier this year and they talked about the difficulty of speaking to someone else from the community about domestic violence and felt that they weren't ready to talk about it. In addition, some women don't have a phone, don't have access to a phone, may not be able to use one, could be worried about other people overhearing her conversation or finding out what the last called number was although it is possible to have protections around confidentiality of the number (NZ Police, pers. comm., 24 November 2011).

The Police are also emphatic that legislative change is needed and that clear legislation would provide them with a mandate to act.

Legislation is currently unclear and should provide more clarity around obligations around offending in terms of marriage. It's vague and not specific because it was never drafted with cognisance of forced marriage and needs to be updated to reflect an increasingly complex society and increased understanding of issues, and it's problematic (ibid.). 


\section{$\underline{\text { Prevention }}$}

Shakti has and will continue to play a substantive role in terms of raising the profile of the issue and bringing it to the attention of both key decision-makers as well as the general public. Other non-government organisations and UN agencies with an advocacy role such as Women's Refuge, UN Women and UNICEF will also undoubtedly lend their voices to the cause.

For the issue to be addressed effectively through the development of a strategic plan, however, it would require high-level commitment from the Government sector as well as political traction. Legislation would provide a mandate for service provision agencies to act and for a national education campaign to promote awareness of the issue as a human rights violation.

Such a commitment may result in a reallocation of resources such that the data that is currently being collected by organisations like Shakti is considered sufficient evidence for government agencies and quasi-government agencies to act. All the government agencies interviewed cited prevalence as one of their main concerns and primary constraints. Most agreed that qualitative data that could provide an insight as to how and why forced marriage takes place, would suffice initially but that quantitative data would be required eventually to provide an idea of the size and scale of the issue.

Service provision agencies such as Shakti and Women's Refuge, however, require resources to be able to provide such data. Even with adequate resourcing, it is unreasonable to expect these organisations to provide potentially sensitive information that may jeopardise the safety of the women and girls concerned, to government agencies in order for them to be convinced that there is a need.

Given that agencies such as the MWA and OEA are comparatively small with limited resources, they need to be strategic about resource allocation. Such agencies must have a clear understanding of what the needs are so that they can aim to address them effectively. MWA is interested in exploring the possibility of supporting further research into 'cultural' components, unique risk factors and various needs of women and girls who are subjected to this human rights violation. The OEA has adopted a more long term view and is focused on creating an environment that would allow specific issues such as forced marriage to be addressed effectively. Their viewpoint is that Government intervention would fail if the 
landscape in which the interventions take place does not support the interventions. For example, interventions to address forced marriage, a specific form of violence against women, in an environment that denies the very existence of domestic violence, would not be effective. As such, the agency suggests that a multi-pronged strategy including both intervention and prevention may be required. Such a strategy would ensure that perpetrators are held accountable while simultaneously providing victims and survivors with adequate protections. It should also include education, awareness raising and training for both majority and minority populations as well as service provision agencies potentially including the judiciary.

Most agencies who attended the workshop session were in agreement that a stand-alone campaign may not generate sufficient Government buy-in and felt that addressing it as part of a wider campaign against domestic violence was the way forward. There was considerable debate on the focus of a national campaign. However, participants were divided on the finer details of the strategy in terms of whom it should target and the key message it should deliver.

Shakti, which was the only NGO present, felt that the campaign should be victim-centred and should initially focus on youth rights and services. In their view, the campaign needs to be promoted online and be mobile such that it can be taken to schools and reach the intended target audience effectively. The rationale behind this is that firstly, in Shakti's experience it is women from the $12-24$ demographic who seek support specifically for forced marriage. Secondly, in keeping with the widely acknowledged view that violence against women stems from a power imbalance and the issue of power and control, young people are disadvantaged and especially vulnerable as power lies in the hands of the adults. Shakti is concerned that a campaign targeting adults, especially adults from communities that already deny the existence of domestic violence, would only serve to drive the issue further underground. The campaign could eventually be broadened to include messages targeted at both minority and majority communities.

Other agencies including the Families Commission, Human Rights Commission and Office of Ethnic Affairs supported the view that a national campaign should focus on community engagement and deliver its message to parents and entire communities instead. They argued that targeting potential victims and survivors alone was insufficient as it is a general mind-set change that is required. It is not enough for young people to get the message that forced 
marriage is illegal; until the community rallies around the view that forced marriage must be stopped, such a campaign could potentially further isolate women and young girls such that they are "stuck in limbo" (HRC; Families Commission, pers. comm., 16 December 2011). They felt, quite strongly, that a campaign solely targeted at young people without communicating the message to communities as a whole would also only serve to camouflage the issue. These agencies emphasised that community leaders had to be engaged to drive much-needed social change from within these vulnerable communities. As the HRC stressed, during the interview session, however, engagement with community leaders should be undertaken very carefully so as to ensure that these leaders themselves are not perpetrators.

The need to hold the New Zealand Government accountable to its international obligations was also emphasised by the HRC. This comment was made with specific reference to New Zealand's ratification of UN CEDAW and the CEDAW committee's recent recommendation that the Government address the issue of forced marriage as a violation of basic women's rights. Both the HRC and the OEA also emphasise the need for the majority population to recognise that this issue is not merely an 'ethnic issue' but is one that holds relevance to New Zealand society as a whole.

The Families Commission has invested, in the past, in awareness campaigns and behaviour change campaigns. Their campaigns have emphasised the need to acknowledge the interconnectedness between individuals and their societies so that change that is promoted in a holistic manner (Families Commission, pers. comm., 28 October 2011). The Commission's work priorities, however, are set well in advance of each financial year and clearly depend on a political mandate (ibid.).

The main role that the MOJ would play is to ensure that the legislative framework appropriately addresses the issue and outlines appropriate penalties. The issues that women's rights activists in New Zealand have with the existing legislation will be covered in the next chapter. Apart from legislative change, MOJ may also be able to play a secondary role in terms of education and awareness raising although this would have to part of a wider strategy and would need to be undertaken strategically (MOJ, pers. comm., 11 November 2011). Finally, the MOJ would definitely require a political mandate from the current Minister of Justice, Hon. Judith Collins before any progress can be made on the issue.

UNICEF views the issue of forced underage marriage as a child protection issue and is, therefore, committed to playing its part to address the practice under the 1990 Convention on 
the Rights of the Child (UN CRC). Although the agency is supportive of the need for more research and information on the issue, it is funded only for advocacy and programmes and receives no funding for research. However, UNICEF is keen to lend its voice and branding to a national strategy aimed at deterring forced marriage and is also keen to convene an advisory group to address the issue.

UN Women is a firm believer of the need to prioritise legislative analysis and change over education and awareness-raising. Legislative analysis needs to be undertaken to determine whether the issue is one of strengthening existing legislation or creating new legislation. The agency would support advocacy for appropriate legislation on the issue of forced marriage as a starting point which would then provide the mandate for further action and encourage the public to take notice of the issue. While UN Women would not be able to provide funding, the agency would be keen to promote fundraising activities carried out by network agencies (UN Women, pers. comm., 28 October 2011).

The debate on legislation, at the workshop session, revolved around the merits of legislative change and whether changing existing legislation alone would contribute sufficiently towards deterring the practice. The general consensus was that it would be more effective if it were part of a wider strategy to deter the practice of forced marriage.

\section{$\underline{\text { Conclusion }}$}

This chapter provided an overview of the work that has been and continues to be done to address the issue of forced marriage from two angles: intervention and prevention. The gaps that exist within service provision in the area of honour-based violence and forced marriage as well as key concerns and needs of stakeholder agencies were also discussed. Key concerns include the lack of resources, minimal awareness of the practice and concerns around determining the prevalence of the issue. Most agencies felt that further research is required on the nature of honour-based violence and forced marriage. The need for increased awareness and in-depth understanding of the issue, potentially in the form of a national awarenessraising campaign was also identified. There was cognisance that a significant amount of work needs to be done to bring controversial issues like domestic violence within the ethnic community into the public sphere before specific forms of violence such as forced marriage can be addressed effectively. Most agencies agreed that laws pertaining to marriage need to 
be clarified and made relevant to address the issue of forced marriage. Such change would provide agencies, like the Police, with a mandate for action. The critical need for a political mandate at a central Government level was also identified. Engagement with stakeholder agencies revealed the need for a multi-sector, collaborative approach to the issue so that opportunities and individual strengths are maximised. The next chapter elaborates on key findings of the study and provides specific recommendations that will hopefully contribute towards deterring the practice. 


\section{Chapter Eight: Conclusion}

This chapter begins with a reflection on the research aims outlined in Chapter One and looks at how they have been achieved. The discussion then centres on an analysis of key findings and specific recommendations for social and legislative change, in relation to GAD policy and practice. The recommendations are aimed at providing those impacted by forced marriage with adequate protections under New Zealand law and ensuring that those with agency in forced marriage are held accountable.

\section{How Have the Research Aims been Achieved?}

The first three chapters created the foundation upon which the rest of the study was constructed. Chapters One and Two situated the research study personally, politically and geographically. The first chapter defined forced marriage, outlined the history of related activism, explained my decision to embark upon this particular research journey, and situated it within a GAD approach. Since this is the first piece of research on the issue, the second chapter was devoted to explaining the intersections between genderbased violence and 'honour' as they manifest in home countries, diaspora communities internationally and here, in New Zealand. Chapter Three focused on the methodological and epistemological framings of this study and outlined the research methods. In keeping with feminist framings, it included a detailed analysis of the challenges involved in 'doing' this research and briefly discussed the values and limitations of the study.

The first two research aims of the study are achieved in Chapters Four and Five. Chapter Four was dedicated to the narration of two women survivors' stories. It was designed to privilege their voices through the liberal use of direct quotes and by keeping my analysis to minimum. Chapter Five analyses the types of change required to deter the practice, as detailed by the women, and their recommendations for achieving such change.

The sixth chapter addressed the third research aim by analysing existing New Zealand legislation relevant to the practice of forced marriage. It situated the analysis against a backdrop of New Zealand's international obligations to ensure that basic rights, in relation to marriage, are upheld. 
Chapter Seven addressed the final two research aims by exploring measures that are currently being taken by various stakeholder agencies to address the practice of forced marriage from the angles of intervention and prevention. Chapter Seven also included key discussion points from the stakeholder engagement workshop held in December 2011.

\section{$\underline{\text { Key Findings }}$}

\section{$\underline{\text { Intervention }}$}

Culturally-appropriate emergency accommodation, with advocacy support, that specifically caters to the needs of younger survivors of violence is virtually non-existent in New Zealand. Shakti has a process in place to identify needs that are specific to young migrant and refugee women and provide them with specialist support. Shakti's safe houses, while culturally appropriate, are limited in number and capacity and are, therefore, almost constantly occupied to full capacity. Women's Refuge member refuges cover a much larger geographical area but face challenges in terms of the awareness and understanding of culturally-nuanced forms of violence against women. In both cases, the emergency accommodation options are not specifically tailored to the needs of younger survivors. They are also not monitored twenty-four hours and therefore may be unsuitable for younger survivors who require additional support for issues like depression.

Gaps in service provision also include the lack of an appropriate transition programme specifically tailored to address the needs of young survivors of honour-based violence and forced marriage. A distinct lack of understanding around the dynamics and effects of such violence on its victims has a negative impact on the development of appropriate services and the quality of existing services. The lack of in-depth understanding also appears to have negatively affected the development of appropriate processes and protocols within statutory agencies, specifically to address honour-based violence and forced marriage. Concerns regarding access to relevant information and existing services were also alluded to in the survivor stories. Neither Fazia nor Pisey had heard about Shakti until much later in their stories when they were referred, by concerned friends, to Women's Refuge and Shakti respectively.

CYF's commitment to child protection in relation to forced and underage marriage as well as honour-based violence is commendable. However, the dilemma faced by NGOs like Shakti, 
as a result of the CYF requirement for women to access their service before protocols may be refined and funding justified, is of concern. As noted by the Police in Chapter Seven, this places undue pressure on such NGOs to ensure that survivors under the age of 17 are referred to CYF. More importantly, the requirement for automatic referral to a statutory agency strips survivors' of their right to choose the service they want to access and takes away their sense of agency. Also, service provision agencies like Shakti that are founded on feminist philosophies are inadvertently forced to work in ways that further disempower the women who access their services.

\section{$\underline{\text { Prevention }}$}

The need for both preventative measures and short-term interventions was identified by stakeholder agencies in Chapter Seven. The need for both short- and long-term measures is in keeping with GAD theory, which advocates for both immediate practical steps as well and more long-term measures (see Chapters One and Three). GAD thought highlights the intersections between and within social, economic and political structures and the implications of these intersections on gender relations. The consensus reached at the workshop on the need for legislative change, not as a stand-alone measure but as part of a multifaceted, integrated strategy to deter genderbased violence, was therefore, in accordance with a GAD approach. GAD policy and practice advocates multi-sector responses that promote change at different levels (Sen, Östlin, \& George, 2007).

One of the overarching needs identified through this study, was the need for education and awareness-raising at various levels. An in-depth understanding of the dynamics of honourbased violence and forced marriage appears to be lacking amongst most agencies. This lack of understanding coupled with the lack of national data specifically on the issue, has resulted in the inability to address the issue effectively across the spectrum of intervention and prevention. As the Ministry of Women's Affairs (MWA) noted, even a general understanding of ethnic women's advancement and the factors that impede advancement, in New Zealand is difficult to obtain given the use of non-standardised data sets by various agencies.

The Ministry of Justice (MOJ) also stressed the need for clear communication between and within agencies in the interests of consistency and efficiency. During the workshop session, MOJ stated that they had been told that migrants could enter New Zealand on the basis of an 
impending arranged marriage. When they sought to clarify this with sources within Immigration New Zealand, however, they were told that it was not possible. Later, they found out that there was indeed a specific Visitor Visa that could be applied for specifically for the purpose of culturally arranged marriage that had a validity of three months. This incident was cited as an example of the need for improved communication and information-sharing between stakeholder agencies.

Funding was also acknowledged, during the workshop session, as a potential stumbling block. Participants observed that Government funding is limited for both service provision as well as research and therefore, difficult to access.

The need for a paradigm shift within the ethnic community towards different definitions of honour and shame was highlighted both by stakeholder agencies such as the Office of Ethnic Affairs (OEA) and the Human Rights Commission (HRC) as well as by Pisey and Fazia. Both stakeholder agencies were emphatic about the need for attitudinal change within the ethnic community such that issues like genderbased violence are discussed and addressed. Both agencies also acknowledged the importance of cultural and religious sensitivity so as not to inadvertently promote further discrimination against ethnic minority groups.

Recent developments in the UK with regards to the issue of forced marriage and Immigration controls were also briefly discussed at the stakeholder engagement workshop. It was acknowledged that honour-based violence and forced marriage are primarily issues of power and control and violence against women. Although one of the survivor stories in this thesis sheds light on the use of coercion and marriage for monetary gain and New Zealand citizenship, there does not appear to be substantial evidence (nationally or internationally) that Immigration status is an overwhelming reason for forced marriage. As such, addressing forced marriage as an Immigration issue rather than a violation of human rights per se would only serve as a smokescreen. The need to de-link forced marriage and immigration is supported by the Southall Black Sisters (SBS), a specialist NGO in the UK established to meet the needs of Asian and African Caribbean women and to challenge violence against women (Southall Black Sisters, n.d.). It is also supported by a recent Supreme Court ruling in the UK ((The Supreme Court of the United Kingdom, 2011).

In 2008, Paragraph 277 of the UK Immigration Rules was amended to raise the minimum age, from 18 to 21 , for a person to be granted a visa to settle in the UK as a spouse or to sponsor another person for the purpose of obtaining such a visa. A Supreme Court ruling in 
October 2011 on two such cases stated that the "purpose of the amendment was not to control immigration but to deter forced marriages" (The Supreme Court of the United Kingdom, 2011, p.1). However, there was insufficient evidence on a number of issues including how prevalent "the motive of applying for UK citizenship is in the genesis of forced marriages" (ibid.). SBS supports the Supreme Court ruling that "the government's ban... is an unlawful interference on the couple's right to [and] respect for private and family life" (Southall Black Sisters, n.d., Landmark Supreme Court Ruling section).

SBS goes on to state that:

We believe that the issue of immigration control and forced marriage must be delinked. There are other, more effective ways of addressing the problem, for example providing funding for specialist organisations, undertaking preventative work in schools, improving access to education and supporting those who are trying to tackle the root causes of forced marriage from within their communities. This judgment makes it clear that the link between forced marriage and entry to the UK has not been clearly established. We therefore urge the government to think again about using the issue of forced marriage to justify its latest unnecessary and discriminatory proposals on family-related migration. Forced marriage is a serious issue but it should not be used in a cynical way to create a moral panic to justify the government's immigration agenda (ibid.).

\section{$\underline{\text { Specific Recommendations }}$}

\section{Intervention}

The need for a dedicated service targeted at younger survivors of honour-based violence and forced marriage could be met through the provision of a culturally-appropriate refuge for them along with a transition programme tailored to their requirements. A 2009 report funded by the European Union and based on a two-year study, substantiates the need for specific accommodation support for survivors, and especially younger survivors, of honour-based violence and forced marriage (Ministry for Social and Family Affairs, Health and Consumer Protection, 2009). As highlighted in both Pisey's and Fazia's stories, forced marriage is often accompanied by high levels of emotional abuse and the breakdown of the family. Despite this, in both cases, the women maintained a link to their cultural and religious identities. As 
such, it is important to offer survivors counselling services that understand and respect the socio-cultural contexts within which honour-based violence and forced marriage take place and do not require them to disown their cultural identities. A dedicated transition programme is also important to ensure that young survivors are provided with adequate support to reenter society in a manner that takes their physical and emotional safety into consideration. When establishing a service, including accommodation, that is dedicated to survivors of honour-based violence and forced marriage, it is crucial that the anonymity of both service users and support staff, is ensured (ibid.). The need for anonymity for support staff is highlighted in the 2009 EU report and is also a concern that has been noted by Shakti support staff, myself included. Many of us belong to the same ethnic communities as the survivors we support. As mentioned previously, many of these communities are in denial of existence of genderbased violence within their community and therefore, appear to shift their resentment towards members of their own community who work in such fields. The negative reputation accorded to and safety risks encountered by women's rights activists within diaspora communities is also recorded in 'From Homebreakers to Jailbreakers,' an SBS publication.

A good-practice model that is currently being considered by Shakti, is that of Papatya, an "anonymous crisis and transitional centre" in Berlin that was founded in 1986 for girls and young women with a "background in migration" (Ministry for Social and Family Affairs, Health and Consumer Protection, 2009, p. 66). The service prioritises both safety and the empowerment of the girls. Service provision is centred around the girls' needs and encourages each survivor to "search for her perspective on her life, her past and her future and [supports her] to make her voice heard" (ibid., p. 66). In recognition of the young age of some of the service users, round-the-clock service is provided and strict curfews are imposed to ease the worries of the girls' parents. In addition, the shelter is for girls only. Papatya's shelter can accommodate up to nine girls at any one time, is accessed by approximately 60 girls per year and is primarily funded by the City of Berlin (ibid.).

The lack of knowledge of and access to services, as expressed by Fazia in her analyses of her experience, could be mitigated by her suggestion of disseminating relevant information through schools and perhaps through appropriate channels at religious institutions. Orient Express, which is a specialised organisation in Austria, organises school workshops aimed at "reaching out to potential clients before marriage" (ibid., p. 52). Specially-trained counsellors from Orient Express conduct 50 minute long workshops with groups of young people aged between 13 and 18 years. Workshop materials are discussed beforehand and planned with 
guidance from the schools' teachers. Workshops focus on how forced marriages may occur and what students could do if it happens to them. It also highlights the "intrinsic link" (ibid., p. 53) between forced marriage and violence, gives them information on relevant Austrian laws and makes use of positive examples to encourage students to shape their own futures. Students are also provided with information sheets on relevant organisations and phone numbers as well as stickers with the phone number of their school's counselling contact point, to help them memorise the number. Orient Express has found that the best time for these workshops is just before the school holidays, as the issue of forced marriage is usually raised during the holidays (ibid.).

The lack of an in-depth understanding of honour-based violence and forced marriage across the service provision spectrum needs to be addressed immediately in the interests of safety and the protection of young women who may need to access support services. Understanding may be improved through increased collaboration with and training provided by specialist agencies $^{41}$ to service providers, statutory agencies and NGOs alike, and potentially to the judiciary as well. It is important that training is tailored to provide an in-depth understanding of the dynamics of honour-based violence and forced marriage so that individuals involved in the care and protection of survivors are able to act appropriately and in a timely manner. The potential risk to the safety of women subjected to honour-based violence including forced marriage, given the potential for social collusion, is often much higher. As such, these cases should not be subjected to the same processes as regular family violence callouts. The increased vulnerability of younger survivors should also be considered.

CYF's need for 'test cases' to further inform the detailed development of appropriate internal processes and protocols may be circumvented by the use of real-life case studies provided by specialist agencies.

\section{$\underline{\text { Prevention }}$}

As mentioned in Chapter Three, this thesis has attempted to provide readers with a preliminary understanding of the dynamics of honour-based violence and more specifically, the dynamics of forced marriage. However, further research is required to ensure evidence-

\footnotetext{
${ }^{41}$ Specialist agencies referred to here are those agencies whose services are both culturally-sensitive as well as rights-based.
} 
based intervention and prevention. I believe that such research should ideally be premised on post-colonial feminist framings so that knowledge on culturally-nuanced forms of violence against women is not constructed within a cultural vacuum. It should also be based on ethnic women's lived experiences and their analyses of their own realities. This does not mean that non-ethnic researchers should necessarily be excluded from conducting research on issues within ethnic communities (Sharp, Briggs, Yacoub \& Hamed, 2003). It means that researchers must privilege ethnic women's ways of knowing and their experiences. It is important, as well, that research on genderbased violence within ethnic communities is conducted from a rights-based perspective and not through a lens of cultural relativism. Emphasis should be placed on gender relations, in accordance with GAD thought, so that issues like genderbased violence are not framed as 'women's issues'.

A focus on gender relations shifts the onus of addressing the issue from women to entire societies. It also brings ethnic men into the conversation. Only then can currently controversial issues, like genderbased violence, be brought into the public sphere and addressed. As Sharma (2012) points out on the issue of forced and underage marriage in India, "if you shine a bright light into a dark corner, you might not scare away the problem, but you will at least see that it is there" (p.3).

The need to shed light on issues of honour-based violence and forced marriage in the form of a national education and awareness-raising strategy has been identified by most of the agencies that participated in this research study. The focus and framing of the strategy was debated during the workshop and as outlined in Chapter Seven, there were opposing views expressed by agencies with varied foci and philosophical bases. Shakti stressed that a national strategy should be survivor-focused initially, taking power differentials between youths and their parents into consideration and given the increased vulnerability of young survivors.

Shakti's approach could be viewed as being more in line with a WID Empowerment approach, which places women at the centre of its focus. The shift from WID to GAD, in its initial stages, faced significant opposition from women. Women who opposed the move felt that including men and masculinities into the development discourse and shifting the focus away from women would erode the "limited terrain which has been won for women in development" (White, 2000, p. 34). The other agencies that attended the workshop, such as the OEA, HRC and Families Commission, felt that a national strategy should be focused on entire communities and carry the message that practices like forced marriage, are violations 
of human rights. Such a strategy would be more in line with a GAD approach since it focuses on the social relations between men and women, which require transformation. Awareness should also be raised internally by service provision agencies through continued training for staff members and a medium-term plan to develop appropriate resources, including guidelines, for service provision.

A concerted effort is needed to focus on the issue from a rights-based perspective and to move away from an approach that frames the entire ethnic community as one that is guilty of "barbarism in NZ" (Farrar, 2012, headline). It is important that the media is part of the concerted effort since the "mass media play a crucial role in the persuasive reproduction of dominant ideologies in general, and of ethnic ideologies in particular" (van Djik, 1987, p. 221).

Therefore, although the potential power of the media to deliver messages aimed at the general public should be harnessed as suggested by participants at the workshop session, the framing of the message is extremely important. Journalists must be aware of potential threats to the safety of women survivors who choose to speak about controversial issues such as domestic violence. Articles must be written with sensitivity such that 1) the identities of the women are adequately protected 2) photographs of the women are not included and 3) the message is portrayed in a manner that focuses on the aspect of rights rather than race relations.

Journalism that is sensitive to the framings of messages would play an important role in paving the way for the ethnic community to be able to take the first step towards attitudinal change. Perhaps this first step could be in the form of a unified, collective effort on the part of ethnic community leaders and the media spokespeople of cultural organisations to acknowledge that domestic violence exists within the ethnic community. They should collectively stand against the social collusion of genderbased violence and take a rigorous stand against those who perpetrate violence against women. Many stakeholder agencies believed that a grassroots, participatory approach was required for sustainable change. As such, the move to redefine notions of honour and shame must be driven from within the community.

Long-term preventative measures should include ways in which the prevalence of forced marriage could be determined nationally so that the burden of proof is not squarely on the shoulders of one NGO. As mentioned by MWA (see Chapter Seven), the standardisation of data sets to promote statistical consistency is also necessary. Finally, high level political 
commitment is crucial for the development of a successful national strategy that is able to address and deter honour-based violence, including forced marriage, at various levels. A committed Government is needed to ensure that interventions and preventative measures are evidence-based, appropriately resourced and effectively target the real needs of the community.

A community-driven paradigm shift that privileges women may be the most effective and sustainable change in the long term. In the short- and medium-term, however, the safety of women and children impacted by forced marriage needs to be adequately protected and perpetrators (including those with agency) must be held suitably accountable, under New Zealand law. The recommendations for legislative change are especially important considering New Zealand has only partially fulfilled it international obligations to safeguard New Zealand women's rights in relation to marriage (see Chapter Six).

The following recommendations concentrate on the requirement for consent which "exists in law but not universally" (Innes-Kent, 2007, p.60), the need for adequate monitoring of marriage rituals and the need to legislate specifically against agency in forced marriage. More research is needed before it can be determined whether agency in forced marriage should be a criminal or civil offence.

Recommendations:

\section{Consent}

a. To make 'free and full' consent from both parties a requirement for application of marriage license. This would also reduce the current over-reliance on the words used during a marriage ceremony, to imply consent (see Section 31(3) of the Marriage Act 1955).

b. To make it a requirement for "all those officiating at marriages to be satisfied that consent of the intending spouses has been given in each individual case" (ibid., p.60).

c. To increase the minimum age of marriage to 18 in keeping with suggestions by UNICEF International and UN CEDAW (this would automatically result in the repeal of Section 18 of the Marriage Act 1955 which allows parents to provide consent on behalf of minors). 
2. Marriage Celebrants

a. To make it a requirement for all organisations officiating at marriages to be registered under Section 9 of the Marriage Act 1955 (ibid.). This would ensure that all marriage rituals, regardless of religious affiliation, are subjected to the same monitoring process

3. Making agency in forced marriage an offence

a. To introduce specific legislation that creates an offence of Forced Marriage,

which states clearly that forced marriage is unlawful, provides for prosecution of anyone whose agency in coercion [defined as physical, emotional or psychological] has been extreme... and of those who knowingly or otherwise officiate at a marriage where the free and full consent of either party has not been determined; and in line with State responsibility, provides clear penalties and offers compensation to victims (ibid.).

The current provision for a caveat to be lodged (see Section 25, Marriage Act 1995) is problematic as the burden of proof is placed on the survivor. In addition, the caveat expires after a maximum period of one year and may be discharged easily, especially given the lack of understanding of the issue within the current landscape.

\section{Final Observations \& Reflections}

Menjivar and Salcido (2002) stress that women's experiences of domestic violence are inextricably linked to and impacted by political, economic and social forces. These forces “create multiple layers of oppression and hierarchies within which [immigrant] women's lives are enacted" (ibid., p.900). The impact of broader structural forces on women's experience was echoed by Pisey, in her analyses of her personal experience. She referred to the negative implications of factors like economic status on young women's experiences of forced marriage (see Chapter Five). The interconnectedness of women's experiences with social, economic and political forces highlights the importance of gender mainstreaming, a concept which gained popularity with the conceptual shift from WID to GAD. Gender mainstreaming ensures that gender and its influence on "women's position in the household, 
market, state and community" are consciously factored into policy and legislation (Razavi \& Miller, 1995, p.13).

Issues like honour-based violence and forced marriage, therefore, need to be addressed with cognisance of the interplay of various other social, economic and political factors and their overarching impact on violence against women in the ethnic community. Any national strategy that hopes to address these issues must promote multi-sectoral collaboration.

While women ín NGOs and grassroots organizations have an important role to play in creating space for women to politicize their demands, there are serious limits to what institutions of civil society can achieve. The state still remains responsible for "regulating macro-level forces in a more gender-equitable manner” (Razavi \& Miller, 1995, p.ii).

The dual goals of “improving women's immediate situations and of encouraging long-term empowerment and change in gender relations" (Sharp et al., 2003, p. 291) as recognised in GAD thought, are both important aspects of a national strategy. As such, a strategy aimed at deterring practices of honour-based violence and forced marriage must improve women's immediate situations by addressing their service provision needs, providing them with protections under the law and by ensuring that all those who have agency in forced marriage are held suitably accountable. Long-term empowerment goals would require agencies such as OEA, HRC, Families Commission, MOJ, MWA, UNICEF and UN Women to ensure that further research into the issue is undertaken and to lay the groundwork for attitudinal change within both majority and minority populations. To this end, the ethnic community also needs to be provided with a 'safe space' within which it could bring about a much-needed paradigm shift so that controversial issues are acknowledged and addressed in the public sphere. The media also plays a significant role in the creation of a 'safe space' by being cognisant about the ways in which media articles are framed.

It is crucial that men within the ethnic community recognise the need to transform gender relations before issues like genderbased violence can be addressed effectively. As Kabeer (cited in Proudlock, 2004) argued, it is important to "emphasise the importance of a relational concept of gender for understanding the distribution of power between men and women" (p. 6). Interestingly, it has been observed that despite a conceptual shift from WID to GAD, from 'women' to 'gender relations' as the category of analysis over the years, men still appear to be missing from the development agenda (Proudlock, 2004). Kaufman (2003) suggests that "men may be opposed to working towards gender equality for ideological 
reasons, because of unquestioned assumptions, or, on a more conscious level, to preserve entrenched privileges" (p. 3). If this is so, the definition of 'privilege' needs to change, as OEA pointed out (see Chapter Seven), before issues like honour-based violence and forced marriage can be brought into the public sphere and dealt with appropriately.

\section{$\underline{\text { Conclusion }}$}

This research study is the first piece of work of its kind in New Zealand. As such, it has been framed by epistemologies that aim to lend primacy to the survivor stories shared and to acknowledge the sociocultural context within which these stories played out. The survivor stories were shared to provide a better understanding of the dynamics of forced marriage and to highlight that forced marriage may be practised inadvertently by well-meaning parents and also by parents forced by circumstance to 'sell off' their child (Pisey, pers. comm., 15 September 2011). It must be understood that "violence against women is not an inherent part of anyone's culture" (Menjívar \& Salcido, 2002). It is an issue of power and control that, in the case of immigrants, may be exacerbated by issues such as isolation, changes in economic status and language barriers. Forced marriage is a reality in New Zealand, as it is in many other parts of the world. This research aims to contribute to change so that the horrors experienced by Pisey and Fazia in their relatively short lives, along with those of many more women who remain silent, are never repeated. 


\section{Epilogue $^{42}$}

At the time of writing this thesis, a young girl slightly over the age of 17, who had been forced into marriage and had subsequently left the marriage despite threats made to her life, was in need of Shakti's support to ensure her safety. I was the caseworker on duty.

The Police were involved at the beginning of the process as the girl could not, initially, be located and I had fears for her safety. She was finally located and asked to stay where she was and wait for Police assistance. The girl was waiting at her workplace, afraid to step outside in case her in-laws, who knew where she worked, turned up there and carried out threats to harm her. Shakti required Police assistance to ensure her safety.

Individual police officers were keen to be of assistance. However, Police response was delayed by a few hours as officers were unable to act without the approval of their superiors. This left the young woman in a potentially unsafe position for a significant period of time.

Unsure of the appropriate protocols and in an attempt to speed up the process, the young woman was asked to call the local police station (not Emergency Services) to report her situation. When she called, the individual who answered her call did not understand the seriousness of the situation she was in and asked her to make her own way to the police station. By this time, the young woman had been waiting for an hour for assistance. I was then informed that the callout would be treated as a regular family violence callout. However, as the dynamics were different from regular family violence incidents and officers did not appear to have an in-depth knowledge of the dynamics of honour-based violence, it did not appear to fit into any of the established police protocols. The lack of specific protocols possibly added to the confusion and resulted in the delay.

I made additional phone calls to the Police before the girl was provided with the necessary support. I worked from nine o'clock in the morning to five o'clock in the evening repeating the potential danger to each police officer individually to ensure their understanding of the complexity of the case at hand.

Once the officers were apprised of the situation and were able to get the requisite approval from their superiors, the service provided was satisfactory. However, it took eight hours for the young woman to be located and removed to safety.

\footnotetext{
${ }^{42}$ The details of this case have not been included in order to maintain the girl's confidentiality and in an attempt to protect her identity.
} 


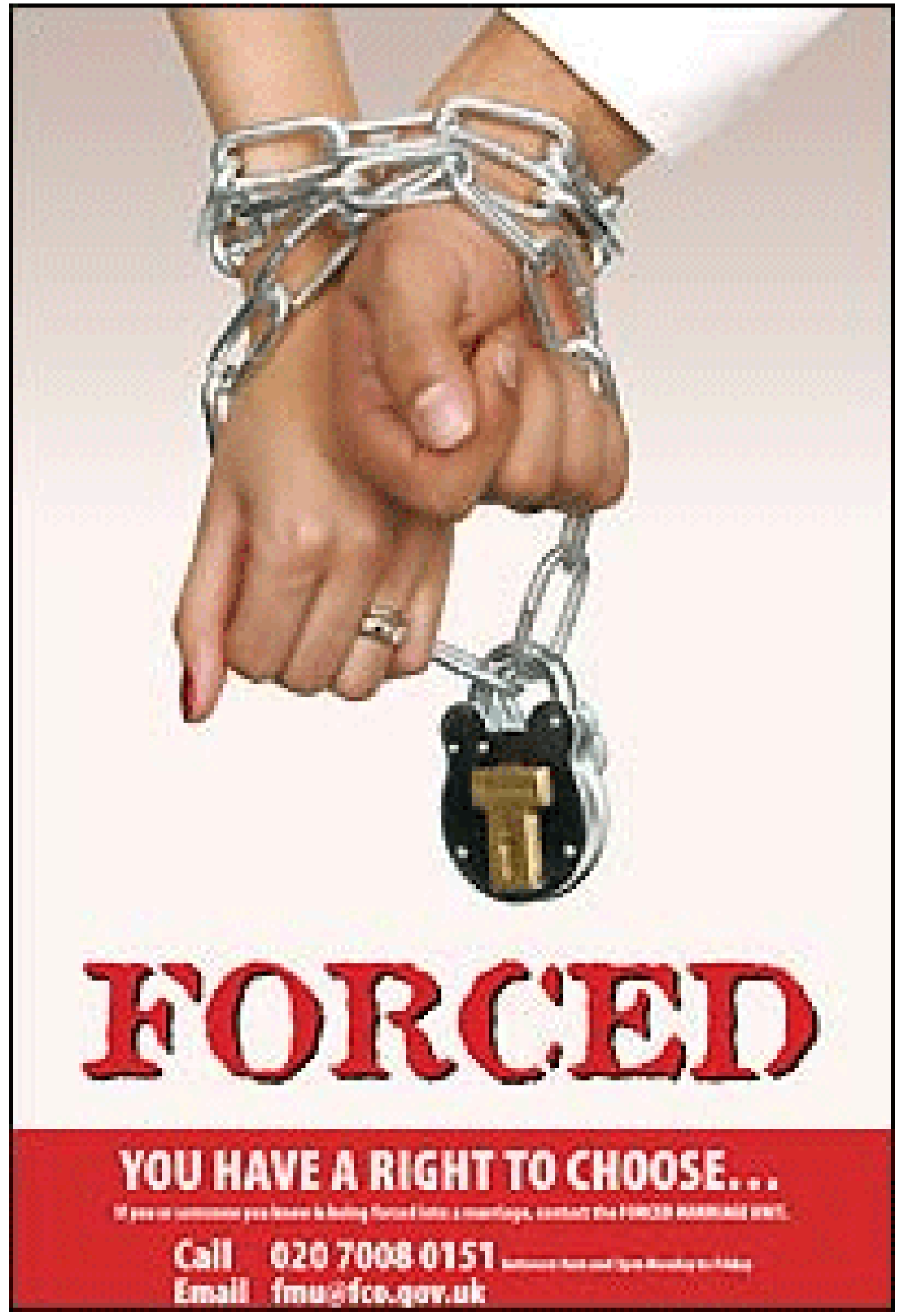

Image source: http://www.mixtogetherandfriends.org/forced-marriage/forced-marriage-tour-karma-nirvana/ 


\section{Appendix 1: Participant Information Sheet (Women Survivors)}

TE WHARE WĀNANGA O TE OPOKO O TE IKA A MĀU

Participant Information Sheet for a Research Study on Forced and Underage Marriage in New Zealand.

Dear

I am pursuing a Masters in Development Studies at Victoria University of Wellington. As part of this degree I am undertaking a research project leading to a thesis. My research study aims to document the experiences of girls and young women in New Zealand who have either been married forcibly or have been threatened with forced marriage.

I would like to invite you to participate, have your voice heard and be part of a research study that aims both to document what women survivors have been through and to promote change to reduce the practice of forced and underage marriage.

If you choose to participate, you will be requested to share your experiences with me and will also be provided the opportunity (if you are comfortable with this) to analyse your experience and express your opinions on social and legislative changes that may reduce the practice. If you are not comfortable with the interview being conducted in English, an interpreter could be provided. All interpreters will be required to sign a confidentiality agreement which means that they cannot reveal any information from the interview sessions to anyone. In addition, I will check the suitability of the interpreter (i.e. whether this person is known to your family) before the interpreter is confirmed. If, for any reason, you feel uncomfortable with this person being in the room during the interview, we will look for another interpreter, no questions asked.

Information will be collected through individual interviews. To ensure accuracy and effectiveness of data collection, you may be needed to attend up to three interview sessions. These will be conducted at a suitable location and the address will not be revealed to anyone. Interviews will be tape recorded, but you may ask for it to be switched off at any point during the interview, no questions asked. Transcripts of your interview will be made available to you and you will be provided the opportunity to edit them as you see fit before I use them in my analysis. Nobody other than my supervisor, Sara Kindon, and I will see the interview transcripts. Your participation is voluntary and you may withdraw from the study at any stage up to four weeks after you have viewed your transcript, no questions asked.

All information will be treated as confidential, your name will not be used and your identity will be protected by adopting writing techniques that do not reveal identifying features (i.e. specific ethnicity, city you live in etc). Reimbursement of your transport expenses may be possible and can be discussed when we meet, prior to the first session. 
Responses collected will be analysed and the findings published in the form of a thesis. The thesis will be submitted for marking to the School of Geography, Environment and Earth Sciences and deposited in the University Library. It is possible that one or more articles will be submitted for publication in academic journals and/or be used during professional conference presentations. In all cases, your identity will not be revealed. Although direct quotes may be used, the final report will be written such that it will not be possible for you to be identified. You will remain anonymous and any information collected will be kept confidential.

Interview transcripts and all other raw data will either be stored digitally on a passwordprotected home computer or in lockable filing cabinets and will be destroyed two years after the end of the project.

If you would like a summary of the findings of this study, please indicate this on the attached consent form and you will be sent a copy at the end of the research process.

If you have any questions or would like to receive further information about the project, please contact me at priyanca02@gmail.com or my supervisor, Sara Kindon, at the School of Geography, Environment and Earth Sciences at Victoria University of Wellington at Sara.Kindon@vuw.ac.nz 


\title{
Appendix 2: VUW ethics application
}

\author{
VICTORIA UNIVERSITY OF WELLINGTON \\ Te Whare Wananga o te Upoko o te Ika a Maui
}

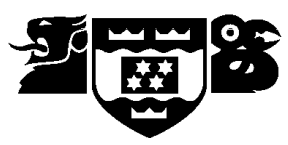

HUMAN ETHICS COMMITTEE

Application for Approval of Research Projects

Please write legibly or type if possible. Applications must be signed by supervisor (for student projects) and Head of School

Note: The Human Ethics Committee attempts to have all applications approved within three weeks but a longer period may be necessary if applications require substantial revision.

\section{NATURE OF PROPOSED RESEARCH:}

(a) Staff Research/ Student Research (delete one)

(b) If Student Research Degree: Masters in Development Studies

Course Code

(c) Project Title: Forced and Underage Marriage in New Zealand

2 INVESTIGATORS:

(a) Principal Investigator

Name: Priyanca Radhakrishnan

E-mail address: priyanca02@gmail.com

School/Dept/Group: School of Geography, Environment and Earth Sciences/ Development $\underline{\text { Studies }}$

(b) Other Researchers Name Position NA

(c) Supervisor (in the case of student research projects)

$\underline{\text { Sara Kindon }}$ 
(a) Proposed starting date for data collection: $\underline{\text { uly } 2011}$

(Note: that NO part of the research requiring ethical approval may commence prior to approval being given)

(b) Proposed date of completion of project as a whole: March 31st 2012

PROPOSED SOURCE/S OF FUNDING AND OTHER ETHICALCONSIDERATIONS

(a) Sources of funding for the project

Please indicate any ethical issues or conflicts of interest that may arise because of sources of funding e.g. restrictions on publication of results

Funding for fieldwork within New Zealand has been obtained from Shakti Community Council Inc. and funding for fieldwork in the United Kingdom has been applied for through the Minister's Discretionary Fund (Lottery Grants Board) and I am currently awaiting their response.

(b) Is any professional code of ethics to be followed

$\mathbf{Y} \square \mathbf{N} \nabla$

If yes, name

(c) Is ethical approval required from any other body

$\mathbf{Y} \square \mathbf{N} \nabla$

If yes, name and indicate when/if approval will be given

\section{DETAILS OF PROJECT}

Briefly Outline:

(a) The objectives of the project

This study explores the issues of forced and underage marriage (FuM) internationally and in New Zealand within the context of gender and development. More specifically the study. documents the experiences of girls and young women in New Zealand who have either been married forcibly or have been threatened with forced marriage and situates the practice of forced and underage marriage within a wider continuum of violence against women 1 also examine the issue of 'honour' which is often linked to the practice.

The study documents survivor experiences and is framed such that survivors are encouraged to share and analyse their experience and the impact fuM has had on their emotional social and economic well-being as well as discuss measures that may deter future practices of FuM It also examines measures - both legislative and educational - taken internationally to deter FUM and also look at gaps in relevant current New Zealand legislation that may. unintentionally allow the practice to take place. My findings and recommendations are discussed with relevant stakeholders such that the final research is relevant, credible and action-oriented.

(b) Method of data collection 
Data will be collected through primary research methods as well as secondary data analysis. Primary data will be generated with women survivors of Forced and Underage Marriage (FUM) as well as government and non-governmental agencies both in New Zealand and in the United Kingdom (if funding is obtained) who will be interviewed for information on their level of knowledge of, experiences with and commitment to deter FuM.

Secondary data collection and analysis will involve a review of relevant texts and literature such as The Marriage Act 1955, Crimes Act 1961 as well as other government and select committee responsses to the petitition and supporting submisnossions on on foum.

(c) The benefits and scientific value of the project

As far as I am aware, there has not been any research done in New Zealand on the topic of Forced and Underage Marriage in New Zealand. It is a practice that is often disguised as a "cultural" practice but which in fact is a human rights violation. This research is framed by a FPAR (Feminist Participatory Action Research) epistemology and hopes to shed some light on the issue of FUM as well as engage both survivors as well as key stakeholders in a discussion on effective methods to deter the practice. As such, the research study strives to fill a knowledge gap on the issue as well as prompt some positive action towards deterring the practice and contributing towards a safer New Zealand.

(d) Characteristics of the participants

Research participants include women survivors of FuM aged from 16 years, individuals and agencies- government and non-governmental organisations (NGOS), UN agencies and marriage celebrants in New Zealand who are key stakeholders. I will also attempt to include government and non-governmental stakeholders in the United Kingdom. However, this is subject to funding.

(e) Method of recruitment

\section{(i) Women Surivors}

Women survivors of FUM will be recruited with support from Shakti Community Council Inc. as they will be women who have previously accessed the NGO's support services undergone counselling and/or therapy and are considered, by Shakti counsellors and or/caseworkers, to be able to recount and analyse their experiences in a safe manner.

The first step in the recruitment process is to obtain a list of potential candidates from caseworkers at Shakti and discuss each case with the view of short listing potential candidates based on the amount of counselling they have received and the caseworker's feedback At this stage I will find out whether any of the participants would potentially. require an interpreter. The second step is to approach each potential participant along with her caseworker, explain the aims of this research, the importance placed on confidentiality, offer her the possibility of using a pseudonym (if names are to be used) and explain that the research is designed such that she is welcome to participate as much or as little as she chooses to. I will also emphasise that participants' identities will be protected and that they will remain anonymous and will not be identifiable.

Women and/or girls who have been subjected to or threatened with FuM but who have not accessed Shakti's services may also be recruited as participants I will discuss this possibility. with the caseworkers at Shakti who inform me of these women/girls. I will prepare a one 
page information sheet on the purpose and design of the research study which the caseworkers can pass on to them. If they agree to participate, I will meet them individually. and go over the same options offered to the other participants

I will also explain that one of the main aims of this research is to advocate for change that will, hopefully ensure that other girls and women are not subjected to FuM. Once a potential participant has had a few days to consider her participation I will contact her for her decision. If she chooses to participate, I will meet with her again to obtain her written consent and depending on the level of involvement she chooses, schedule one or two meeting dates and times for the interview(s) to take place.

\section{(ii) Marriage Celebrants}

A list of registered marriage celebrants will be obtained from the office of the Registrar of Marriages and five celebrants belonging to different religious groups will be invited to participate in the study:

\section{(iii) Key stakeholders - government, NGOs and UN agencies in New Zealand}

Agencies invited to participate will include government and non-governmental agencies, relevant UN agencies such as UNICEF and UN Women.

Government stakeholders include the Ministry of Justice Department of Internal Affairs, Ministry of Women's Affairs, Ministry of Social Development, Office of Ethnic Affairs and Office for the Community and Voluntary Sector.

Non-governmental organisations (NGOS) include Shakti Community Council Inc. the National Collective of Independent Women's Refuges, National Network of Stopping Violence Services Fatimah Foundation and Umma Trust Cultural associations who have been part of the debate on FUM such as the Islamic Women's Council, Indian Association Women's Group Sikh Women's Association and Somali Women's groups may also be invited to participate.

Individuals and teams who have been directly involved in the debate/response to FuM wil!! be contacted via email and invited to participate in the research. They will be sent a letter informing them of the purpose of the research and the role their involvement will play in the study and the number of interviews they will be requested to attend. They will also be informed that while they will not necessarily be named individually in the research study, their organisations will be named and as such, they should ensure that they have the authority to speak on behalf of their agency/organisation. The letter will also include information on the workshops that will be held towards the end of the research process in order to present them with consolidated feedback that they could take back to their teams.

Government agencies and NGOS who have participated in the research study will be invited to attend the workshops which will take place towards the end of the research process. 
If funding is approved for this phase of the research study, both government and NGO stakeholders in the UK will be contacted via email and invited to participate in this research study. They will be informed of the nature of the research, advocacy and lobbying efforts to date to deter FuM in New Zealand and the role that they could play in informing stakeholders in New Zealand of the benefits and potential pitfalls of the approach taken by the UK in deterring FUM.

Government agencies will include the Home office and the Forced Marriage Unit. NGO invitees will include Karma Nirvana, Imkaan, Southall Black Sisters and Shakti Women's Aid.

(f) Payments that are to be made/expenses to be reimbursed to participants

Women survivors who have participated in the research study will not be paid for their involvement but will be given a token of appreciation for their participation. This will most probably be a supermarket voucher.

\section{(g) Other assistance (e.g. meals, transport) that is to be given to participants}

Women survivors who have participated in the research study will be reimbursed for their transport costs and refreshments will be provided at each session.

(h) Any special hazards and/or inconvenience (including deception) that participants will encounter

As this research study deals with the extremely sensitive topic of violence against women within the ethnic sector, there is a safety risk for both participants (women survivors) as well as myself as a researcher striving to raise awareness of the issue and governmental action to deter it. These may include both physical and emotional risks to participants and researcher.

The issue of violence against women is still considered a taboo topic within ethnic communities and individuals and organisations working towards eliminating domestic and family violence are often targeted by members of ethnic communities as we are seen to be promoting the "breaking of families". As such, I would take special precautions to ensure that participants' identities are kept confidential that locations chosen for the interviews are secure and kept confidential and that participants are made aware of the potential risks of participation as part of the information and consent process. With regards to safeguarding participants' identities, there are a number of strategies that I am currently considering. These are further discussed in section (k).

I have worked within the arena of family violence intervention and prevention in New Zealand for close to five years now and am well aware of the risks to my safety. As I have been targeted and followed by male members of various ethnic groups during these five years, ensuring that I take the necessary precautions to keep myself physically safe is critical. These will include ensuring that my cellphone is always charged and within easy reach when l'm outside the house that l am alert when outside the house and especially at night making sure that $I$ do not stay in the office alone after dark and ensuring that $I$ have 
good links with the police such that I can contact a known police officer who is aware of the safety risks posed by my work and will respond appropriately. I also have 111 on speed dial.

For participants I am aware that recounting traumatic experiences could potentially lead to retraumatisation of the survivors. Bearing this in mind the research study is structured such that the narrative style allows me to adopt conversation-guiding technniques that could contribute to the participants curative or healing process so that the research process is supportive rather than burdensome (Rosenthal, 2003) $20 .{ }^{43}$

In the case of participants who may require the services of an interpreter l am aware of the potential risks associated with this considering ethnic communities in New Zealand are comparatively small and close-knit. This increases the possibility of the interpreter knowing either the participant or her family. In order to mitigate this risk, I will try to ensure that ! have a staff member or volunteer from Shakti, who already understands this and whose suitability has already been vetted by the organisation, to interpret during the interview sessions. If this is not possible, I will attempt to engage the services of an accredited interpreter and check the interpreter's suitability with the participant before confirmation to ensure that the participant is comfortable having this person interpret for her.

I am also mindful that I do not encourage participants to open up and then be "left with nowhere to go"..(Appelbaum, 2008 p. 273) 44... Those who feel they require further social work support will be re-directed appropriately either to the caseworker who attended to their case previously, or in the event that this person has left the organisation, to another suitable caseworker. Those who require further counselling and therapy will also be appropriately referred on, either to counsellors within Shakti or to other suitable services by their caseworker. Shakti staff members have access to a list of support services and network agencies that women can be referred to.

Given the nature of the research it is important that I am able to develop a rapport with the participants. However, I am also aware of the need to maintain professional boundaries and also of the need to ensure that my emotional welfare is safeguarded throughout the course of the research study. (Dickson-Swift et al, 2007) (5) $^{4}$. have access to counselling and external supervision through my work with Shakti Community Council and will also ensure that I give myself adeguate breaks and pamper myself occascionally..(Jordann, $2008)^{46}$ in order to relieve some of the stress.

Marriage celebrants face the potential risk of being targeted by members of their ethnic or religious communities if they choose to reveal information that may be controversial. As such their identities will also be protected through the use of pseudonyms and the omission of identifying factors (e.g. specific ethnic identity and city they live in). This will! apply to the final thesis and in the case of subsequent publications and conference presentations.

\footnotetext{
${ }^{43}$ Rosenthal, G. 2003. The Healing Effects of Storytelling: On the Conditions of Curative Storytelling in the contect of Research and Counselling. Qualitative Inquiry. Vol: 9, No: 6, pp. 915 - 933. University of Gottingen.

${ }^{44}$ Appelbaum,J. 2008. Trauma and Research: Bearing Responsibility And Witness. Women's Studies Quarterly Vol. 36, No. 1/2, Witness (Spring-Summer 2008). Pp. 272 - 275. The Feminist Press, City University of New York. Retrieved on May $11^{\text {th }} 2011$ from http://www.jstor.org/stable/27649761

${ }^{45}$ Dickson-Swift, V; James, E; Kippen, S; Liamputtong, P. (2007). Doing Sensitive Research: What challenges do qualitative researchers face? Qualitative Research. Vol: 7, No: 3, pp. 327 - 353. La Trobe University.

${ }^{46}$ Jordan, J. (2008). Serial Survivors: Women's Narratives of Surviving Rape. Sydney: The Federation Press.
} 
I do not foresee any specific risks, hazards or inconveniences in the case of government and NGO participants or participating UN agencies.

(i) State whether consent is for (delete where not applicable):

(i) the collection of data

(ii) attribution of opinions or information

(iii) release of dathers

(iv) use for a conference report or a publication

(v) use for some particular purpose (specify)

Consent from the women survivors and marriage celebrants is for the collection of data, and its use in my thesis and the possibility of using the data collected in other publications, papers and/or conference reports. With regards to these participants, confidentiality and their anonymity within written reports and publications will be emphasised and I will also clarify that raw materials (tape recordings and interview transcripts) will only be viewed by myself and if required by my supervisor only findings, composite stories and quotes that cannot be traced to the specific participant will be used in other publications, papers and presentations.

The consent form will be translated orally for research participants who do not understand English or who have a limited knowledge of the English language. For these women, services of an interpreter will be sought.

Consent from government UN agencies and non-governmental agencies is for the collection of data including opinions and information provided by their representatives during interviews and workshops in my thesis as well as for its use in other publications and conference presentations. While individuals will not be named organisations will not be eligible for anonymity and the consent form will emphasise that representatives should have the authority to speak on behalf of their organisations. In the case of nongovernmental service provision agencies any information disclosed that pertains to client cases will be written up in a such a way that the identity of those girls/women is protected and the girls/women are not identifiable.

Attach a copy of any questionnaire or interview schedule to the application

(j) How is informed consent to be obtained (see sections 4.1, 4.5(d) and 4.8(g) of the Human Ethics Policy)

(i) the research is strictly anonymous, an information sheet is supplied and informed consent is implied by voluntary participation in filling out a questionnaire for example (include a copy of the information sheet) 
(ii) the research is not anonymous but is confidential and informed consent will be obtained through a signed consent form (include a copy of the consent form and information sheet)

(iii) the research is neither anonymous or confidential and informed consent will be obtained through a signed consent form (include a copy of the consent form and information sheet)

$\mathbf{Y} \vee \mathbf{N}$

(iv) informed consent will be obtained by some other method (please specify and provide details)

Both (ii) and (iii) are applicable as (ii) applies to women survivors of FUM who participate in the research and (iii) applies to government agencies and NGOs who choose to participate in the research.

With the exception of anonymous research as in (i), if it is proposed that written consent will not be obtained, please explain why

My research study examines the issues of both forced and underage marriage. As such research participants may fall below the legal age of consent of 16 years. In such cases, obtaining parental consent would not be deemed appropriate since in most cases it is the parents and/or legal guardians who force the girl into marriage In the event that my research does involve a participant below the age of 16 years, the implications of the research will be explained to her as to all other participants.

(k) If the research will not be conducted on a strictly anonymous basis state how issues of confidentiality of participants are to be ensured if this is intended. (See section 4..1(e) of the Human Ethics Policy). (e.g. who will listen to tapes, see questionnaires or have access to data). Please ensure that you distinguish clearly between anonymity and confidentiality. Indicate which of these are applicable.

(i) access to the research data will be restricted to the investigator

(ii) access to the research data will be restricted to the investigator and their supervisor (student research)

$\mathbf{Y} \mathbf{N}$

(iii) all opinions and data will be reported in aggregated form in such a way that individual persons or organisations are not identifiable

$\mathbf{Y} \vee \mathbf{N}$

(iv) Other (please specify)

Women survivors and marriage celebrants who participate in this research study will be informed that they will remain anonymous to readers of the thesis and when findings and quotes are used in subsequent publications and conference presentations. Confidentiality of information obtained from them will be paramount; access to raw data will be restricted 
to my supervisor and myself. The women's stories will be reported such that their identities are protected and they remain anonymous Some of the strategies to achieve this are to write their stories in a composite form such that their voices are heard but individuals are not identifiable, to employ narrative methodologies wherein participants' stories are related in a different form. In some cases, participant stories are written up in the form of letters to someone or in a similar form that has relevance to the participant. Another strategy is to work on participant stories while writing them up such that the crux of the story is kept while key identifies are omitted. Regardless of the strategy adopted the identity of the participant will be protected and they will not be identifiable in any written account Confidentiality will only be breached if the safety of a participant is at stake or a participant discloses being at immediate risk or harm, at which point the Police will be informed. Anonymity will not apply to governments agencies and NGOs involved in the research . In the case of these research participants individuals will remain anonymous (will! not be named in the thesis or subsequent publications and/or conference presentations) but their opinions and data will be attributed to the organisation their represent. This will be clarified in the information sheet and consent form given to them.

(I) Procedure for the storage of, access to and disposal of data, both during and at the conclusion of the research. (see section 4.12 of the Human Ethics Policy). Indicate which are applicable:

(i) all written material (questionnaires, interview notes, etc) will be kept in a locked file and access is restricted to the investigator $\quad \mathbf{Y} \sqrt{ } \mathbf{N}$

(ii) all electronic information will be kept in a password-protected file and access will be restricted to the investigator

$\mathbf{Y} \mathbf{N}$

(iii) all questionnaires, interview notes and similar materials will be destroyed:

(a) at the conclusion of the research

$\mathbf{Y} \square \mathbf{N} \square$

or (b) _2 years after the conclusion of the research

$\mathbf{Y} \vee \mathbf{N}$

(iv) any audio or video recordings will be returned to participants and/or electronically wiped

(v) other procedures (please specify):

If data and material are not to be destroyed please indicate why and the procedures envisaged for ongoing storage and security

N.A 
(m) Feedback procedures (See section 7 of Appendix 1 of the Human Ethics Policy). You should indicate whether feedback will be provided to participants and in what form. If feedback will not be given, indicate the reasons why.

\section{Women Survivors \& Marriage Celebrants}

These participants will be given the option of requesting feedback in the form of a written summary at the end of the study. This will be outlined in the consent form. Those who indicate that they would like to be provided with feedback will be contacted at the end of the study and posted a copy of the summary.

\section{Key stakeholders - government, NGO and UN agency participants}

Stakeholders in New Zealand will be invited to attend workshops towards the end of the research process wherein feedback will be provided and discussed. Depending on the number of stakeholders, I may organise one workshop session (with two breakout groups to facilitate discussion) for both NGOs and government agencies to attend or I may organise two separate ones for each sector. As the thesis will become public knowledge once it has been approved, all participants will be able to obtain a copy of the findings and analysis at that stage.

\section{Stakeholders in the UK}

These participants will be given the option of requesting a summary through the consent form. Those who indicate that they would like to receive a summary will have this posted to them at the end of the research process.

(n)Reporting and publication of results. Please indicate which of the following are appropriate. The proposed form of publications should be indicated on the information sheet and/or consent form.

(i) publication in academic or professional journals

(ii) dissemination at academic or professional conferences

(iii) deposit of the research paper or thesis in the University Library (student research)

(iv) other (please specify)

It will be clearly indicated that the findings may be used in other publications and/or conference presentations and that the thesis will be deposited in the University library. It will also be clarified that raw data will only be accessible to my supervisor and myself and will not be released publicly. 


\section{Appendix 3: Participant Consent Form (Women Survivors)}

TE WHARE WĀNANGA O TE OPOKO O TE IKA A MĀU

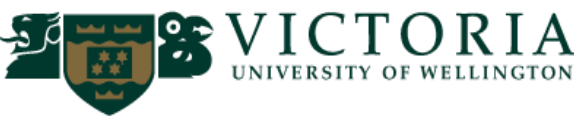

\section{CONSENT TO PARTICIPATION IN RESEARCH}

Title of project: Forced and Underage Marriage in New Zealand

I have been given and have understood an explanation of this research project. I have had an opportunity to ask questions and have them answered to my satisfaction. I understand that the interview session will be tape recorded but that I can ask to have the recording stopped at any point without having to give a reason.

I understand that I may check and edit my interview transcript and withdraw myself (or any information I have provided) from this project up to four weeks after I have viewed my transcript without having to give reasons and without penalty of any sort.

I understand that any information I provide will be kept confidential to the researcher, the supervisor and the person who transcribes the tape recordings of our interview. I understand that the published results will not use my name, and that I will not be identifiable in any way. I understand that the findings may be used in other academic publications and conference presentations. I understand that the tape recording of interviews will be destroyed two years after the end of the project.

I agree to take part in this research.

Name of participant/ Date

Signature of participant

(Please print clearly)

Please tick $[\mathrm{V}]$ the appropriate box:

1. Yes, I would like to receive a summary of the results of this research when it is completed. Please post/email the summary to the address provided below

2. No, I would not like to receive a summary of the results of this research when it is completed

THANK YOU! 


\section{Appendix 4: Aide Memoire (Women Survivors)}

These are just the key areas, divided into themes, that I would like to discuss with the survivors and are not the exact questions that will be asked. As some of the areas to be discussed are very sensitive, they will be broached so as not to retraumatise participants, but to allow them to recount and try and make sense of their experience. Participants will also not be pushed into to answering questions with which they are visibly uncomfortable. Questions pertaining to demographic details that may be key identifiers will not be included in the final thesis.

\section{Demographic details}

- Name, age, date of birth, address, contact numbers, email address, Immigration status, work/study details

\section{Coming to New Zealand}

- When and how did migration take place?

- How was life in New Zealand vs life in the home country i.e. did you face any challenges and if so, what were they?

- How was life at home in New Zealand? Who was the head of the household? Was your family life different to that of your friends?

3. $\quad$ Identity \& Attitudes

- Do you identify with New Zealand?

- Do you identify with your ethnicity or your religion?

- What does your ethnic/religious community's support mean to you/what did it mean to you?

- What is the prevalent attitude towards FUM in your home country?

- What is the prevalent attitude towards FUM in your ethnic/religious community here in New Zealand?

- Do you think this should change?

- What is the best way to promote this change in attitudes?

4. Education and Employment

- Were you studying or working before you got married?

- Did you want to continue? Were you told that you could continue studying after your marriage?

- Were you allowed to continue studying/working after you got married? Did you want to?

- How do you feel about not being allowed to continue studying/working and the reasons given for this? 


\section{Marriage}

- Did you know your prospective husband?

- Did this take place in the home country or in New Zealand?

- Cultural marriage in New Zealand or registered?

- If it was a legal marriage overseas, what visa did you have when you came to New Zealand?

- Where was it conducted? Who attended? Was it conducted by a celebrant?

- Did you realise that what you were attending was your marriage ceremony?

- Coercion - was it physical, emotional, psychological or a combination?

- Was there dowry involved?

- Did you sign your marriage licence?

\section{Giving Permission}

- Were you ever asked if you wanted to get married?

- Were you ever asked if you wanted to get married to this person?

- Did you object?

- If so, how did you convey your objection?

- If you felt like you could not object, why do you think that was?

- Did you know about the legal requirement for one party to sign a statutory declaration at least 3 days before the ceremony?

- Did you give your permission in the end?

- What made you give it/stop objecting?

- Were you, at any point, afraid for your physical/emotional safety?

- Did you ever think of escaping the marriage?

- What stopped you from escaping/ how did you escape?

- How do you feel about it now?

- (in the case of marriages that took place in the home country) Did you know that you were being taken back to your home country to get married?

- If not, what were you told?

- When did you realise the real reason for the trip?

- How did you feel? 
- (in the case of marriage below 18 years) Did you know beforehand that your parents had provided their consent to your marriage?

\section{Marriage Celebrants}

- Did the celebrant meet with you prior to the wedding?

- Was the celebrant known to your family?

- Why was he/she picked to conduct the wedding ceremony?

- Did you ever think that you could tell the celebrant, before or during the wedding, that you did not want to go through with the marriage?

- Did the celebrant know that you did not want this wedding to go ahead?

- Did you exchange vows?

- Can you remember what the words were?

- Can you speak and understand the language they were in?

- Did you know what you were saying?

- Do you know of other celebrants who conduct wedding ceremonies even when they know that the bride does not consent?

- Do you know how much your celebrant was paid to conduct your wedding?

\section{Accessing support services}

- Did you consider calling the police? When?

- Was there anyone who could speak up on your behalf?

- Was there anyone who could support you to get out of the marriage?

- (if relevant) How did you get out of the marriage?

- Did you have a plan/strategy?

- Who/what helped you to succeed in getting out?

- What are some of the barriers to accessing support services?

- What do you think needs to change for more girls to get help?

9. Prevalence

- Do you know of other girls who have been forced into marriage in New Zealand?

- Do you know if there are girls who are being taken back to their home country specifically to get married forcibly? 
- How many girls do you know who are in a similar situation?

- Do you think any of them will come out and get help to stop the marriage from taking place?

10. Looking Forward

- What are your plans for the future?

- How do you feel about them?

- If you hadn't been forced into marriage, how different would your life have been?

\section{Recommendations}

- What do you think needs to change for this practice to stop?

- Are you aware that the UK has laws that make forced marriage illegal?

- Do you think something similar would make a difference for girls in New Zealand?

- Do you think your parents/extended family/ethnic or religious community knew that forcing you to get married was wrong?

- If they didn't, what do you think would be the best way to get the message across to them? 


\section{Appendix 5: Participant Information Sheet (Stakeholder Agencies)

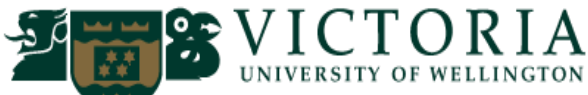

\section{Participant Information Sheet for a Research Study on Forced and Underage Marriage in New}

Zealand.

I am pursuing a Masters in Development Studies at Victoria University of Wellington. As part of this degree I am undertaking a research project leading to a thesis. My research study aims to document the experiences of girls and young women in New Zealand who have either been married forcibly or have been threatened with forced marriage. The study documents survivor experiences, discusses measures that may deter the practice of forced and underage marriage (FUM), looks at gaps in relevant New Zealand legislation that may unintentionally allow the practice to take place and goes on to examine measures - both legislative and educational - taken internationally to deter the practice.

I would like to invite you to participate in this study and share your experiences of working with victims/survivors of FUM and/or your views on the issue. While individual participants will not be named, the organisation/department/agency you represent will be named and the information provided by you will be taken to represent the view of this organisation or agency. If you are not participating in an individual capacity, please ensure that you have the necessary authority to speak on behalf of the organisation/department/agency you represent. If you disclose information pertaining to individual women's cases, their names will not be used and key identifiers will be omitted such that the women are not identifiable in any written account.

Information will be collected through a face-to-face interview session and participants may be requested to attend a second interview if further information or clarification is required. Participants will also be given the opportunity to attend a workshop towards the end of the research process that will be organised to discuss the findings of the research study before the final thesis is written up. All interviews sessions and workshops will be tape recorded. Participants could request to view transcripts of their interview(s) by indicating their choice in the attached consent form. Research participation is voluntary and you may withdraw from the study at any stage up to four weeks after the data is analysed.

All interview transcripts and other raw data will be kept confidential. No other person besides me and my supervisor, Sara Kindon, will see the interview transcripts. Responses collected will be analysed and the findings written up in the form of a thesis. The thesis will be submitted for marking to the School of Geography, Environment and Earth Sciences and deposited in the University Library. It is possible that one or more articles will be submitted for publication in academic journals and/or be used during professional conference presentations. Tape recordings, interview transcripts and all other raw data will be destroyed two years after the end of the project.

If you have any questions or would like to receive further information about the project, please contact me at priyanca02@gmail.com or my supervisor, Sara Kindon, at the School of Geography, Environment and Earth Sciences at Victoria University of Wellington at Sara.Kindon@vuw.acnz. 


\section{Appendix 6: Aide Memoire (Stakeholder Agencies)}

All government, quasi-government, non-governmental and UN agencies were asked the following questions. Follow-up questions were also asked.

1. Can you tell me a little bit about what your agency has done, to date, or is doing, to deter the practice of forced and underage marriage in New Zealand?

2. What measures could your agency take to deter the practice?

3. Are you aware of any campaigns/measures that your agency has been involved in, in the past, that may be relevant to the issue of forced marriage? (this could be advocacy for legislative reform, a national campaign, the development of processes/protocols/research etc)

4. What constraints to action does your agency face? i.e. what holds your agency back from taking further measures and what are your agency's needs?

5. What do you think the next step should be, in terms of New Zealand's response to the issue of forced marriage? (this question is accompanied with a brief overview of steps taken internationally). 


\section{Appendix 7: Participant Consent Form (Stakeholder Agencies)}

TE WHARE WĀNANGA O TE OPOKO O TE IKA A MÃUI

\section{CONSENT TO PARTICIPATION IN RESEARCH}

\section{Title of project: Forced and Underage Marriage in New Zealand}

I have been given and have understood an explanation of this research project. I have had an opportunity to ask questions and have them answered to my satisfaction. I understand that interview sessions and workshops will be tape recorded but that I may ask, at any time, for the tape recording to be switched off, no questions asked. I understand that I may check my interview transcript and withdraw myself (or any information I have provided) from this project up to four weeks after the data has been analysed without having to give reasons and without penalty of any sort.

I understand that any information I provide will be kept confidential to the researcher, the supervisor and the person who transcribes the tape recordings of our interview. I understand that the published results will not use my name but that opinions that I express will be attributed to the organisation/department/agency that I represent. I understand that the findings may be used in other academic publications and conference presentations. I understand that the tape recordings, interview transcripts and all other raw data will be destroyed two years after the end of the project. I understand that I have the opportunity to attend a workshop at which feedback from the study will be discussed.

I agree to take part in this research.

Name of participant/ Organisation (Please print clearly)

\section{Signature of participant/ Date}

Please tick $[\mathrm{V}]$ the appropriate box:

I would like my interview transcript posted to me at:

1) I would like my interview transcript emailed to me at:

2) Yes, I would like to attend the workshop

3) No, I would not like to attend the workshop

THANK YOU! 


\section{Appendix 8: Chart, Stakeholder Engagement Workshop}

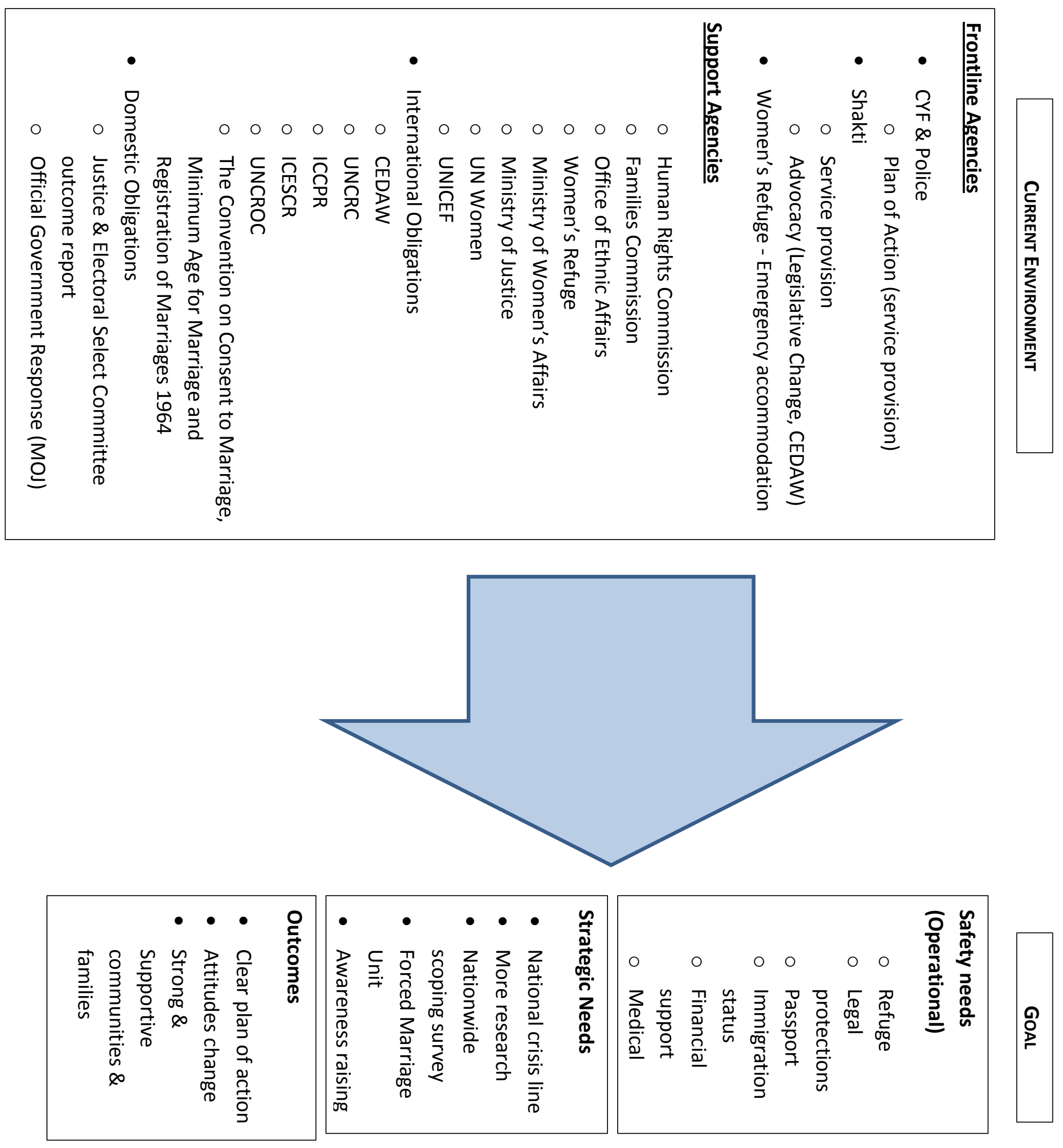




\section{Reference List}

Academy for Educational Development. (2006). New Zealand. Retrieved January 27, 2012, from humantrafficking.org: http://www.humantrafficking.org/organizations/182

Adamu, F. (1999). A Double-Edged Sword: Challenging Women's Oppression within Muslim Society in Northern. Gender and Development, 56-61.

Al-Johar, D. (2005). Muslim Marriages in America: Reflecting new Identities. The Muslim World, 557-574.

Aotearoa Ethnic Network. (2005). About. Retrieved February 11, 2012, from Aotearoa Ethnic Network: http://www.aen.org.nz/about_contact.html

Associated Press. (2011, 23 February). US jury convicts Iraqi immigrant in 'honour killing'. Phoenix, Arizona, United States of America. Retrieved February 22, 2011 from http://www.stuff.conz/world/americas/4694084/US-jury-convicts-Iraqi-immigrant-inhonour-killing

Barrett, P. (Director). (1997). Henna on my Hands [Motion Picture].

Baxi, P., Rai, S., \& Sardar Ali, S. (2006). Legacies of Common Law: 'Crimes of Honour' in India and Pakistan. Third World Quarterly, 1239-1253.

Bay of Plenty Times. (2009). Bay ethnic refuge fears for women. Retrieved 23 February 2012, from http://www.bayofplentytimes.co.nz/news/bay-ethnic-refuge-fears-forwomen/1010652/

BBC News. (2011, April 21). Pakistan: Acquittals in Mukhtar Mai gang rape case. Retrieved February 14, 2012, from BBC News South Asia: http://www.bbc.co.uk/news/worldsouth-asia-13158001

BBC News London. (2010, October 11). Man Jailed for life for killing girlfriend Aliza Mirza. London, United Kingdom. Retrieved on February 20, 2011, from http://www.bbc.co.uk/news/uk-england-london-11512831

BBC Two. (2007, October 22). Harsh Reality of India's unwanted girls. Retrieved February 23, 2011 from http://news.bbc.co.uk/2/hi/programmes/this_world/7050657.stm.

Beetham, G., \& Demetriades, J. (2007). Feminist research methodologies and development:overview and practical application. Gender and Development, 199-216.

CEDAW. (2007). Concluding Comments of the Committee onthe Elimination of All Forms of Discrimination Against Women: New Zealand. CEDAW.

Census Commissioner of India. (2011). Census of India: Provisional Population Totals. Retrieved February 12, 2012, from Census of India: http://censusindia.gov.in/2011census/censusinfodashboard/index.html\# 
Centre for Social Research and Evaluation. (2011). Vulnerable Children: numbers and risk factors. Wellington: Ministry of Social Development.

Central Intelligence Agency. (2011, March 16). The World Factbook: India. Retrieved on April 5, 2011 from https://www.cia.gov/library/publications/the-worldfactbook/geos/in.html

Chile, L. M. (2002). The Imported Underclass: Poverty and Social Exclusion of Black African Refugees in Aotearoa New Zealand. Asia Pacific Viewpoint, 355-366.

Cismaru, M., \& Lavack, A. (2011). Campaigns Targeting Perpetrators of Intimate Partner Violence. Trauma, Violence and Abuse, 183-197.

Coates, K. \&. (2005). Skilled Immigrants and Selection Bias: A Theory-based Field Study from New Zealand. International Journal of Intercultural Relations, 577-599.

Coffey, A., \& Atkinson, P. (1996). Making Sense of Qualitative Data: Complementary Research Strategies. Thousand Oaks: Sage Publications.

Coomaraswamy, R. (2005). Violence against Women and 'crimes of honour'. In S. Hossein, \& L. Welchman (eds), 'Honour' Crimes, Paradigms and Violence against Women. London: Zed Books Ltd, pgs xi-xiv.

Cummings, M. (2011, 12 28). Editorial: Child abuse not a racial problem. Retrieved 02 14, 2012, from Manawatu Standard: http://www.stuff.co.nz/manawatustandard/opinion/6194824/Editorial-Child-abuse-not-a-racial-problem

Dauvergne, C., \& Millbank, J. (2010). Forced Marriage as a Harm in Domestic and International Law. The Modern Law Review, 57-88.

De Bres, J. (2011, October). Immigration and the Changing Face of New Zealand. Wanaka, New Zealand: Human Rights Commission.

De Kock, L. (1992). Interview with Gayathri Chakravorty Spivak: New Nation Writers Conference in South Africa. ARIEL: A Review of International English Literature, 2947.

Defence Forum of India. (2012). India's Population 2012. Retrieved February 12, 2012, from Defence Forum of India: http://defenceforumindia.com/politics-society/30771-indiaspopulation-2012-a.html

De Silva-de-Alwis, R. (2008). Child Marriage and the Law: Legislative Reform Initiative Paper Series. New York: UNICEF.

Department of Internal Affairs. (2011). How to Get a Marriage Licence. Retrieved February 1, 2012, from Department of Internal Affairs: 
http://www.dia.govt.nz/diawebsite.nsf/wpg_URL/Services-Births-Deaths-andMarriages-How-to-Get-a-Marriage-Licence?OpenDocument\#four

Dickson, S., Herbert, R., \& Hill, A. (2009, April). Violence Against Women in Aotearoa New Zealand. Retrieved February 23, 2011, from Roundtable on Violence Against Women: http://roundtablevaw.org.nz/Integrated.pdf

Dowling, R. (2010). Power, Subjectivity, and Ethics in Qualitative Research. In I. Hay, Qualitative Research in Human Geography (pp. 26-39). Ontario: Oxford University Press.

Du Chateau, C. (2006, April 8). The deadly price of domestic violence. Retrieved August 28, 2011, from New Zealand Herald: http://www.nzherald.co.nz/hinduism/news/article.cfm?c_id=500822\&objectid=10376 559

Dunn, K. (2010). Interviewing. In I. Hay, Qualitative Research Methods in Human Geography (pp. 101-138). Ontario: Oxford University Press.

Engeler, Eliane. (2008, December 02). Rich World Needs more Foreign Workers: report. Retrieved on March 15, 2011 from: http://www.foxnews.com/wires/2008Dec02/0,4670,EUWorldMigrationReport,00.htm

Fanslow, J \& Robinson, E. (2004). Violence against women in New Zealand: prevalence and health consequences. The New Zealand Medical Journal.

Farrar, D. (2012, January 31). Barbarism in NZ and Canada. Retrieved February 19, 2012, from stuff.conz Politics: http://www.stuff.conz/national/politics/blogs/david-farrar-bythe-numbers/6342169/Barbarism-in-NZ-and-Canada

Faqir, F. (2001). Intrafamily Femicide in Defence of Honour: The Case of Jordan. Third World Quarterly, 65-82.

Fine, M. (1994). Dis-stance and Other Stances: Negotiations of Power Inside Feminist Research. In A. Gitlin, Power and Method: Political activism and educational research (pp. 13-35). New York: Routledge.

Foreign and Commonwealth Office. (2010, July 1). More men being forced into marriage. Retrieved February 9, 2012, from Foreign and Commonwealth Office: http://www.fco.gov.uk/en/news/latest-news/?view=News\&id=22463083

George, K., \& Stratford, E. (2010). Oral History and Human Geography. In I. Hay, Qualitative Research Methods in Human Geography (pp. 139-151). Ontario: Oxford University Press.

Ghori, S. (2008). The application of religious law in North American courts: a case study of_ mut'a marriages. Journal of Islamic Law and Culture, 29-40. 
Glass, G. (1976). Primary, Secondary and Meta-Analysis of Research. Educational Researcher, 3-8.

Goldberg, A. (2010, October 24). Tale of gay woman forced to marry to protect 'honour'. Retrieved February 22, 2011, from BBC News UK: http://www.bbc.co.uk/news/uk11613992

Gracia, E. (2004). Unreported cases of domestic violence against women: towards an epidemiology of social silence, tolerance, and inhibition. Journal of Epidemiology and Community Health, 536-537.

Guillemin, M., \& Gillam, L. (2004). Ethics, Reflexivity, and "Ethically Important Moments" in Research. Qualitative Inquiry, 261-280.

Gupta, R. (2003). From Homebreakers to Jailbreakers: Southall Black Sisters. London: Zed Books.

Hämäläinen, K., Pirskanen, H., \& Rautio, S. (2011). Studying sensitive and contradictory family situations: Considerations from three family studies. Journal of Comparative Social Work, 1-17.

Haraway, D. J. (1997).

Modest_Witness@Second_Millennium.FemaleMan $\mathbb{C} \_$Meets_Oncomouse ${ }^{\mathrm{TM}}$. Feminism and Technoscience, New York: Routledge.

Hayden, A. (2010). Why Rock the Boat? Non-Reporting of Intimate Partner Violence. Auckland: Auckland University of Technology.

Herbert, R., Hill, A., \& Dickson, S. (2009). Violence Against Women in Aotearoa New Zealand: The Case for an integrated plan of action. Wellington: Roundtable on Violence Against Women.

House of Representatives. (2009). Journals of the House of Representatives of New Zealand. Wellington: House of Representatives.

Howitt, R., \& Stevens, S. (2010). Cross-Cultural Research: Ethics, Methods and Relationships. In I. Hay, Qualitative Research Methods in Human Geography (pp. 4068). Toronto: Oxford University Press.

Huberman, M., \& Miles, M. (2002). The Qualitative Researcher's Companion. California: Sage Publications.

Human Rights Commission. (2008). New Zealand and the International Instruments. Retrieved February 1, 2012, from Human Rights Commission: http://www.hrc.conz/international-human-rights/new-zealand-and-the-internationalinstruments 
Human Rights Commission. (2011). A fair go for all? Wellington: Human Rights Commission.

Human Rights Commission. (2011). Tui Tui Tuituia: Race Relations Report 2010. Wellington: Human Rights Commission.

Husain, Y. J. (1967). The Story of a Wedding in Pakistan. Asian Folklore Studies, 119-127.

IMSED Research and Department of Labour. (2011). Perceptions of Migrants and Immigration-2010 Community Survey. Wellington : Department of Labour.

Indian Weekender. (2011, February 17). After 'honour killing' it is 'forced teen marriage'. Auckland: Indian Weekender.

Innes-Kent, S. (2007). New Zealand's Obligations at International Law in Relation to the Human Rights Issue of Forced Marriage: Should New Zealand Criminalise Forced Marriage? Wellington: Victoria University of Wellington.

International Labour Organisation. (1998, November). A Conceptual Framework for gender analysis and planning, Geneva: ILO.

International Organisation for Migration. (2010). World Migration Report 2010, The Future of Migration: Building Capacities For Change. Geneva: IOM.

Innocenti Research Centre. (2001). Early Marriage: Child Spouses. Florence: United Nations Children's Fund.

Jackson, C., \& Pearson, R. (1998). Feminist Visions of Development. New York: Routledge.

Jordan, J. (2008). Serial Survivors: Women's Narratives of Surviving Rape. Sydney: The Federation Press.

Kabeer, N. (1994). Reversed Realities: Gender Hierarchies in Development Thought. London: Verso.

Kaufman, M. (2003, March 31). The AIM Framework: Addressing and Involving Men. Retrieved February 26, 2012, from Kaufman: http://www.michaelkaufman.com/articles/

Kimura, M. (2008). Narrative as a site of subject construction: The 'Comfort Women' debate. Feminist Theory, Vol. 9. Issue 1, 5-24.

Kindon, S. (2010). Participatory Action Research. In I. Hay, Qualitative Research Methods in Human Geography (pp. 259-277). Ontario: Oxford University Press.

Kindon, S., Pain, R., \& Kesby, M. (2007). Participatory Action Research: Origins, approaches and methods. In S. Kindon, R. Pain, \& M. Kesby, Participatory Action Research Approaches and Methods (pp. 9-18). Abingdon: Routledge. 
Leitner Centre for International Law and Justice. (2009). "It's not OK": New Zealand's Efforts to Eliminate Violence Against Women. New York: Fordham Law School.

Lieblich, A., Zilber, T., \& Tuval-Mashiach, R. (2008). Narrating Human Actions: The Subjective Experience of Agenc, Structure, Communion, and Serendipity. Qualitative Inquiry, 613-631.

Llewelyn, S. (2007). A Neutral Feminist Observer? Observation-Based Research and the Politics of Feminist Knowledge Making. Gender and Development, 299-310.

Mai, M. (2006). In The Name of Honour. London: Virago Press (UK).

Mail Online News (2010, October 12). First picture of mother stabbed to death at her luxury home as son and 16-year-old are charged with murder. Aylesbury, Buckinghamshire, United Kingdom. Retrieved on February 21, 2011, from http://www.dailymail.co.uk/news/article-1319650/First-picture-mother-stabbed-deathluxury-home-son-16-year-old-charged-murder.html

Mansvelt, J., \& Berg, L. (2010). Writing Qualitative Geographies, Constructing Meaningful Geographical Knowledges. In I. Hay, Qualitative Research Methods in Human Geography (pp. 333-355). Ontario: Oxford University Press.

Marsden, M. (2007). Love and elopement in Northern Pakistan. Journal of the Royal Anthropological Institute, 91-108.

Martin, R. C. (2004). Encyclopedia of Islam and the Muslim World. New York: Macmillan Reference USA.

Martin, J., \& Pritchard, R. (2010). Learning from Tragedy: Homicide within Families in New Zealand 2002-2006. Wellington: Ministry of Social Development.

McCloskey, L., \& Eisler, R. (2008). Family Structure and Family Violence. San Diego: Academic Press.

Menjívar, C., \& Salcido, O. (2002). Immigrant Women and Domestic Violence: Common Experiences in Different Countries. Gender and Society, 898-920.

Ministry of Justice. (2002). Child Trafficking. Retrieved January 27, 2012, from Ministry of Justice: http://www.justice.govtnz/publications/publicationsarchived/2002/protecting-our-innocence/child-trafficking

Ministry of Justice. (2010). The New Zealand Crime And Safety Survey 2009: Main Findings Report. Wellington: Ministry of Justice.

Ministry of Justice. (2011). Government Response to Report of the Justice and Electoral Committee on Petition 2008/52 of Jane Prichard and 46 others. Wellington: Ministry of Justice. 
Ministry of Social Development. (n.d.). Taskforce for Action on Violence within Families.

Retrieved January 26, 2012, from Ministry of Social Development:

http://www.msd.govtnz/about-msd-and-our-work/work-

programmes/initiatives/action-family-violence/

Ministry for Social and Family Affairs, Health and Consumer Protection . (2009). Active Against Forced Marriage. Hamburg: Ministry for Social and Family Affairs, Health and Consumer Protection .

Ministry of Women's Affairs. (2011, February 4). Convention on the Elimination of All

Forms of Discrimination against Women. Retrieved February 1, 2012, from Ministry

of Women's Affairs: http://www.mwa.govtnz/our-work/international/cedaw.html

Narayan, U. (2008). The Project of Feminist Epistemology: Perspectives from a NonWestern Feminist. In A. Bailey, \& C. Cuomo, The Feminist Philosophy Reader (pp. 756-765). New York: McGraw-Hill.

National Collective of Independent Women's Refuges (Women's Refuge), pers comm. 25 October 2011.

Newsweek. (2008, March 29). The Opium Brides of Afghanistan. Retrieved on February 22, 2011 from http://www.newsweek.com/2008/03/29/the-opium-brides-ofafghanistan.html

New Zealand Herald. (2011, January 30). No Excuse for barbarism - regardless of culture. Auckland: New Zealand. Retrieved on February 15, 2011 from http://wwwnzherald.conz/New Zealand/news/article.cfm?c_id=1\&objectid=10702955

New Zealand House of Representatives. (2010, November 19). Report of the Justice and Electoral Committee. Retrieved January 10, 2012, from New Zealand Parliament: http://www.parliamentnz/enNZ/PB/SC/Documents/Reports/c/3/a/49DBSCH_SCR4916_1-Petition-2008-52-ofJane-Prichard-and-46-others.htm

New Zealand Parliament. (2009, November 24). Papers and petitions presented. Retrieved January 10, 2012, from New Zealand Parliament: http://www.parliamentnz/enNZ/PB/Presented/Petitions/1/a/6/49DBHOH_PET2988_1-Petition-of-Jane-Prichardand-46-others-requesting.htm

New Zealand Parliament. (2011, April 1). New Zealand Legislation: Acts. Retrieved February 9, 2012, from Parliamentary Counsel Office: http://www.legislation.govtnz/act/public/1969/0041/latest/whole.html\#DLM392353

Office of Ethnic Affairs and Immigration New Zealand. (2011). Trailblazers: Inspirational Journeys of Migrant Women Entrepreneurs in New Zealand. Wellington: Office of Ethnic Affairs and Department of Labour. 
Office of Ethnic Affairs. (n.d.). Director's Message. Retrieved January 12, 2012, from Office of Ethnic Affairs: http://www.ethnicaffairs.govtnz/oeawebsite.nsf/wpg_url/About-UsWho-We-Are-Directors-Message?OpenDocument

Office of Ethnic Affairs. (n.d.). Speak Up Seek Help Safe Home. Retrieved January 26, 2012, from The Office of Ethnic Affairs: http://www.ethnicaffairs.govtnz//oeawebsite.nsf/wpg_URL/Whats-HappeningMessage-Board-Speak-up-Seek-help-Safe-home?OpenDocument

Office of Ethnic Affairs. (n.d.). New Zealand's Diversity. Retrieved January 12, 2012, from Office of Ethnic Affairs: http://www.ethnicaffairs.govtnz/oeawebsite.nsf/wpg_URL/Resources-Policy-andstatistics-Index/\$file/NZDiversity.pdf

Office of the United Nations High Commissioner for Human Rights. (1964, December 9). Convention on Consent to Marriage, Minimum Age for Marriage and Registration of Marriages. Retrieved February 1, 2012, from Office of the United Nations High Commissioner for Human Rights: http://www2.ohchr.org/english/law/convention.htm

Office of the United Nations High Commissioner for Human Rights. (1966, December 16). International Covenant on Civil and Political Rights. Retrieved February 1, 2012, from Office of the United Nations High Commissioner for Human Rights: http://www2.ohchr.org/english/law/ccpr.htm

Office of the United Nations High Commissioner for Human Rights. (1976, January 3). International Covenant on Economic, Social and Cultural Rights. Retrieved February 1, 2012, from Office of the United Nations High Commissioner for Human Rights: http://www2.ohchr.org/english/law/cescr.htm

Pacific Women's Watch (NZ) . (2009, November 21). Reports. Retrieved January 10, 2012, from Pacific Women's Watch New Zealand: http://www.pacificwomenswatch.orgnz/reports/PWWNZ\%20Conference\%20Invitatio n-21Nov2009.pdf

Parackal, S., Ameratunga, S., Tin Tin, S., Wong, S., \& Denny, S. (2011). Youth'07: The health and wellbeing of secondary school students in New Zealand: Results for Chinese, Indian and other Asian students. Auckland: The University of Auckland.

Pearson, D. (2011, March 11). Ethnic Inequalities - Occupation and Education. Retrieved January 12, 2012, from Te Ara: The Encyclopedia of New Zealand: http://www.TeAra.govtnz/en/ethnic-inequalities/6 
Pember, W. (1899). The Long White Cloud. Middlesex: The Echo Library. E-book retrieved February 23, 2012, from The Project Gutenberg: www.gutenberg.com/files/12411/12411-h/12411-h.htm

Pillai, S. (2001). Domestic Violence in New Zealand: An Asian Immigrant Perspective. Economic and Political Weekly, 965-974.

Pio, E. (2005). Knotted Strands:Working lives of Indian Women Migrants in New Zealand. Human Relations , 1277-1299.

Population Council (2011). India Fast Facts. Retrieved March 13, 2011 from http://www.popcouncil.org/countries/india.asp

Population Council. (2012). Child Marriage. Retrieved February 12, 2012, from Population Council : http://www.popcouncil.org/topics/youth_childmarriage.asp

Proudlock, K. (2004). 'New' Masculinities, Old Shortcomings? The Implications of a New Male Focus for Gender and Development (GAD). Masters Term Paper, University of Sussex, 10pp.

Racine, L. (2011). The Impact of Race, Gender, and Class in Postcolonial Feminist Fieldwork: A Retrospective Critique of Methodological Dilemmas. Aporia: The Nursing Journal, 15-27.

Raj, A., Saggurti,Niranjan., Lawrence,Danielle., Balaiah,Donta., Silverman,Jay G. (2010). Association between adolescent marriage and marital violence among young adult women in India. International Journal of Gynecology and Obstetrics, 35-39.

Rathgeber, E. (1990). WID, WAD, GAD: Trends in Research and Practice. The Journal of Developing Areas, 489-502.

Razavi, S., \& Miller, C. (1995). From WID to GAD: Conceptual Shifts in the Women and Development Discourse. Geneva: United Nations Development Programme.

Razavi, S. (1997). Fitting Gender into Development Institutions. World Development, 11111125.

Robertson, N., Busch, R., D'Souza, R., Sheung, F., Anand, R., Balzer, R., et al. (2007). Living at the Cutting Edge: Women's Experiences of Protection Orders. Wellington: Ministry of Women's Affairs.

Rosenthal, G. 2003. The Healing Effects of Storytelling: On the Conditions of Curative Storytelling in the contect of Research and Counselling. Qualitative Inquiry. Vol: 9, No: 6, pp. 915 - 933. University of Gottingen.

Rosenberg, G. (1991). The Hollow Hope: Can Courts Bring About Social Change? Chicago: University of Chicago Press. 
Sanghera, J. (2007). Shame. London: Hodder \& Stoughton.

Sarantakos, S. (2004). Social Research. Hampshire: Palgrave MacMillan.

Sen, G., Östlin, P., \& George, A. (2007). Unequal, Unfair, Ineffective and Inefficient Gender Inequity in Health: Why it exists and how we can change it. Women and Gender Equity Knowledge Network.

Shakti Community Council Inc. (n.d.). About Shakti . Retrieved March 20, 2011, from Shakti Community Council Inc: http://www.shakti.orgnz/

Shakti Community Council Inc. (2010, June 3). Additional information on Forced/Underage Marriages. Retrieved February 20, 2011, from Committee documents

Evidence/Submissions: http://www.parliamentnz/enNZ/PB/SC/Documents/Evidence/d/e/6/49SCJE_EVI_49DBHOH_PET2988_1_A507 55-Shakti-Community-Counsel-Supp.htm

Shakti Community Council Inc. (2010, February 3). Committee documents Evidence/Submissions. Retrieved February 22, 2011, from New Zealand Parliament: http://www.parliamentnz/enNZ/PB/SC/Documents/Evidence/6/a/8/49SCJE_EVI_49DBHOH_PET2988_1_A351 22-Shakti-Community-Council.htm

Sharma, B. R., \& Gupta, M. (2004). Gender Based Violence in India - A Never-ending Phenomenon. Journal of International Women's Studies, 113-122.

Sharma, K. (2012, February 19). When Children Marry. The Hindu, p.3, Magazine Section.

Sharp, J., Briggs, J., Yacoub, H., \& Hamed, N. (2003). Doing gender and development: understanding empowerment and local gender relations. Transactions of the Institute of British Geographers, 281-295.

Sheahen, Laura. Fighting Child Labor, Early Marriage in India. Retrieved March 14, 2011, from Catholic Relief Services: http://crs.org/india/child-labor-marriage/

Siddiqui, H (2003). "It was written in her kismet": forced marriage. In R. Gupta, From homebreakers to jailbreakers: Southall Black Sisters (pp. 67-91). London: Zed Books.

Siddiqi, D. M. (2005). Of Consent and contradiction: forced marriages in Bangladesh. In S. Hossein, \& L. Welchman (eds), 'Honour' Crimes, Paradigms and Violence Against Women. London: Zed Books Ltd, pg. 282-307.

Siddiqui, H. (2005). 'There is no "honour" in domestic violence, only shame!' Women's struggles against 'honour' crimes in the UK. In S. Hossein, \& L. Welchman (eds), 'Honour' Crimes, Paradigms and Violence Against Women. London:Zed Books Ltd, pg. 263-281. 
Southall Black Sisters. (n.d.). Landmark Supreme Court Ruling: Immigration policy on forced marriage is unlawful. Retrieved February 1, 2012, from Southall Black Sisters: http://www.southallblacksisters.org.uk/

Southall Black Sisters. (2005). Forced Marriage Law. Retrieved July 5, 2012, from Southall Black Sisters: http://www.southallblacksisters.org.uk/campaigns/forced-marriagecampaign/

Spindel, C., Levy, E., \& Connor, M. (2000). With An End In Sight: Strategies from the UNIFEM Trust Fund to Eliminate Violence Against Women. New York: UN Women Headquarters.

Statistics New Zealand. (2006). 2006 Census information page. Retrieved January 12, 2012, from Statistics New Zealand: http://www.stats.govtnz/searchresults.aspx?ds=1\&q=2006\%20census\%20asian

Statistics New Zealand. (2007). Profile of New Zealander Responses, Ethnicity Question: 2006 Census. Wellington: Statistics New Zealand.

Television New Zealand. (2010, March 10). Child Brides. Auckland, New Zealand: Television New Zealand.

Television New Zealand. (2011, September 7). Real Life: Broken Promises Broken Brides. New Zealand: Television New Zealand.

The Crown Prosecution Service. (n.d.). Honour Based Violence and Forced Marriage: Legal Guidance. London: The Crown Prosecution Service. Retrieved February 18, 2012 from The Crown Prosecution Service:

http://www.cps.gov.uk/legal/h_to_k/honour_based_violence_and_forced_marriage/\#a 21

The Department of Internal Affairs. (2010). Marriage Celebrant: A Guide to the Role of Marriage Celebrants in New Zealand. Retrieved February 1, 2012, from The Department of Internal Affairs:

http://www.dia.govtnz/Pubforms.nsf/URL/MarriageCelebrantbrochureBlackandWhite .pdf/\$file/MarriageCelebrantbrochureBlackandWhite.pdf

The Department of Internal Affairs. (2011). Becoming a Marriage Celebrant. Retrieved February 2, 2012, from The Department of Internal Affairs: http://www.dia.govtnz/diawebsite.nsf/wpg_URL/Services-Births-Deaths-andMarriages-Becoming-a-Marriage-Celebrant?OpenDocument

The Guardian. (2008, June 5). 15 child brides used to settle Pakistan feud. Islamabad. Retrieved February 28, 2011 from http://www.guardian.co.uk/world/2008/jun/05/pakistan.humanrights 
The New York Times. (2005, November 27). Forced to Marry Before Puberty, African Girls Pay Lasting Price. New York. Retrieved February 28, 2011 from http://www.wehaitians.com/forced\%20to\%20marry\%20before\%20puberty\%20african $\% 20$ girls\%20pay\%20lasting\%20price.html

The Supreme Court of the United Kingdom. (2011, October 12). Press Summary. Retrieved February 1, 2012, from The Supreme Court: http://www.supremecourt.gov.uk/decidedcases/docs/UKSC_2011_0024_PressSummary.pdf

The Telegraph. (2009, December 18). Tulay Goren murder: 'honour' crimes doubling every year, figures show. United Kingdom. Retrieved February 28, 2011 from http://www.telegraph.co.uk/news/uknews/crime/6835482/Tulay-Goren-murderhonour-crimes-doubling-every-year-figures-show.html

The Timaru Herald. (2011, February 01). Psychiatric report for burnt body murder-accused. New Zealand. Retrieved March 3, 2011 from http://www.stuff.conz/national/crime/4604622/Psychiatric-report-for-burnt-bodymurder-accused

The Times of India. (2009, December 10). Getty Images. Retrieved March 14, 2011 from http://timesofindia.indiatimes.com/topic/photo/05XQ5Ib6ss7Sh?q=forced+marriage

The Times of India. (2011, March 9). 43\% of underage married girls suffer marital violence: Survey. Retrieved March 12, 2011 from: http://timesofindia.indiatimes.com/india/43of-underage-married-girls-suffer-marital-violence-Survey/articleshow/7659629.cms

The Washington Post. (2003, October 5). Mom gave long-distance order for honor killing, police say. Washington. Retrieved March 5, 2011 from http://www.boston.com/news/world/articles/2003/10/05/mom_gave_long_distance_or der_for_honor_killing_police_say/

Tolich, M., \& Davidson, C. (1999). Starting Fieldwork: An Introduction to Qualitative Research in New Zealand. Auckland: Oxford University Press.

Tse,S. (2007). Family Violence in Asian Communities, Combining Research and Community Development. Social Policy Journal of New Zealand, 170-194.

UNICEF Innocenti Research Centre. (2001). Early Marriage: Child Spouses. Florence: UNICEF.

United Nations. (1964, December 23). Convention on Consent to Marriage, Minimum Age for Marriage and Registration of Marriages. Retrieved February 1, 2012, from United Nations Treaty Collection:

http://treaties.un.org/pages/ViewDetails.aspx?src=TREATY\&mtdsg_no=XVI$3 \&$ chapter $=16 \&$ lang=en 
United Nations. (1969, May 23).Vienna Convention on the Law of Treaties. Retrieved February 1, 2012, from International Law Students'Association http://www.ilsa.org/jessup/jessup11/basicmats/VCLT.pdf

United Nations. (1994). General Recommendation No 21: Convention on the Elimination of all forms of Discrimination Against Women. New York: United Nations.

United Nations. (1996). Declaration on the Elimination of Violence against Women . Retrieved August 20, 2011, from United Nations High Commissioner for Human Rights: http://www.unhchr.ch/huridocda/huridoca.nsf/(symbol)/a.res.48.104.en

United Nations CEDAW. (2007). Concluding comments of the Committee on the Elimination of Discrimination against Women: New Zealand. New York: United Nations.

UNDP. (2007). MDG Monitor. Tracking the Millennium Development Goals. New York: UNDP.

United Nations Human Rights Council. (2007). Report of the Special Rapporteur on the Human Rights aspect of the Victims of Trafficking in Persons, especially women and children. New York: OHCHR

United Nations. (2009). Convention on the Elimination of All Forms of Discrimination against Women. Retrieved February 1, 2012, from Division for the Advancement of Women: Department of Economic and Social Affairs: http://www.un.org/womenwatch/daw/cedaw/text/econvention.htm\#article16

United Nations. (2011, March 7). Secretary-General's Message on International Women's Day March 8 2011. New York.

United Nations. (2011, June 2). Understanding the Convention on the Rights of the Child. Retrieved February 9, 2012, from UNICEF: http://www.unicef.org/crc/index_understanding.html

UN Women. (2011). Progress of the World's Women: In Pursuit of Justice. New York: UN Women.

UN Women. (2011). About Us. Retrieved January 28, 2012, from UN Women: http://www.unwomen.org/about-us/

van der Gaag, N. (2012). Because I'm a Girl:The State of the World's Girls. Surrey: Plan UK. van Djik, T. (1987).Mediating rascism: the role of the media in the reproduction of rascism. In Language, Power and Ideology: Studies in Political Discourse, R. Wodak (ed), pp. 199-222. Amsterdam: Benjamins.

Walker, R. (1994). Te Karanga. Metro . Auckland, New Zealand: ACP Media. 
What's On Xiamen. (2010, October 12). Rich UK mum Assia Shahzad reported killed by 2 sons over new lover. Retrieved February 24, 2011 from http://www.whatsonxiamen.com/news15086.html

White, S. (2000). 'Did the Earth Move?' The Hazards of Bringing Men and Masculinities into Gender and Development. IDS Bulletin, 33-41.

Wilson, F. H. (2006). The Sociology of Racial and Ethnic Relations. In C. Bryant, \& D. L. Peck, 21 st Century Sociology: A Reference Book. (pp. 237-246). Thousand Oaks: Sage Publications.

Wing, A. K. (2006). "International Conventions" Encyclopedia of Women \& Islamic Cultures. Retrieved February 1, 2012, from Brill Online: http://brillonline.nl/public/international-conventions.html

World Health Organisation. (2009, November). Violence Against Women. Retrieved February 20, 2011, from World Health Organisation: http://www.who.int/mediacentre/factsheets/fs239/en/

Yang, Fenggang and H.R. Ebaugh. "Religion and Ethnicity: The Impact of Majority/Minority Status in the Home and Host Countries." The Journal for the Scientific Study of Religion 40 (3) 2001: 367-378.

Zapfl-Helbling, R. (2005). Forced marriages and Child Marriages in Parliamentary Assembly. Documents Working Papers 2005 Ordinary Session (Third Part). Volume 5, Documents 10566-10615. Strasbourg: Council of Europe Publishing, pg. 223 231.

\section{Stakeholder Agency Interviews}

Child, Youth and Family, pers comm. 9 December 2011.

Families Commission, pers comm. 28 October 2011.

Human Rights Commission, pers comm. 9 December 2011.

Ministry of Justice, pers comm. 11 November 2011.

Ministry of Women's Affairs, pers comm. 11 November 2011.

New Zealand Police, pers. comm. 24 November 2011.

Office of Ethnic Affairs, pers comm. 23 November 2011.

Shakti Youth, pers comm. 8 December 2011.

United Nations Children's Fund New Zealand (UNICEF), pers comm. 31 October 2011. 
UN Women, pers comm. 28 October 2011.

\section{Stakeholder Engagement Workshop}

Families Commission (2011), pers. comm., 16 December

Human Rights Commission (2011), pers. comm., 16 December

Ministry of Justice (2011), pers. comm., 16 December

New Zealand Police (2011), pers. comm., 16 December 2011

Office of Ethnic Affairs, pers comm. 16 December 2011.

Shakti Youth, pers comm. 16 December 2011. 